LBNL-53027

\title{
Evaluation of Metrics and Baselines for \\ Tracking Greenhouse Gas Emissions Trends: \\ Recommendations for the California Climate Action Registry
}

\author{
Lynn Price, Scott Murtishaw, Ernst Worrell \\ International Energy Studies \\ Energy Analysis Department \\ Environmental Energy Technologies Division \\ Lawrence Berkeley National Laboratory \\ Berkeley, CA 94720
}

Prepared for the California Energy Commission under the Public Interest Energy Research (PIER) Program

June 2003

This work was supported by the California Energy Commission and the California Institute for Energy Efficiency using support from the California Energy Commission through the U.S. Department of Energy under Contract No. DE-AC03-76SF0098.

Downloadable from http://eetd.lbl.gov/ea/ies/ieua/Pubs.html 



\section{Table of Contents}

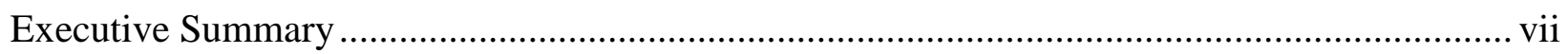

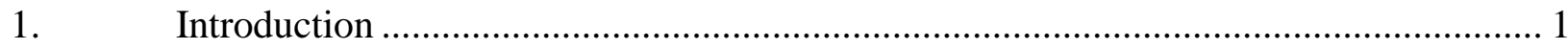

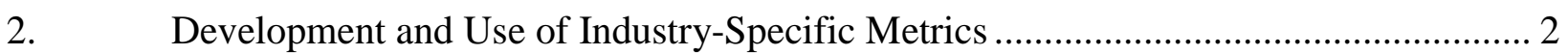

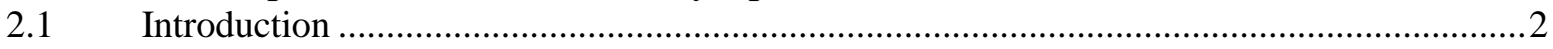

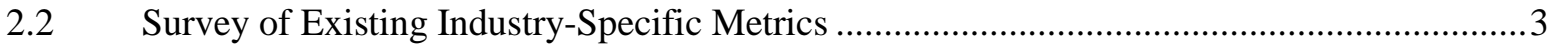

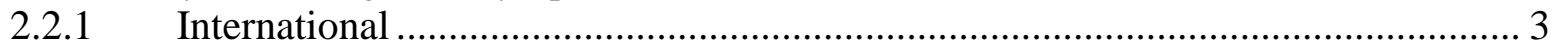

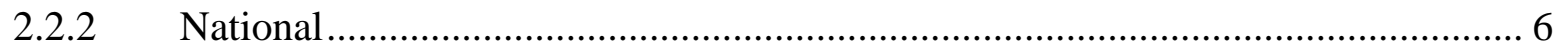

2.2.3 Metrics Used by Individual Companies.......................................................... 10

2.3 Identifying and Developing Industry-Specific Metrics for Use in the California Climate Action

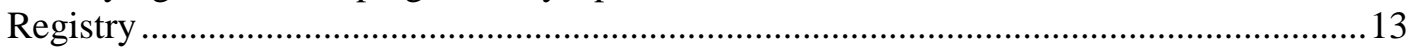

2.3.1 California Energy and $\mathrm{CO}_{2}$ Emissions - All Sectors.......................................... 13

2.3.2 Buildings Sector Energy Use and $\mathrm{CO}_{2}$ Emissions.............................................. 13

2.3.3 Transportation Sector Energy Use and $\mathrm{CO}_{2}$ Emissions ...................................... 15

2.3.4 Industrial Sector Energy Use and $\mathrm{CO}_{2}$ Emissions ............................................ 16

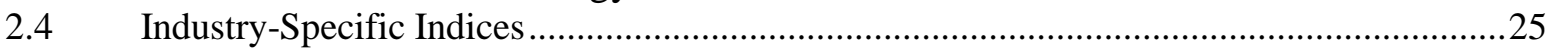

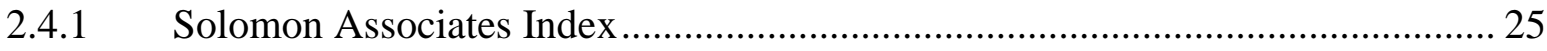

2.4.2 Canadian Association of Petroleum Producers............................................... 25

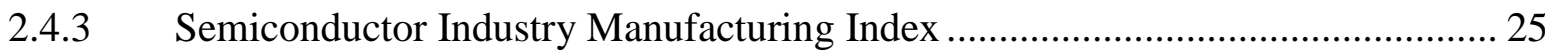

2.4.4 Netherlands - Industrial Sector Agreements ................................................... 26

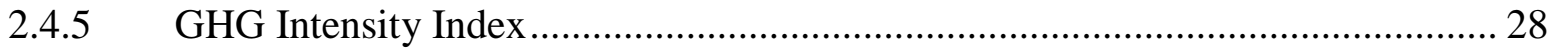

3. Establishing Baselines for Calculating Greenhouse Gas Emissions Reductions ......... 29

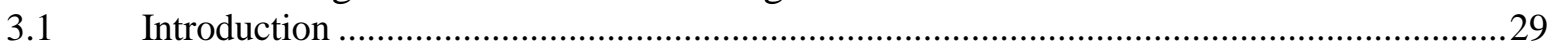

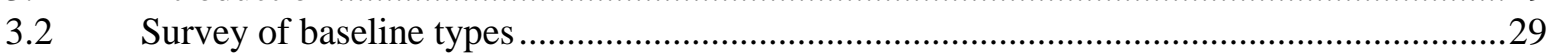

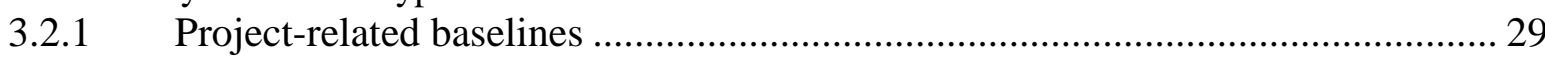

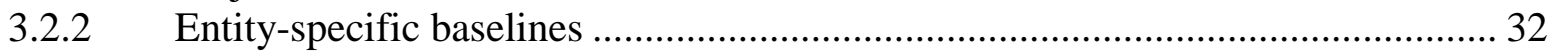

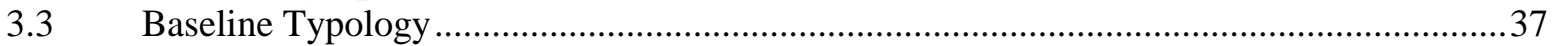

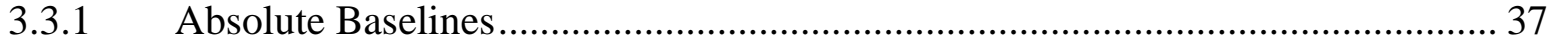

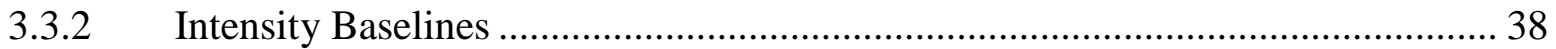

3.3.3 Reconstructed Baselines ..................................................................................... 39

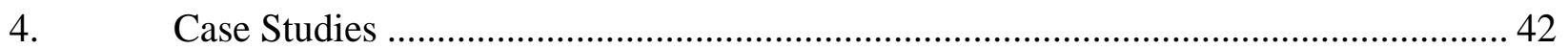

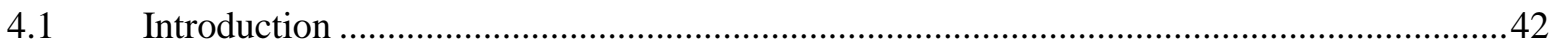

4.2 Electronics Manufacturing: Advanced Micro Devices Case Study.........................................42

4.2.1 Sector Background ................................................................................. 42

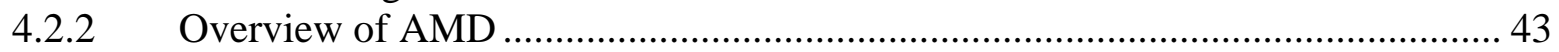

4.2.3 Analysis of Possible Metrics............................................................................ 44

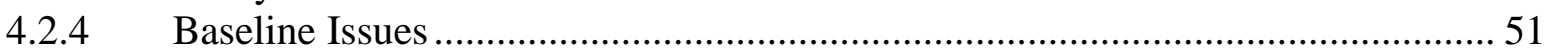

4.3 Agricultural Crop Production and Food Processing: Fetzer Vineyards Case Study ..............57

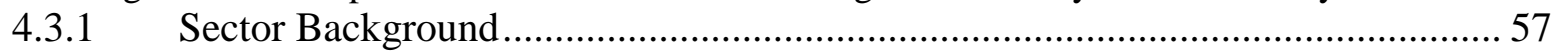

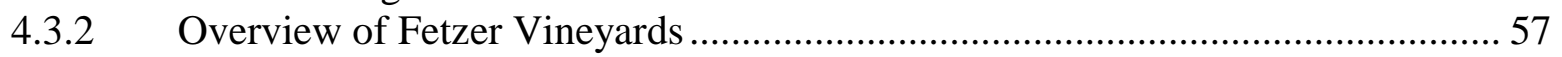

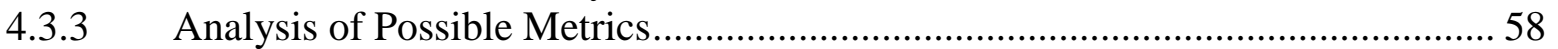

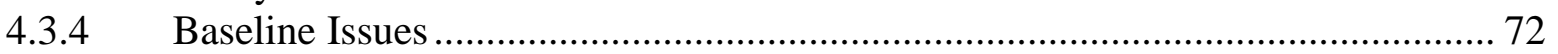

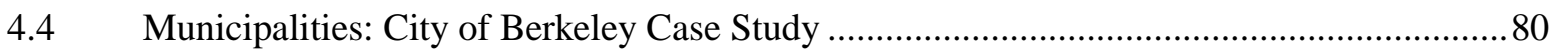




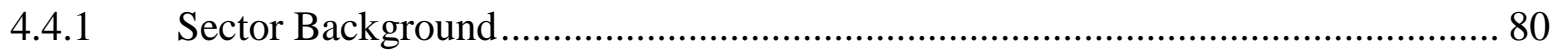

4.4.2 Overview of City of Berkeley ................................................................. 80

4.4.3 Analysis of Possible Metrics......................................................................... 82

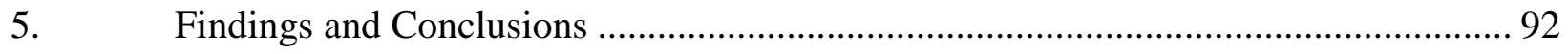

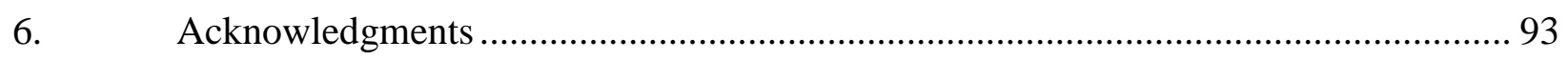

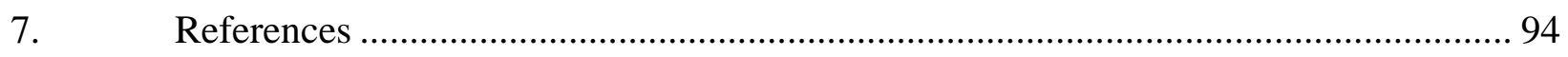

Appendix A: Calculation of the Energy Efficiency Index.................................................. 104 


\section{List of Figures and Tables}

Figure 1. Total Electricity Consumption at AMD's Sunnyvale and Austin Sites, 1997-2001.... 47 Figure 2. Electricity Consumption Metrics for AMD's Sunnyvale and Austin Sites, 1997-2001.

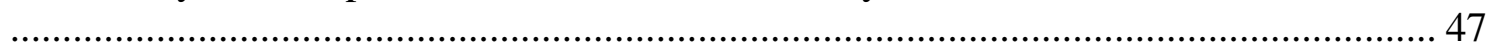

Figure 3. Total GHG Emissions of AMD's Sunnyvale and Austin Sites, 1997-2001_.................. 50

Figure 4. GHG Emissions Metrics for AMD's Sunnyvale and Austin Sites, 1997-2001 ............ 50

Figure 5. GHG Intensity Index for AMD's Sunnyvale and Austin Sites, 1997-2001.................. 50

Figure 6. Absolute Baselines for AMD's Sunnyvale and Austin Sites ....................................... 53

Figure 7. Intensity Baselines for AMD's Sunnyvale and Austin Sites ........................................ 54

Figure 8. Ex Post Reconstructed Baseline for Austin Site, 2001................................................ 55

Figure 9. Energy Consumption by Activity (Agricultural Crop Production, Food Processing, Other Transportation, and Other Buildings) and Fuel at Fetzer Vineyards, 1999-2002. 63

Figure 10. Indexed Energy Consumption for Agricultural Crop Production at Fetzer Vineyards:

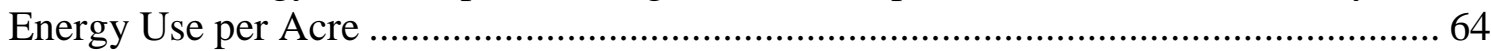

Figure 11. Indexed Energy Consumption for Agricultural Crop Production at Fetzer Vineyards:

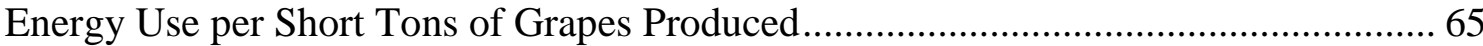

Figure 12. Fetzer Vineyards Energy Use Indexed to Cases Produced, 1999 to 2002 ................... 66

Figure 13. Fetzer Vineyards Winery and Bottling Facility Energy Use Indexed to Gallons

Moved, Gallons Racked, and Cases Produced, 1999 to 2002 .......................................... 67

Figure 14. GHG Emissions by Activity (Agricultural Crop Production, Food Processing, and

Other) and Fuel at Fetzer Vineyards, 1999 - 2002 ..........................................................6 68

Figure 15. Indexed GHG Emissions for Agricultural Crop Production at Fetzer Vineyards ........ 70

Figure 16. Fetzer Vineyards GHG Emissions Indexed to Cases Produced, 1999 to 2002 ............ 71

Figure 17. Absolute Emissions Baselines for Agricultural Activity .............................................. 72

Figure 18. Absolute Emissions Baselines for Food Processing................................................... 73

Figure 19. Intensity-Derived Agricultural Crop Production Baselines Using "Tons of Grapes"

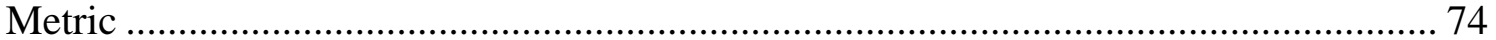

Figure 20. Intensity Based Agricultural Crop Production Baselines Using the Acreage Metric . 75

Figure 21. Intensity Based Food Processing Baselines, Using Cases Produced Metric ................ 76

Figure 22. Ex-Post Baseline for Agricultural Crop Production....................................................... 77

Figure 23. Ex-Post Baseline for Food Processing ..................................................................... 78

Figure 24. Shares of City of Berkeley's $2001 \mathrm{CO}_{2}$ Emissions by Major Fuel and End Use,

Excluding Street Lights, Miscellaneous Vehicles, and Landfill Methane …………....... 81

Figure 25. City of Berkeley Energy Use and Associated GHG Emissions, 1994-2001............... 84

Figure 26. Total $2001 \mathrm{CO}_{2}$ Emissions by Building Type ………............................................. 84

Figure 27. City of Berkeley Municipal Buildings GHG Emissions Metrics by Fuel ................... 86

Figure 28. City of Berkeley Municipal Buildings GHG Emissions Metric by Building Type .... 87

Figure 29. Carbon Metric for Traffic Signals ......................................................................... 91

Table 1. Sector-Specific Metrics Used for Commercial Buildings, Transportation, Industry, and

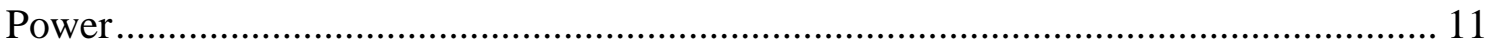

Table 2. Final Energy Use and Fossil-Fuel-Related $\mathrm{CO}_{2}$ Emissions in California in 1999 .......... 13

Table 3. California Commercial Buildings Ranked by Energy Consumption (Largest to Smallest

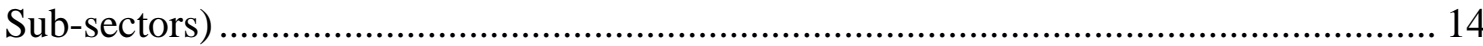


Table 4. Metrics for Buildings Energy Consumption and GHG Emissions 15

Table 5. Data Available for Development of Metrics for Commercial Buildings in California .. 15

Table 6. Metrics for Transportation Energy Consumption and GHG Emissions.......................... 16

Table 7. Industries Ranked by Energy Consumption (Largest to Smallest Subsectors) ............... 16

Table 8. Metrics for Industry Energy Consumption and GHG Emissions* ................................. 18

Table 9. Data Available for Development of Metrics for Industry in California ......................... 19

Table 10. Industry-Specific Metrics, Ranked by California Industrial Combined Electricity and

Natural Gas Consumption (Largest to Smallest Subsectors) ……….............................. 20

Table 11. Characteristics of Various Baselines Used to Calculate Energy Use or GHG Emissions

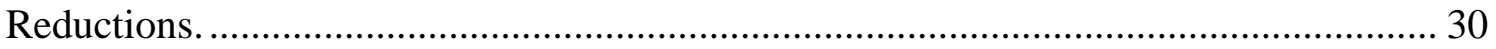

Table 12. Typology and Qualitative Assessment of Baselines for Estimating Entity-Wide GHG

Savings ............................................................................................................. 40

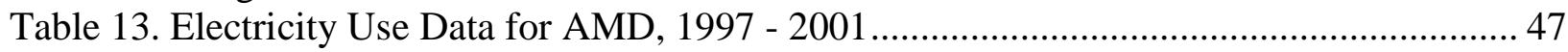

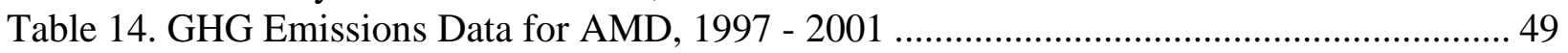

Table 15. Comparison of the Use of Various Baselines for AMD Sunnyvale and Austin Sites

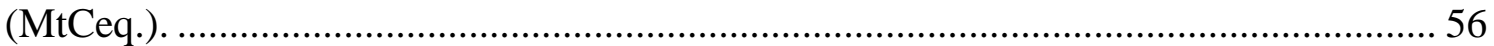

Table 16. Energy End-Uses, Non-Energy GHG Sources, and Production Metrics at Fetzer

Vineyards by Economic Activity ………………………............................................. 60

Table 17. Energy Use and Production Data for Fetzer Vineyards, 1999 - 2001 ........................... 62

Table 18. GHG Emissions Data for Fetzer Vineyards, 1997 - 2001 ............................................ 69

Table 19. Comparison of the Use of Various Baselines for Estimating 2002 GHG Savings for

Agricultural Crop Production and Food Processing at Fetzer Vineyards (tC)................ 79

Table 20. 2001 Energy Consumption, Square Footage, and Energy Intensity of Berkeley

Municipal Buildings .................................................................................................. 83

Table 21. City of Berkeley Building Energy Consumption and GHG Emissions, 1994-2001 .... 83

Table 22. City of Berkeley Municipal Building Energy and GHG Metrics ................................. 86

Table 23. City of Berkeley Vehicle Fleet Fuel Consumption and GHG Emissions...................... 88

Table 24. City of Berkeley Vehicle Fleet Metrics ......................................................................... 89 


\section{List of Abbreviations and Acronyms}

\begin{tabular}{|c|c|}
\hline $\mathrm{AGO}$ & Australian Greenhouse Office \\
\hline AIJ & Activities Implemented Jointly \\
\hline AMD & Advanced Micro Devices \\
\hline $\mathrm{BP}$ & British Petroleum \\
\hline BPI & Baseline Protection Initiative \\
\hline CAPP & Canadian Association of Petroleum Producers \\
\hline CAST & Coalition to Advance Sustainable Technology \\
\hline $\mathrm{CCP}$ & Cities for Climate Protection \\
\hline CDM & Clean Development Mechanism \\
\hline CEI & Carbon Energy Intensity \\
\hline $\mathrm{CH}_{4}$ & methane \\
\hline CIEEDAC & Canadian Industry Energy End-use Database and Analysis Centre \\
\hline CIPEC & Canadian Industry Program for Energy Conservation \\
\hline $\mathrm{CO}_{2}$ & carbon dioxide \\
\hline DEFRA & Department for Environment, Food and Rural Affairs \\
\hline EEI & energy efficiency index \\
\hline EHS & Environment, Health \& Safety \\
\hline EIA & Energy Information Administration \\
\hline EII & energy intensity index \\
\hline EPA & Environmental Protection Agency \\
\hline ERUPT & Emissions Reduction Unit Procurement Tender \\
\hline ETS & Emissions Trading Scheme \\
\hline GDP & Gross Domestic Product \\
\hline GHG & greenhouse gas \\
\hline GHGPI & Greenhouse Gas Protocol Initiative \\
\hline GJ & gigajoule \\
\hline GSP & gross state product \\
\hline GWh & gigawatt hour \\
\hline GWP & global warming potential \\
\hline $\mathrm{HCFC}$ & hydrochlorofluorocarbon \\
\hline HFCs & hydrofluorocarbons \\
\hline HVAC & heating, ventilation, and air conditioning \\
\hline ICLEI & International Council for Local Environmental Initiatives \\
\hline IEA & International Energy Agency \\
\hline IEEN & Industrial Energy Efficiency Network \\
\hline INEDIS & International Network for Energy Demand Analysis in the Industrial Sector \\
\hline IPCC & Intergovernmental Panel on Climate Change \\
\hline JI & Joint Implementation \\
\hline $\mathrm{kg}$ & kilogram \\
\hline $\mathrm{kgCeq}$ & kilogram carbon equivalent \\
\hline $\mathrm{km}$ & kilometer \\
\hline $\mathrm{kWh}$ & kilowatt hour \\
\hline LBNL & Lawrence Berkeley National Laboratory \\
\hline LED & light-emitting diode \\
\hline
\end{tabular}




$\begin{array}{ll}\text { LHV } & \text { lower heating value } \\ \text { LTA } & \text { Long-Term Agreement } \\ \text { MBtu } & \text { thousand British thermal units } \\ \text { MMBtu } & \text { million British thermal units } \\ \text { MI } & \text { manufacturing index } \\ \text { MtC } & \text { million metric tons carbon } \\ \text { MtCeq. } & \text { million metric tons carbon equivalent } \\ \text { MWh } & \text { megawatt hour } \\ \text { NOAA } & \text { National Oceanic and Atmospheric Administration } \\ \text { N }{ }_{2} \text { O } & \text { nitrous oxide } \\ \text { OECD } & \text { Organization for Economic Cooperation and Development } \\ \text { OSHA } & \text { Occupational Safety and Health Administration } \\ \text { PCI } & \text { Production Carbon Intensity } \\ \text { PEI } & \text { Production Energy Intensity } \\ \text { PEII } & \text { Production Energy Intensity Index } \\ \text { PFCs } & \text { perfluorocarbons } \\ \text { PG\&E } & \text { Pacific Gas \& Electric } \\ \text { R\&D } & \text { research \& development } \\ \text { SB } & \text { Senate Bill } \\ \text { SEC } & \text { specific energy consumption } \\ \text { SF } & \text { sulfur hexafluoride } \\ \text { SIC } & \text { Standard Industrial Classification } \\ \text { TBtu } & \text { thousand British Thermal Units } \\ \text { tC } & \text { tonne carbon } \\ \text { TWh } & \text { terawatt hours } \\ \text { UNEP } & \text { United Nations Environment Programme } \\ \text { UNFCCC } & \text { United Nations Framework Convention on Climate Change } \\ \text { VCR } & \text { Voluntary Challenge and Registry } \\ \text { VMT } & \text { Vehicle mile traveled } \\ \text { WBCSD } & \text { World Business Council on Sustainable Development } \\ \text { WEC } & \text { World Energy Council } \\ \text { WRI } & \text { World Resources Institute } \\ \text { WSC } & \text { World Semiconductor Council } \\ & \end{array}$




\section{Executive Summary}

The California Climate Action Registry, which was initially established in 2000 and began operation in Fall 2002, is a voluntary registry for recording annual greenhouse gas (GHG) emissions. The purpose of the Registry is to assist California businesses and organizations in their efforts to inventory and document emissions in order to establish a baseline and to document early actions to increase energy efficiency and decrease GHG emissions. The State of California has committed to use its "best efforts" to ensure that entities that establish GHG emissions baselines and register their emissions will receive "appropriate consideration under any future international, federal, or state regulatory scheme relating to greenhouse gas emissions". Reporting of GHG emissions involves documentation of both "direct" emissions from sources that are under the entity's control and "indirect" emissions controlled by others. Electricity generated by an off-site power source is considered to be an indirect GHG emission and is required to be included in the entity's report.

Registry participants include businesses, non-profit organizations, municipalities, state agencies, and other entities. Participants are required to register the GHG emissions of all operations in California, and are encouraged to report nationwide. For the first three years of participation, the Registry only requires the reporting of carbon dioxide $\left(\mathrm{CO}_{2}\right)$ emissions, although participants are encouraged to report the remaining five Kyoto Protocol GHGs $\left(\mathrm{CH}_{4}, \mathrm{~N}_{2} \mathrm{O}, \mathrm{HFCs}\right.$, PFCs, and $\mathrm{SF}_{6}$ ). After three years, reporting of all six Kyoto $\mathrm{GHG}$ emissions is required. The enabling legislation for the Registry (SB 527) requires total GHG emissions to be registered and requires reporting of "industry-specific metrics" once such metrics have been adopted by the Registry.

The Ernest Orlando Lawrence Berkeley National Laboratory (Berkeley Lab) was asked to provide technical assistance to the California Energy Commission (Energy Commission) related to the Registry in three areas: 1) assessing the availability and usefulness of industry-specific metrics, 2) evaluating various methods for establishing baselines for calculating GHG emissions reductions related to specific actions taken by Registry participants, and 3) establishing methods for calculating electricity $\mathrm{CO}_{2}$ emission factors. The third area of research was completed in 2002 and is documented in Estimating Carbon Dioxide Emissions Factors for the California Electric Power Sector (Marnay et al., 2002). This report documents our findings related to the first areas of research.

For the first area of research, the overall objective was to evaluate the metrics, such as emissions per economic unit or emissions per unit of production that can be used to report GHG emissions trends for potential Registry participants. This research began with an effort to identify methodologies, benchmarking programs, inventories, protocols, and registries that use industryspecific metrics to track trends in energy use or GHG emissions in order to determine what types of metrics have already been developed. The next step in developing industry-specific metrics was to assess the availability of data needed to determine metric development priorities. Berkeley Lab also determined the relative importance of different potential Registry participant categories in order to assess the availability of sectoral or industry-specific metrics and then identified industry-specific metrics in use around the world. While a plethora of metrics was identified, no one metric that adequately tracks trends in GHG emissions while maintaining confidentiality of data was identified. As a result of this review, Berkeley Lab recommends the 
development of a GHG intensity index as a new metric for reporting and tracking GHG emissions trends.

For the second research area, Berkeley Lab evaluated various methods used to calculate baselines for documentation of energy consumption or GHG emissions reductions, noting those that use industry-specific metrics. Accounting for actions to reduce GHGs can be done on a project-by-project basis or on an entity basis. Establishing project-related baselines for mitigation efforts has been widely discussed in the context of two of the so-called "flexible mechanisms" of the Kyoto Protocol to the United Nations Framework Convention on Climate Change (Kyoto Protocol) - Joint Implementation (JI) and the Clean Development Mechanism (CDM). Issues regarding the development of entity-specific baselines, which can be used by such entities as companies, municipalities, and organizations, have been explored in the context of baseline protection, emissions trading, credit for early action initiatives, and climate change registries. Berkeley Lab developed a baseline typology and assessed the complexity and robustness of each type of baseline vis-à-vis potential future emissions limits and/or emissions trading schemes.

Finally, Berkeley Lab conducted three case studies in order to explore issues related to both industry-specific metrics and baselines. These case studies were done for Advanced Micro Devices (AMD), Fetzer Vineyards, and the City of Berkeley. The case studies demonstrated numerous issues related to the use of metrics and recommended that industry-specific metrics be disaggregated to a certain degree, depending upon both the specific sector and data availability, in order to best capture the energy or GHG emissions trends experienced at the participant's facilities. The case studies also discussed various baseline issues and concluded that it is difficult to clearly identify any one baseline that is preferable to another based on the limited number of years of data available as well as due to the wide variation observed in the differences between the baselines and actual GHG emissions. Data availability, baseline complexity, baseline robustness, and the ultimate desired use of the baseline must all be considered when choosing a baseline upon which to measure future GHG emissions reductions. 


\section{Introduction}

The California Climate Action Registry, which was initially established in 2000 and began operation in Fall 2002, is a voluntary registry for recording annual greenhouse gas (GHG) emissions (California Climate Action Registry, 2002). The purpose of the Registry is to assist California businesses and organizations in their efforts to inventory and document emissions in order to establish a baseline and to document early actions to increase energy efficiency and decrease GHG emissions. The State of California has committed to use its "best efforts" to ensure that entities that establish GHG emissions baselines and register their emissions will receive "appropriate consideration under any future international, federal, or state regulatory scheme relating to greenhouse gas emissions" (California Senate, 2001). Reporting of GHG emissions involves documentation of both "direct" emissions from sources that are under the entity's control and "indirect" emissions controlled by others. Electricity generated by an off-site power source is considered to be an indirect GHG emission and is required to be included in the entity's report (Arthur D. Little, Inc., 2002).

Registry participants include businesses, non-profit organizations, municipalities, state agencies, and other entities. Participants are required to register the GHG emissions of all operations in California, and are encouraged to report nationwide. For the first three years of participation, the Registry only requires the reporting of carbon dioxide $\left(\mathrm{CO}_{2}\right)$ emissions although participants are encouraged to report the remaining five Kyoto Protocol GHGs $\left(\mathrm{CH}_{4}, \mathrm{~N}_{2} \mathrm{O}\right.$, HFCs, PFCs, and $\mathrm{SF}_{6}$ ). After three years, reporting of all six Kyoto $\mathrm{GHG}$ emissions is required (California Climate Action Registry, 2002). The enabling legislation for the Registry (SB 527) requires total GHG emissions to be registered and requires reporting of "industry-specific metrics" once such metrics have been adopted by the Registry (SB 527, Section 11).

The Ernest Orlando Lawrence Berkeley National Laboratory (Berkeley Lab) was asked to provide technical assistance to the California Energy Commission (Energy Commission) related to the Registry regarding assessing the availability and usefulness of industry-specific metrics and evaluating various methods for establishing baselines for calculating GHG emissions reductions related to specific actions taken by Registry participants and recommends the development of a GHG intensity index as a new metric for reporting and tracking GHG emissions trends. This report begins with an evaluation of the metrics that can be used to report GHG emissions trends for potential Registry participants. The report then covers issues related to various methods used to calculate baselines for documentation of energy consumption or GHG emissions reductions, noting those that use industry-specific metrics, and concludes that data availability, baseline complexity, baseline robustness, and the ultimate desired use of the baseline must all be considered when choosing a baseline upon which to measure future GHG emissions reductions. This report concludes with the presentation of three case studies that were conducted for Advanced Micro Devices (AMD), Fetzer Vineyards, and the City of Berkeley in order to explore issues related to both industry-specific metrics and baselines. 


\section{Development and Use of Industry-Specific Metrics}

\subsection{Introduction}

The enabling legislation for the California Climate Action Registry (SB 527) requires participating entities to register total GHG emissions and requires reporting of "industry-specific metrics" once such metrics have been adopted by the Registry (SB 527, Section 11). The legislation specifies that Registry "participants shall also report using industry-specific metrics once the registry adopts an industry-specific metric for the industry in question" (SB 527, Section 11). In support of this, the California Energy Commission is directed by the legislation to "Review...industry-specific greenhouse gas reporting metrics linked to or based on international or federal standards, as these become available periodically, and advise the registry of its opinion as to whether the adoption of sectoral or industry-specific metrics complement the reporting procedures" (SB 527, Section 16).

Sectoral and industry-specific metrics, also called indicators, are commonly used by businesses, governments, and analysts to track trends in GHG emissions or energy consumption. ${ }^{1}$ These metrics, which are designed to measure improvements in $\mathrm{CO}_{2}$ intensity or energy efficiency independent of economic growth or growth in production, use either an economic or a physical value for the denominator. For example, the energy intensity of cement production can be measured as energy use per dollar of value added by the cement industry (economic metric) or energy use per ton of cement produced (physical metric). Economic metrics are typically used when aggregating across heterogeneous entities that do not produce comparable products (e.g. the entire manufacturing sector). Physical metrics are typically used to compare entities that have similar production outputs.

Recent analyses have shown that there is great variability in economic metrics and that metrics based on physical values more accurately trace actual trends in emissions or energy intensity, although the heterogeneity of the industrial sector can make development of such metrics difficult for some industries (Freeman et al., 1996; Worrell et al., 1997). As a result, there have been increasing efforts to develop suitable physical metrics (Farla, 2000; LBNL, 1999; Nyboer and Laurin, 2001a; Nyboer and Laurin, 2001b; Phylipsen et al., 1996; Phylipsen et al., 1998).

The first step in developing industry-specific metrics is to identify methodologies, benchmarking programs, inventories, protocols, and registries that use intensity-based metrics to track trends in energy use or GHG emissions in order to determine what types of metrics have already been developed. We identified such metrics through literature survey, web-searching, and contacting other researchers or policy-makers who have experience with either registry projects or development of metrics for measuring and tracking GHG emissions. Section 2.2 describes the international, national, sector-specific, and company-specific efforts that utilize sector-specific metrics.

The next step in developing industry-specific metrics is to assess the availability of data needed to determine metric development priorities. Such data will be required to gain an understanding of the relative importance of specific building types, transport fleet modes, and

\footnotetext{
${ }^{1}$ For an extensive review of energy and carbon emissions indictors used by analysts, see Schipper et al., 2001.
} 
industrial/manufacturing/agriculture facilities in California. Section 2.3 of this report summarizes the data sources we have identified.

Section 2.4 provides a description of various industry-specific indices that have also been developed to track trends in energy use or GHG emissions. Such indices can be helpful in situations where data confidentiality is an issue. This section also contains Berkeley Lab's recommendation for the development of a GHG intensity index for use by the Registry.

\subsection{Survey of Existing Industry-Specific Metrics}

Below we review the sector-specific metrics used in a number of international, national, state, and other efforts aimed at understanding the underlying trends in GHG emissions, energy use and energy intensity. We provide general information about the development of the approach and then we describe the sector-specific metrics used to tracking emissions, energy use, and intensity trends. A summary of the metrics used for each program or methodology reviewed is presented in Table 1.

\subsubsection{International}

\subsubsection{Greenhouse Gas Protocol Initiative}

The Greenhouse Gas Protocol Initiative (GHG Protocol), a joint project of the World Resources Institute and World Business Council for Sustainable Development, is a collaborative effort to develop a standard GHG reporting methodology for emissions from business entities. Current participants in the "road test" phase of the protocol include DuPont, British Petroleum, Ford Motor Company, and IBM among others. The methodology is compatible with Intergovernmental Panel on Climate Change (IPCC) guidelines, has received input from both the public and private sector, and has been reviewed by experts and stakeholders. Moreover, the methodology is relatively simple and standardized (GHGPI, 2000; GHGPI, 2001a).

Under the GHG Protocol, companies may choose to report so-called ratio indicators in order to look at performance over time compared to targets and base years and to normalize comparisons between different size businesses. The Protocol recommends that businesses design their own indicators to support their internal decision-making. The Protocol distinguishes three types of ratio indicators. Productivity/efficiency ratios measure the outputs of the company in relation to GHG impacts and include ratios that measure resource productivity (e.g. sales per GHG emissions) and process eco-efficiency (e.g. production volume per GHG emissions). Intensity ratios measure GHG emissions per unit of activity or value and include emissions intensity (e.g. tonnes of $\mathrm{CO}_{2}$ emissions per electricity unit generated) and resource intensity (e.g. GHG emissions per function or service). Finally, percentage indicators measure current year GHG emissions as a percentage of base year GHG emissions (GHGPI, 2001b).

\subsubsection{The GHG Indicator: UNEP Guidelines for Calculating Greenhouse Gas Emissions from Businesses and Non-Commercial Organizations}

The United Nations Environment Programme (UNEP) GHG Indicator was initiated by a report by the Centre for Environmental Technology at London's Imperial College published in 1997 
that discussed establishing a standardized methodology for measuring a company's GHG emissions. The guidelines have been developed in partnership with accountants, academics, companies, consultants, environmentalists, financial institutions, government agencies, and nongovernmental organizations. Some of the partner organizations include the World Resources Institute, the World Business Council for Sustainable Development, the International Energy Agency, the European Bank for Reconstruction and Development, and Blue Circle Industries. The GHG Indicator has been developed to be most useful for companies and as such can be applied to individual sites, specific lines of the business, or to the entire parent company (Thomas et al., 2000). It is being used in the World Energy Council GHG Emissions Reductions Pilot Programme to record emissions reductions (WEC, 2001).

The guidelines recommend the use of four denominators for measuring company activity when constructing an intensity measurement: turnover (or sales), value added, number of employees, and unit of production. Since these various denominators have advantages and disadvantages for normalizing, the guidelines state that "no single normalizing value or unit of turnover was chosen for these guidelines since all the proposed denominators are easily applicable and have relevance to different target audiences" (Thomas et al., 2000).

\subsubsection{The International Council for Local Environmental Initiatives (ICLEI)}

The ICLEI analytical framework for urban GHG emissions and emissions reductions is designed as a tool for local government energy and emissions analysis. The framework was developed through ICLEI's Urban $\mathrm{CO}_{2}$ Reduction Project and ten years of collaboration with cities from around the world to develop a standardized approach to emissions analysis. The framework tracks $\mathrm{CO}_{2}$ emissions from fuels, electricity, and waste (ICLEI, 2001; Torrie Smith Associates, 1999).

ICLEI members can use the Cities for Climate Protection (CCP) software to calculate emissions. The software has two packages: one for local governments to make their own inventories and another to assess community plans for reducing GHG emissions. The CCP software asks for certain types of data needed to generate indicators for the indicator report section. For buildings, the indicators are energy use and $\mathrm{CO}_{2}$ eq. Per operating hours, occupants, floor space, and commercial establishments. For the vehicle fleet, the indicators are energy use and $\mathrm{CO}_{2}$ eq. per vehicle kilometers traveled and per vehicle. For industry, the indicators are energy use and $\mathrm{CO}_{2}$ eq. per floor area, industrial employees, and industrial establishments (Torrie Smith Associates, 2001a).

\subsubsection{International Energy Agency}

The International Energy Agency (IEA) is an autonomous agency within the Organization for Economic Cooperation and Development (OECD) that carries out a comprehensive program of energy cooperation among OECD member countries. The IEA recently published a report on Indicators of Energy Use and Efficiency: Understanding the Link Between Energy and Human Activity (IEA, 1997). This report outlines the construction of energy efficiency indicators for all sectors of the economy. These indicators are designed to provide a more detailed understanding of overall energy use and energy-related GHG emissions trends. 
The IEA divides buildings into the residential sector (households) and the commercial or services sector. Residential sector indicators include energy (fuel and electricity) use per capita, energy use (fuel and electricity) per square meter, $\mathrm{CO}_{2}$ emissions per capita, and $\mathrm{CO}_{2}$ emissions per square meter. The service sector is comprised of non-residential, non-industrial, and nonagricultural buildings such as offices, hospitals, schools, shops, warehouses, etc. Indicators for the service sector include space heating energy consumption per square meter, electricity consumption per capita, electricity consumption per unit of floor area, electricity consumption per unit of service sector gross domestic product (GDP), electricity consumption per employee, and total primary energy per unit of service sector GDP.

The IEA divides the transport sector into travel and freight. Travel is defined as using vehicles to transport people whereas freight comprises the vehicles used to transport goods. Indicators for understanding travel trends include energy use per passenger kilometer, travel-related energy use per total national GDP, and tonnes of $\mathrm{CO}_{2}$ per capita. For freight, indicators include energy use per tonne-kilometer, freight-related energy use per total national GDP, and freight $\mathrm{CO}_{2}$ emissions per capita.

For industry, the IEA focuses on manufacturing and does not address agriculture, mining, construction. Indicators based on physical production, such as energy use per tonne of steel, can be used for those sectors for which there are adequate data. However, since the manufacturing sector is extremely diverse, IEA relies more heavily on economic indicators such as energy use per $\$$ value added, in order to be able to compare trends across manufacturing sub-sectors. Finally for $\mathrm{CO}_{2}$, IEA uses $\mathrm{CO}_{2}$ emissions per unit of manufacturing energy use and $\mathrm{CO}_{2}$ emissions per unit of manufacturing GDP.

\subsubsection{European Commission Energy Efficiency Indicators Project}

The Energy Efficiency Indicators in Europe project, funded by the European Commission (Directorate General on Energy), has developed the ODYSSEE database that uses data collected by the energy agencies in 15 member states of the European Union to generate indicators. The methodology for the system of energy efficiency indicators was developed by the French energy agency ADEME and the German Fraunhofer Institute (Bosseboeuf et al., 1997; ODYSSEE, 2001).

The database contains $\mathrm{CO}_{2}$ and energy efficiency indicators from 1980 to 1999 at the macro level, defined as the level of the economy as a whole, as well as for sectors and specific enduses, e.g. industrial process, mode of transport, or energy service in the household or service sectors. Energy is reported in metric tons of oil equivalent, e.g. 41.9 gigagoule (GJ)/metric ton. Data are reported for the different member states on the level of sectors, and is based on national statistics in each of the member states. No individual company data are included in this database.

For the services sector (i.e. buildings) energy intensity is reported as function of value added, number of employees or floor space. The energy use indicators are climate corrected.

Transport energy use in this sector is reported as part of transport energy use, not as part of the other sectors. Transport is sub-divided in freight (using grams of oil equivalent per ton-km) and passenger (using grams of oil equivalent per person-km). Indicators are sub-divided in energy 
intensity per mode of transport (i.e. cars and light duty vehicles (average stock and new), trucks, bus and train).

For industry, energy efficiency indicators are calculated for 18 sectors using value added as the activity indicator. For specific energy-intensive industries it also gives an energy intensity using a physical indicator for activity, e.g. steel, cement, and paper.

\subsubsection{International Network for Energy Demand Analysis in the Industrial Sector}

The International Network for Energy Demand Analysis in the Industrial Sector (INEDIS) is an international network of industrial sector experts who have developed a comprehensive database on industrial energy use by key industrial sub-sectors and developed of a standard set of indicators and methodologies for international comparisons in the industrial sector. Members of the INEDIS network are actively involved in defining the methodology for developing indicators and using these metrics to make international comparisons in the industrial sector (Phylipsen et al., 1996; Phylipsen et al., 1998; Farla, 2000; LBNL, 1999).

The INEDIS Network relies predominately on the use of physical production metrics for explaining subsector-specific trends in industrial energy use and for comparing these trends over time and between countries. The network has developed overall indicators as well as explanatory indicators for the following industrial subsectors: steel, aluminum, cement, pulp/paper, petroleum refining, ammonia, ethylene, chlorine, alkali, and petrochemicals (Phylipsen et al., 1998; Farla, 2000; LBNL, 1999).

\subsubsection{National}

\subsubsection{Australia-Greenhouse Challenge}

In 1995, Australia established the Greenhouse Challenge under the administration of the Australian Greenhouse Office (AGO). The Greenhouse Challenge is a voluntary initiative between the national government and industry to reduce, monitor, and report direct and indirect GHG emissions. The program is flexible in that it allows industry to develop methods to reduce GHGs while the government provides technical support. Industry is utilizing a wide array of mitigation strategies including carbon sequestration, energy efficiency, fuel switching, and fugitive emissions capture (AGO, 2000; AGO, 2001).

The Greenhouse Challenge Factors and Methodologies workbook (AGO, 2001) offers participants formulas and factors to estimate emissions from a wide variety of sources, including use of purchased electricity. The workbook provides guidance on the calculation of total GHG emissions. It does not provide any recommendations on activity-based metrics for GHG or energy intensity. Every participant in the Greenhouse Challenge has to report emissions annually or otherwise, as agreed to by the program administration. Some participants report an intensity indicator, including $\mathrm{CO}_{2} / \mathrm{kWh}$ for power generation, $\mathrm{CO}_{2} /$ surface area for services, $\mathrm{kgCO}_{2} /$ transactions for a fast-food restaurant, and $\mathrm{CO}_{2} /$ tonne of product in industry. 


\subsubsection{Canada-Voluntary Challenge Registry}

Canada's Voluntary Challenge Registry was established in 1995 as part of the National Action Program on Climate Change. The registry works with the private and public sector to report GHGs. Companies are encouraged but not required to report entity-wide emissions, and can decide to report emissions of "individual subsidiaries, business units, facilities or even projects" The registry standardizes reporting and allows for comparison among companies. Companies are awarded Gold, Silver, or Bronze Championship status depending on the number of criteria met. For example, to achieve Gold status $\mathrm{CO}_{2}$ reductions must fall below a baseline of 1990 levels (VCR-MRV, Inc. 1999). There are currently 778 organizations participating in the Registry (VCR-MRV, Inc. 2001).

The registry prefers that the calculation of GHG emissions be made in absolute tonnes of $\mathrm{CO}_{2}$ equivalent $\left(\mathrm{CO}_{2} \mathrm{e}\right)$ emissions as well as GHG emissions intensity per unit of production. Participants can choose to report in emissions intensity alone. Industry-specific reporting metrics such as energy per unit of output or energy per square meter of floor space can also be reported (VCR-MRV, Inc. 1999).

Commercial entities that operate buildings only (no manufacturing facilities) report GHG emissions from electricity, fuels, and wastes. The level of detail varies by company; some companies supply only annual total values while others provide total building area, heated building area, number of occupants or employees, and energy source by building (see, for example, VanCity Savings Credit Union 2000).

Industrial companies report GHG emissions from their buildings (office and warehouse), transportation, as well as from manufacturing operations. These include direct and indirect $\mathrm{CO}_{2}$ emissions as well as emissions of other GHGs such as nitrous oxide and methane. Energy intensity metrics are also used. For example, Algoma Steel tracks energy use per tonne shipped steel to measure progress toward its 2010 target. Alcoa tracks an emission index defined as $\mathrm{kgCO}_{2} \mathrm{eq} / \mathrm{kg}$ aluminum. Upstream petroleum producers in Canada use the Production Energy Intensity (PEI) and the Production Carbon Intensity (PCI) measurements, which have been established by the Canadian Association of Petroleum Producers (CAPP 2000). Many of the downstream petroleum producers use the Solomon Associates Energy Intensity Index (VCRMRV, Inc. 2001). These indices are described further in section 2.4.1 and 2.4.2.

Ontario Power Generation reports $\mathrm{CO}_{2}$ emissions per terawatt hours (TWh) for total emissions (including hydropower and nuclear) and for fossil-based generation only. Ontario Power Generation uses the intensity metric in their calculation of what their emissions would have been without the carbon reductions actions taken each year (Ontario Power Generation 2000).

\subsubsection{Canada - Canadian Industry Program for Energy Conservation}

The Canadian Industry Program for Energy Conservation (CIPEC) represents a partnership between government and private industry whose goal is to improve industrial energy efficiency in Canada. Between 1990 and 1999, CIPEC member companies realized average energy intensity improvements of 2 percent per year, significantly higher than the 1 percent per year commitment made by CIPEC in 1994. In turn, the CIPEC industries also reduced energy-related 
GHG emissions in Canada to 1.9 percent below 1990 levels by 1999. During the same period, GDP for these industries grew by 31.5 percent (CIPEC, 2001a). There are 38 trade associations that represent more than 4000 companies and more than 90 percent of secondary industrial energy demand in Canada in CIPEC (CIPEC, 2001b).

Energy efficiency improvement is tracked using both production-based and economic energy intensity metrics for each sector. Energy use per unit of product is used as the metric for numerous industries including aluminum (per tonne aluminum), breweries (per hectoliter of beer), cement (per tonne clinker), dairy (per hectoliter of cream and milk), fertilizers (per tonne fertilizer), lime (per tonne lime), mining (per tonne metal ore), oil sands (per cubic meter synthetic oil), petroleum products (per cubic meter petroleum product), pulp and paper (per tonne of pulp or paper), rubber (per tonne rubber product), and steel (per tonne shipped steel) (CIPEC, 2001a). Energy use per dollar of GDP or gross output is used as a metric for those industries where a production-based metric is not available. Examples include the electrical and electronics sector, food processing, general manufacturing, textiles, transportation equipment manufacturing, and wood products (CIPEC, 2001a).

The Canadian Industry Energy End-use Database and Analysis Centre (CIEEDAC), which provides analytical support for the CIPEC program, has developed extensive energy intensity and GHG intensity indicators for Canadian industry (Nyboer and Laurin, 2001a; Nyboer and Laurin, 2001b). Energy intensity indicators include energy use/tonne of product, energy use per \$ gross output, ${ }^{2}$ and energy use per $\$$ GDP output. GHG intensity indicators include $\mathrm{CO}_{2}$ emissions/tonne product, $\mathrm{CO}_{2}$ emissions/gross output, and $\mathrm{CO}_{2}$ emisison per \$GDP.

\subsubsection{Netherlands - Industrial Sector Agreements}

The industrial sector agreements in The Netherlands provide an example of a program that works with businesses through industry associations. The Dutch Long-Term Agreements (LTAs) on Energy Efficiency set sector-specific targets. These targets were negotiated between government and industry associations over a two-year period and signed in 1992. The agreements were aimed at meeting a national $\mathrm{CO}_{2}$ emission reduction target of $3 \%$ to $5 \%$ in 2000 compared to 1989 . $^{3}$ Each industry association, representing numerous individual companies, signed an agreement with the Dutch Ministry of Economic Affairs committing that industry to achieve specific energy efficiency improvements by 2000. In total, 30 agreements were signed involving about 1000 industrial companies and representing over $90 \%$ of industrial primary energy consumption in The Netherlands.

The process for setting the targets involved making a preliminary assessment of the energy efficiency potential of each industry as well as an inventory of economically viable measures that could be implemented by the companies within an industry association. These assessments, which were made by an independent government research agency, provided the basis for

\footnotetext{
${ }^{2}$ Gross output is defined as the total value of goods and services produced by an industry, a sum of the industry's inputs plus the change in value due to labor and capital investment (Nybour and Laurin, 2001a).

${ }^{3}$ Due to rapid economic growth over the period $1989-2000$, actual $\mathrm{CO}_{2}$ emissions in the year 2000 have increased instead of declined.
} 
discussions and negotiations between the industries and the government. The assessments are further used as a basis for the industry Long Term Plans which include an assessment of energy consumption in the base year (1989 in this case), a survey of opportunities for energy efficiency improvement, company energy plans, monitoring and energy management in each company, research and development of new low-energy technologies, demonstration projects for energy savings measures, assistance to individual companies, and information dissemination (Nuijen, 1998).

Once the Long Term Plan was established, the LTA was signed by the industry association, the Ministry of Economic Affairs, and the independent government research agency. The LTAs are contracts under civil law which are legally binding and pre-empt future regulatory requirements.

Annual emissions are reported using an energy efficiency index (EEI), which is a structureadjusted index of energy use per tonne of product produced. For sectors producing more than one product or intermediates, an EEI can be calculated for each product for the base year (most often 1989) and each subsequent year. For example in the iron and steel industry EEIs are calculated for 20 final products and 6 intermediates. The EEI for the individual products can be added to an EEI for each company. The EEIs of the participating companies are then summed to prepare a sector-wide EEI, which is reported publicly on an annual basis. (For further discussion of the EEI, see section 2.4.4 of this report).

The progress of the LTAs is tracked using the sector-specific EEIs. The EEI is the main monitoring and quantitative evaluation metric to measure progress for the LTAs. A second monitoring instrument is actual project implementation and results measurement of the projects. All sectors in The Netherlands use both measures, while the textiles industry uses only project monitoring.

The average target was a 20\% increase in energy efficiency over 1989 levels by 2000 (Nuijen 1998). At the end of the LTA agreement period, the industrial LTAs resulted in an average improvement in energy efficiency of $22.3 \%$ over the period 1989-2000 (Kerssemeeckers, 2002).

\subsubsection{Norwegian IEEN}

The Norwegian Industrial Energy Efficiency Network (IEEN) is basically an information network that disseminates information through a quarterly newsletter and annual report, as well as provides energy management and analysis support for the members of the network. The IEEN focuses on small and medium enterprises and, by the end of 1998, was comprised of about 600 companies from 13 industrial sectors representing 44\% of industrial energy use in Norway (Institute for Energy Technology 1998). The IEEN also collects energy use data and performs benchmarking by comparing a facility to its peers. Demonstration programs are financed up to $50 \%$ by IEEN and sector and technologies studies are financed completely by IEEN. To date, this program has seen an average annual intensity improvement of $1.4 \%$ among participating sectors (Finden 1998). One analysis found that a majority of the IEEN members experienced increased production and reduced specific energy consumption between 1995 and 1997 (Institute for Energy Technology 1998). 
Benchmarking and tracking of energy consumption is done using an intensity metric for each industry. The energy efficiency progress of a participating industry is tracked by calculating an average specific energy consumption (SEC) value, the participant's SEC, and a best practice SEC. For bakeries, for example, the SEC is defined as energy use $/ \mathrm{kg}$ of bread produced.

\subsubsection{Metrics Used by Individual Companies}

Hundreds, perhaps thousands, of companies worldwide have taken the initiative to report GHG emissions and/or energy use as part of the Environment, Health \& Safety (EHS) reporting, often in response to corporate commitments to reduce GHG emissions or improve energy efficiency. A large number of these companies are members of the World Business Council on Sustainable Development, which has developed the GHG Protocol with the World Resources Institute. However, most companies have developed their own inventorying and reporting methods before the WRI/WBSCD method was available. ${ }^{4}$

While most companies report total GHG emissions, some companies also report either a GHG indicator or an energy intensity indicator. Reporting of total emissions may include emissions from purchased services as energy or emissions from equity-share ownership (e.g. BP), while most companies only report direct emissions, and some include other GHGs (e.g. DuPont).

Intensity indicators vary by company. Some report energy intensity and some GHG intensity. Most use a physical measure of production, e.g. ton of product or number of products. Examples include Baxter International (energy use and GHG emissions/unit of production value), Dow Chemical (energy/lb product), Interface (energy use/unit of production), Holcim (GHG emissions/ton cement), Lafarge (energy/tonne cement), Miller Brewing (GHG emissions/barrel of beer produced), Pfizer (GHG emissions/\$ of revenue), Rio Tinto (GHG emissions/unit of production), Rohm and Haas (energy use/lb output), SC Johnson (GHG emissions/lb product), Shell (energy use/ton product), St. Lawrence Cement (GHG emissions/ton cementitious product), ST Microelectronics (energy use/\$ of production), Toyota (energy use/unit of production), and UTC (energy use/\$ revenue) (Margolick and Russell, 2001; U.S. EPA, 2003a).

\footnotetext{
${ }^{4}$ The official rollout of the WRI/WBSCD method was at the end of October 2001, while many European companies have taken up GHG emissions before that due to national policies in Europe on global warming.
} 
Table 1. Sector-Specific Metrics Used for Commercial Buildings, Transportation, Industry, and Power

\begin{tabular}{|c|c|c|c|c|}
\hline INTERNATIONAL & Commercial Buildings & Transportation & Industry & Power \\
\hline $\begin{array}{l}\text { Greenhouse Gas } \\
\text { Protocol Initiative } \\
\text { (GHGPI 2001) }\end{array}$ & - $\quad$ Sales/GHG emissions & & $\begin{array}{ll}\text { - } & \begin{array}{l}\text { Production volume/GHG } \\
\text { emissions }\end{array} \\
\text { - } & \text { GHG emissions/function } \\
\text { or service }\end{array}$ & $\begin{array}{ll}- & \text { Tonnes of } \\
\mathrm{CO}_{2} / \text { electricity unit } \\
\text { generated }\end{array}$ \\
\hline $\begin{array}{l}\text { UNEP GHG } \\
\text { Indicator } \\
\text { (Thomas et al. 2000) }\end{array}$ & $\begin{array}{ll}\text { - } & \text { GHG emissions/unit of sales } \\
\text { - } & \text { GHG emissions/unit of value } \\
\text { - } & \text { GHded } \\
\text { employees } & \\
\text { emissions/number of } \\
\end{array}$ & & $\begin{array}{l}\text { - } \text { GHG emissions/unit of } \\
\text { value added } \\
\text { GHG emissions/ unit of } \\
\text { production }\end{array}$ & \\
\hline $\begin{array}{l}\text { International Council } \\
\text { for Local } \\
\text { Environmental } \\
\text { Initiatives (ICLEI) } \\
\text { (ICLEI 2001) }\end{array}$ & $\begin{array}{ll}\text { - } & \text { Energy use/operating hours } \\
\text { - } & \text { Energy use/occupants } \\
\text { - } & \text { Energy use/floor space } \\
\text { - } & \text { Energy /commercial } \\
\text { - } & \mathrm{CO}_{2} \text { eq. Emissions/operating } \\
& \text { hours } \\
\text { - } & \mathrm{CO}_{2} \text { eq. Emissions/occupants } \\
\text { - } & \mathrm{CO}_{2} \text { eq emissions/floor space } \\
\text { - } & \mathrm{CO}_{2} \text { eq. Emissions/commercial } \\
& \text { establishments }\end{array}$ & $\begin{array}{ll}\text { - } & \text { Energy/vehicle kilometers } \\
\text { traveled } \\
\text { - } & \text { Energy/vehicle } \\
\text { - } & \mathrm{CO}_{2} \text { eq emissions/vehicle } \\
\text { kilometers traveled } \\
\text { - } \mathrm{CO}_{2} \text { eq emissions/vehicle }\end{array}$ & $\begin{array}{ll}\text { - } & \text { Energy/floor area } \\
\text { - } & \text { Energy/industrial } \\
\text { employees } \\
\text { - } & \text { Energy/industrial } \\
& \text { establishments } \\
\text { - } & \mathrm{CO}_{2} \text { eq. Emissions/floor } \\
\text { area } & \mathrm{CO}_{2} \text { eq. } \\
\text { Emissions/industrial } \\
\text { employees } \\
\mathrm{CO}_{2} \text { eq. } \\
\text { Emissions/industrial } \\
\text { establishments }\end{array}$ & \\
\hline $\begin{array}{l}\text { International Energy } \\
\text { Agency } \\
\text { (IEA, 1997) }\end{array}$ & $\begin{array}{ll}\text { - } & \text { Space heating energy use/square } \\
\text { - } & \text { Electricity use/capita } \\
\text { - } & \text { Electricity use/unit of floor area } \\
\text { - } & \text { Electricity use/unit of service } \\
\text { - } & \text { Eector GDP } \\
\text { - } & \text { Toctricity use/employee } \\
\text { - } & \mathrm{CO}_{2} \text { emissions/capita } \\
\text { - } & \mathrm{CO}_{2} \text { emissions/unit of services } \\
& \mathrm{GDP}^{-}\end{array}$ & $\begin{array}{ll}\text { - } & \text { Energy use/passenger } \\
& \text { kilometer } \\
\text { - } & \text { Travel-related energy } \\
& \text { use/total national GDP } \\
\text { - } & \text { Tonnes of } \mathrm{CO}_{2} / \text { capita } \\
\text { - } & \text { Energy use/tonne- } \\
& \text { kilometer of freight } \\
\text { - } & \text { Freight-related energy } \\
\text { - } & \text { use/total national GDP } \\
\text { Freight } \mathrm{CO}_{2} \\
\text { emissions/capita }\end{array}$ & $\begin{array}{ll}- & \text { Energy use/tonne product } \\
- & \text { Energy use/\$ value added } \\
\text { - } & \mathrm{CO}_{2} \text { emissions/unit of } \\
& \text { manufacturing energy use } \\
- & \mathrm{CO}_{2} \text { emissions/unit of } \\
& \text { manufacturing GDP }\end{array}$ & \\
\hline
\end{tabular}




\begin{tabular}{|c|c|c|c|}
\hline \multicolumn{4}{|l|}{$\begin{array}{l}\text { European } \\
\text { Commission Energy } \\
\text { Efficiency Indicators } \\
\text { Project } \\
\text { (ODYSSEE 2001) }\end{array}$} \\
\hline $\begin{array}{l}\text { International } \\
\text { Network for Energy } \\
\text { Demand Analysis in } \\
\text { the Industrial Sector } \\
\text { (LBNL, 1999) }\end{array}$ & & & $\begin{array}{ll}- & \text { Energy use/tonne product } \\
\text { - } & \mathrm{CO}_{2} \text { emissions/tonne of } \\
& \text { product }\end{array}$ \\
\hline
\end{tabular}

\begin{tabular}{|c|c|c|c|c|}
\hline NATIONAL & Commercial Buildings & Transportation & Industry & Power \\
\hline $\begin{array}{l}\text { Australia - } \\
\text { Greenhouse } \\
\text { Challenge (AGO } \\
\text { 2001) }\end{array}$ & $\begin{array}{l}\text { - } \mathrm{CO}_{2} \text { emissions/surface area } \\
\text { - } \quad \mathrm{CO}_{2} \text { emissions/transactions }\end{array}$ & & - $\mathrm{CO}_{2} /$ tonne of product & - $\mathrm{CO}_{2}$ emissions $/ \mathrm{kWh}$ \\
\hline $\begin{array}{l}\text { Canada - Voluntary } \\
\text { Challenge and } \\
\text { Registry, Inc. } \\
\text { (VCR-MRV, Inc. } \\
\text { 1999) }\end{array}$ & $\begin{array}{l}\text { - } \text { GHG emissions/total building } \\
\text { area } \\
\text { - } \text { GHG emissions/heated building } \\
\text { area } \\
\text { - } \text { GHG emissions/number of } \\
\text { occupants or employees } \\
\text { - } \quad \text { Energy/square meter floor area }\end{array}$ & & $\begin{array}{ll}\text { - } & \mathrm{CO}_{2} \text { eq./cubic meter of oil } \\
\text { eq. } \\
\text { - } & \mathrm{CO}_{2} \text { eq/unit of output } \\
\text { - } & \text { Energy/unit of output }\end{array}$ & $\begin{array}{ll}\text { - } & \text { Total } \mathrm{CO}_{2} \\
\text { emissions/TWh } \\
\text { - } & \text { Fossil CO2 } \\
\text { emissions/TWh }\end{array}$ \\
\hline $\begin{array}{l}\text { Canada - CIPEC } \\
\text { (CIPEC 2001b) }\end{array}$ & & & $\begin{array}{ll}\text { - } & \text { Energy/t product } \\
\text { - } & \text { Energy/gross output } \\
\text { - } & \text { Energy/GDP } \\
\text { - } & \text { GHG emissions/t product } \\
\text { - } & \text { GHG emissions/gross } \\
& \text { output } \\
\text { - } & \text { GHG emissions/GDP }\end{array}$ & \\
\hline $\begin{array}{l}\text { Netherlands - } \\
\text { Industrial Sector } \\
\text { Agreements } \\
\text { (Nuijen 1998) }\end{array}$ & $\begin{array}{l}\text { Climate-corrected energy use/unit } \\
\text { of surface area (square meters) }\end{array}$ & $\begin{array}{l}\text { - Energy use/person- } \\
\text { kilometer }\end{array}$ & & \\
\hline $\begin{array}{l}\text { Norwegian IEEN } \\
\text { (Institute for Energy } \\
\text { Technology 1998) }\end{array}$ & & & - $\quad$ Energy use/t product & \\
\hline
\end{tabular}




\subsection{Identifying and Developing Industry-Specific Metrics for Use in the California Climate Action Registry}

In order to identify and, if needed, develop industry-specific metrics for use by Registry participants, it is necessary to determine the relative importance (based on energy consumption or GHG emissions) of specific building types, industrial/manufacturing/agriculture facilities, and transport fleet modes in California. In the sections below, we rank sub-sectors of the buildings, industrial, and transport sectors by electricity and natural gas consumption. ${ }^{5}$ We then discuss the construction and availability of industry-specific metrics for each of these end-use sectors.

Metrics for measuring the $\mathrm{CO}_{2}$ intensity of electricity production are not described separately since the standard measurement of $\mathrm{CO}_{2}$ emissions per unit of electricity produced is a commonly accepted metric.

\subsubsection{California Energy and $\mathrm{CO}_{2}$ Emissions - All Sectors}

In 1999, GHG emissions in California totaled 398 million metric tonnes $\mathrm{CO}_{2}$ equivalent $\left(\mathrm{MMTCO}_{2}\right.$ eq.). Of this, $90 \%$ of the emissions $\left(356 \mathrm{MMTCO}_{2}\right.$ eq.) were from the combustion of fossil fuels. Table 2 provides information on fossil fuel consumption and related $\mathrm{CO}_{2}$ emissions in California in 1999 for residential and commercial buildings, industry, transportation, and electric power (California Energy Commission, 2002).

Table 2. Final Energy Use and Fossil-Fuel-Related $\mathrm{CO}_{2}$ Emissions in California in 1999

\begin{tabular}{|l|c|c|c|c|}
\hline & $\begin{array}{c}\text { Final Energy Use } \\
(\mathbf{T B t u})\end{array}$ & Share of Total & $\begin{array}{c}\mathbf{C O}_{\mathbf{2}} \text { Emissions } \\
\left(\mathbf{M M T C O}_{\mathbf{2}} \mathbf{e q .}\right)\end{array}$ & Share of Total \\
\hline Residential & 601 & $11 \%$ & 32.0 & $9 \%$ \\
\hline Commercial & 264 & $5 \%$ & 14.2 & $4 \%$ \\
\hline Industrial & 1740 & $31 \%$ & 92.5 & $26 \%$ \\
\hline Transportation & 2926 & $52 \%$ & 209.9 & $59 \%$ \\
\hline Electric Power & 146 & $3 \%$ & 7.7 & $2 \%$ \\
\hline Total & 5677 & & 356.3 & \\
\hline
\end{tabular}

Source: CEC, 2002.

\subsubsection{Buildings Sector Energy Use and $\mathrm{CO}_{2}$ Emissions}

Commercial and residential buildings in California consumed 865 TBtu of final energy in 1999. We focus on commercial buildings only, however, because we expect commercial entities to be more likely participants in the Registry than residential building owners. When commercial buildings electricity and natural gas use are combined, the largest share was consumed in officetype buildings, ${ }^{6}$ followed by restaurants, retail stores, food stores, and warehouses, respectively.

\footnotetext{
${ }^{5}$ LBNL has only used data on natural gas and electricity consumption for the sub-sectors; data on other fuels was not available for this study.

6 "Office-type buildings" is a large category that encompasses large and small offices as well as schools, colleges, hotels, motels, hospitals, and miscellaneous buildings. SICs for this category are 07, 554, 60, 61, 62, 63, 64, 65, 66, $67,70,72,73,75,76,78,79,80,81,82,83,84,86,87,89,91,92,93,94,95,96,97$. SICs for other categories are: restaurants - 58; retail stores - 52,53,55,56,57,59; food stores - 54, 592; warehouses - 42,50,51.
} 
These relative rankings change slightly if only electricity use or only natural gas use are considered (see Table 3).

Our survey of existing metrics for buildings found various metrics in use by international protocols, academic institutions, national governments, and businesses. Table 4 summarizes the buildings-related metrics used to measure GHG emissions and energy use. Physical metrics for measuring the intensity of GHG emissions or energy consumption in commercial buildings are generally based on building floor area (square feet or square meters) or number of building occupants. Emissions or energy use per occupant or employee can also be used, especially for office buildings where each additional employee typically requires conditioned space and office equipment. These metrics can be calculated by specific building types such as office buildings, restaurants, food stores, retail stores, and warehouses. Economic metrics are based on the economic value produced by the occupant of the commercial building. These metrics measure emissions or energy use per dollar of economic value produced.

Table 3. California Commercial Buildings Ranked by Energy Consumption (Largest to Smallest Sub-sectors)

Combined Electricity and Natural Gas Consumption

Office-type Buildings

Restaurants

Retail Stores

Food Stores

Warehouses

Electricity Consumption Only

Office-type Buildings

Retail Stores

Food Stores

Restaurants

Warehouses

Natural Gas Consumption Only

Office-type Buildings

Restaurants

Warehouses

Food Stores

Retail Stores 
Table 4. Metrics for Buildings Energy Consumption and GHG Emissions

\begin{tabular}{|l|l|l|}
\hline & Energy Consumption & GHG Emissions \\
\hline Physical Metrics & & \\
\hline & Energy use/operating hours & Emissions/operating hours \\
\hline & Energy use/occupants & Emissions/occupants \\
\hline & Energy use/employee & Emissions/employee \\
\hline & Electricity use/capita & Emissions/capita \\
\hline & Electricity use/employee & Emissions/employee \\
\hline & Energy use/floor space & Emissions/floor space \\
\hline & Space heating energy use/floor area & Emissions/heated building area \\
\hline & Electricity use/unit of floor area & \\
\hline & Energy/commercial establishments & Emissions/commercial establishments \\
\hline & & \\
\hline & Electricity use/unit of services GDP & Emissions/unit of services GDP \\
\hline & Energy/unit of value added & Emissions/unit of value added \\
\hline & Primary energy/unit of services GDP & Emissions/unit of sales \\
\hline & & Emissions/transactions \\
\hline
\end{tabular}

Table 5 illustrates the type of information available for development of specific metrics in California. As shown, data on total floor space and number of employees by building type are available as well as data on value of sales, receipts, and shipments are available by building type (U.S. Census, 1997).

Table 5. Data Available for Development of Metrics for Commercial Buildings in California

\begin{tabular}{|l|c|c|c|c|c|}
\hline Building Type & $\begin{array}{c}\text { Electricity } \\
\text { Use } \\
\text { (TBtu) }\end{array}$ & $\begin{array}{c}\text { Natural } \\
\text { Gas Use } \\
\text { (TBtu) }\end{array}$ & $\begin{array}{c}\text { Total } \\
\text { Floorspace } \\
\text { (million ft2) }\end{array}$ & $\begin{array}{c}\text { Number } \\
\text { of Employees }\end{array}$ & $\begin{array}{c}\text { Value of Sales, } \\
\text { Receipts, or } \\
\text { Shipments } \\
\mathbf{( 1 0 0 0 )}\end{array}$ \\
\hline Office-type & 188.65 & 151.14 & 806010 & $1,209,576$ & $154,337,339$ \\
\hline Restaurants & 22.71 & 35.58 & 12710 & 861,563 & $30,878,362$ \\
\hline Retail stores & 38.73 & 4.14 & 75457 & 708,962 & $145,802,025$ \\
\hline Food Stores & 27.34 & 6.21 & 20048 & 282,750 & $49,416,145$ \\
\hline Warehouses & 19.83 & 6.87 & 68982 & 520,177 & $225,228,743$ \\
\hline
\end{tabular}

Notes: Electricity, natural gas, and floorspace data are for 2000, employee and value of sales data are for 1997.

Sources: Electricity and natural gas - California Energy Commission; other data - U.S. Census, 1997

\subsubsection{Transportation Sector Energy Use and $\mathrm{CO}_{2}$ Emissions}

Transportation is by far the largest energy-consuming and GHG-emitting sector in California, emitting almost $60 \%$ of total state GHG emissions in 1999 (California Energy Commission, 2002). Transportation is broadly divided in to travel or freight, but can also be divided into passenger transportation (local and interurban), freight transportation by motor vehicles, railroad transportation, water transportation, and air transportation. ${ }^{7}$ Table 6 provides typical energy and GHG emissions metrics for the transportation sector.

\footnotetext{
${ }^{7}$ Statistics are also available for pipelines, transportation services, and the U.S. Postal Service, but have not been included in this report.
} 
Table 6. Metrics for Transportation Energy Consumption and GHG Emissions.

\begin{tabular}{|l|l|l|}
\hline & Energy Consumption & GHG Emissions \\
\hline Physical Metrics & & \\
\hline & Energy/vehicle miles traveled & Emissions/vehicle miles traveled \\
\hline & Energy/vehicle & Emissions/vehicle \\
\hline & Energy/passenger miles & Emissions/capita \\
\hline & Energy/ton-miles of freight & Freight emissions/capita \\
\hline & Freight energy/ton-mile & \\
\hline Economic Metrics & Passenger energy/person km & \\
\hline & & \\
\hline & Travel-related energy/total national GDP & \\
\hline & Freight-related energy/total national GDP & \\
\hline
\end{tabular}

\subsubsection{Industrial Sector Energy Use and $\mathrm{CO}_{2}$ Emissions}

Industry in California consumed 1740 TBtu of final energy in 1999. Of the industrial electricity and natural gas use combined, the largest share was consumed the oil and gas extraction subsector, followed by petroleum and coal products; food and kindred products; stone, clay, and glass products; and chemicals and allied products (see Table 7). These relative rankings change if only electricity use or only natural gas use are considered. For example, the electronic and other equipment sub-sector uses a significantly higher amount of electricity than many of the other sectors and is ranked second when only electricity is considered.

Table 7. Industries Ranked by Energy Consumption (Largest to Smallest Subsectors)

\begin{tabular}{|c|c|}
\hline \multicolumn{2}{|c|}{ Combined Electricity and Natural Gas Consumption } \\
\hline SIC Code & Industrial Sub-Sector \\
\hline 13 & Oil and gas extraction \\
\hline 29 & Petroleum and coal products \\
\hline 20 & Food and kindred products \\
\hline 32 & Stone, clay, and glass products \\
\hline 28 & Chemicals and allied products \\
\hline 1 & Agricultural production-crops \\
\hline 36 & Electronic and other electric equipment \\
\hline 33 & Primary metal industries \\
\hline 26 & Paper and allied products \\
\hline 34 & Fabricated metal products \\
\hline 37 & Transportation equipment \\
\hline 35 & Industrial machinery and equipment \\
\hline 30 & Rubber and miscellaneous plastics products \\
\hline 22 & Textile mill products \\
\hline 24 & Lumber and wood products \\
\hline 14 & Nonmetallic mineral, except fuels \\
\hline 38 & Instruments and related products \\
\hline 27 & Printing and publishing \\
\hline 15 & General building contractors \\
\hline 2 & Agricultural production - livestock \\
\hline 39 & Miscellaneous manufacturing industries \\
\hline 23 & Apparel and other textile products \\
\hline 25 & Furniture and fixtures \\
\hline 10 & Metal mining \\
\hline 31 & Leather and leather products \\
\hline
\end{tabular}




\begin{tabular}{|c|c|}
\hline \multicolumn{2}{|c|}{ Electricity Consumption Only } \\
\hline 29 & Petroleum and coal products \\
\hline 36 & Electronic and other electric equipment \\
\hline 20 & Food and kindred products \\
\hline 28 & Chemicals and allied products \\
\hline 13 & Oil and gas extraction \\
\hline 32 & Stone, clay, and glass products \\
\hline 1 & Agricultural production-crops \\
\hline 35 & Industrial machinery and equipment \\
\hline 37 & Transportation equipment \\
\hline 30 & Rubber and miscellaneous plastics products \\
\hline 26 & Paper and allied products \\
\hline 33 & Primary metal industries \\
\hline 34 & Fabricated metal products \\
\hline 38 & Instruments and related products \\
\hline 24 & Lumber and wood products \\
\hline 27 & Printing and publishing \\
\hline 2 & Agricultural production - livestock \\
\hline 15 & General building contractors \\
\hline 14 & Nonmetallic mineral, except fuels \\
\hline 22 & Textile mill products \\
\hline 39 & Miscellaneous manufacturing industries \\
\hline 23 & Apparel and other textile products \\
\hline 25 & Furniture and fixtures \\
\hline 10 & Metal mining \\
\hline 31 & Leather and leather products \\
\hline \multicolumn{2}{|c|}{ Natural Gas Consumption Only } \\
\hline 13 & Oil and gas extraction \\
\hline 29 & Petroleum and coal products \\
\hline 20 & Food and kindred products \\
\hline 32 & Stone, clay, and glass products \\
\hline 33 & Primary metal industries \\
\hline 28 & Chemicals and allied products \\
\hline 26 & Paper and allied products \\
\hline 1 & Agricultural production-crops \\
\hline 34 & Fabricated metal products \\
\hline 22 & Textile mill products \\
\hline 37 & Transportation equipment \\
\hline 36 & Electronic and other electric equipment \\
\hline 14 & Nonmetallic mineral, except fuels \\
\hline 30 & Rubber and miscellaneous plastics products \\
\hline 24 & Lumber and wood products \\
\hline 35 & Industrial machinery and equipment \\
\hline 15 & General building contractors \\
\hline 27 & Printing and publishing \\
\hline 38 & Instruments and related products \\
\hline 2 & Agricultural production - livestock \\
\hline 25 & Furniture and fixtures \\
\hline 39 & Miscellaneous manufacturing industries \\
\hline 23 & Apparel and other textile products \\
\hline 31 & Leather and leather products \\
\hline 10 & Metal mining \\
\hline
\end{tabular}


Table 8 summarizes the industry-related metrics used to measure GHG emissions and energy consumption that are used by various governments, research institutions, and businesses. Physical metrics for measuring the intensity of GHG emissions or energy consumption in industry are based on floor area (square feet or square meters), number of industrial employees, number of industrial establishments, or units of product produced. Metrics measuring emissions or energy use per unit of product can also be indexed in order to compare company performance to other companies or previous years. Such indexing can be designed to account for variations in products from year-to-year. Economic metrics are based on energy use per dollar of economic value or industrial output.

Table 8. Metrics for Industry Energy Consumption and GHG Emissions*

\begin{tabular}{|l|l|l|}
\hline & Energy Consumption & GHG Emissions \\
\hline Physical Metrics & & \\
\hline & Energy/floor area & Emissions/floor area \\
\hline & Energy/industrial employees & Emissions/industrial employees \\
& Energy/industrial establishments & Emissions/industrial establishments \\
\hline & Energy use/unit of product & Emissions/unit of product \\
\hline & Energy efficiency index (EEI) & Emissions/function or service \\
\hline & Production Energy Intensity (PEI) & Carbon Energy Intensity (CEI) \\
\hline & Enegy Intensity Index (EII) & \\
\hline & Production Energy Intensity Index (PEEI) & Emissions/unit of manufacturing energy \\
& & \\
\hline Economic Metrics & Electricity/kg product & \\
\hline & & Emissions/\$ gross output \\
\hline & Energy/\$ gross output & Emissions/GDP \\
\hline & Energy/GDP & \\
\hline
\end{tabular}

* see Section 2.4 for a discussion of the various indices 
Table 9 illustrates the type of information available for development of metrics in California. As shown, data on number of employees, value of sales, receipts, and shipments are available by industrial sub-sector (U.S. Census, 1997). Information on units of production by industrial subsector may be available through industry associations and other sources.

Table 9. Data Available for Development of Metrics for Industry in California

\begin{tabular}{|c|c|c|c|c|}
\hline & $\begin{array}{c}\text { Electricity } \\
\text { Use } \\
\text { (TBtu) }\end{array}$ & $\begin{array}{c}\text { Natural Gas } \\
\text { Use (TBtu) }\end{array}$ & $\begin{array}{c}\text { Number } \\
\text { of Employees }\end{array}$ & $\begin{array}{c}\text { Value of Sales, } \\
\text { Receipts, or } \\
\text { Shipments } \\
(\$ 1000)\end{array}$ \\
\hline Agricultural production-crops & 10.73 & 14.5 & $\mathrm{NG}$ & $\mathrm{NG}$ \\
\hline Agricultural production - livestock & 3.82 & 1.6 & $\mathrm{NG}$ & NG \\
\hline Metal mining & 0.51 & 0.0 & $(1000-2499)$ & $\mathrm{D}$ \\
\hline Oil and gas extraction & 13.12 & 560.8 & 14,580 & $8,574,829$ \\
\hline Nonmetallic mineral, except fuels & 2.29 & 6.1 & 5,569 & $1,514,417$ \\
\hline General building contractors & 3.38 & 2.2 & 120,159 & $40,598,045$ \\
\hline Food and kindred products & 17.51 & 66.6 & 175278 & $50,715,472$ \\
\hline Textile mill products & 1.65 & 9.8 & 20263 & $2,555,263$ \\
\hline Apparel and other textile products & 1.49 & 0.7 & 151002 & $14,327,187$ \\
\hline Lumber and wood products & 4.80 & 4.8 & 53254 & $7,599,963$ \\
\hline Furniture and fixtures & 1.21 & 0.9 & 57955 & $6,150,031$ \\
\hline Paper and allied products & 8.26 & 15.1 & 38903 & $8,704,253$ \\
\hline Printing and publishing & 4.07 & 2.2 & $(100,000+)$ & $\mathrm{D}$ \\
\hline Chemicals and allied products & 13.34 & 16.3 & 60080 & $18,990,051$ \\
\hline Petroleum and coal products & 21.26 & 143.2 & $(10 \mathrm{k}-24999)$ & $\mathrm{D}$ \\
\hline Rubber and miscellaneous plastics products & 8.45 & 5.2 & 90002 & $12,920,094$ \\
\hline Leather and leather products & 0.10 & 0.1 & $(5000-9999)$ & $\mathrm{D}$ \\
\hline Stone, clay, and glass products & 11.22 & 30.2 & 42748 & $7,490,412$ \\
\hline Primary metal industries & 7.26 & 16.9 & 28705 & $6,905,551$ \\
\hline Fabricated metal products & 6.71 & 11.1 & 149463 & $20,476,539$ \\
\hline Industrial machinery and equipment & 10.35 & 3.8 & 203285 & $56,675,729$ \\
\hline Electronic and other electric equipment & 18.87 & 6.3 & 276711 & $65,019,561$ \\
\hline Transportation equipment & 8.75 & 9.0 & 156046 & $33,605,752$ \\
\hline Instruments and related products & 5.99 & 1.8 & 144543 & $29,102,041$ \\
\hline Miscellaneous manufacturing industries & 1.53 & 0.8 & 46100 & $5,961,448$ \\
\hline
\end{tabular}

$\mathrm{NG}=$ not given in Census report, $\mathrm{D}=$ withheld to avoid disclosure

Table 10 illustrates the types of metrics developed for industrial sub-sectors, in order of the ranking of California industrial sub-sectors by combined electricity and natural gas consumption. 
Table 10. Industry-Specific Metrics, Ranked by California Industrial Combined Electricity and Natural Gas Consumption (Largest to Smallest Subsectors)

\begin{tabular}{|c|c|c|c|c|}
\hline $\begin{array}{c}\text { SIC } \\
\text { Code } \\
\end{array}$ & Description & Energy Metric & Emissions Metric & Source \\
\hline \multirow[t]{2}{*}{13} & Oil and gas extraction & & & \\
\hline & & Production Energy Intensity & $\begin{array}{l}\text { Production Carbon Intensity (PCI) } \\
=\mathrm{CO}_{2} \text { eq./cubic meter oil eq. }\end{array}$ & CAPP, 2000 \\
\hline $\begin{array}{l}131 \\
132 \\
138 \\
\end{array}$ & $\begin{array}{l}\text { Crude petroleum and natural gas } \\
\text { Natural gas liquids } \\
\text { Oil and gas field services }\end{array}$ & & & \\
\hline \multirow[t]{2}{*}{29} & Petroleum and coal products & & & \\
\hline & & $\begin{array}{l}\text { Energy Intensity Index (EII) } \\
\text { Energy/\$ gross output } \\
\text { Energy/GDP }\end{array}$ & $\begin{array}{l}\text { GHG/\$ gross output } \\
\text { GHG/GDP }\end{array}$ & $\begin{array}{l}\text { Solomon Associates, 2001 } \\
\text { Nyboer and Laurin, 2001a } \\
\text { Nyboer and Laurin, 2001b }\end{array}$ \\
\hline 291 & Petroleum refining & $\begin{array}{l}\text { Energy efficiency index } \\
\text { Energy/cubic meter fossil fuels } \\
\text { Energy/\$ gross output } \\
\text { Energy/GDP }\end{array}$ & $\begin{array}{l}\text { GHG/cubic meter fossil fuels } \\
\text { GHG/\$ gross output } \\
\text { GHG/GDP }\end{array}$ & $\begin{array}{l}\text { Ministry of Economic Affairs, } 1998 \\
\text { Nyboer and Laurin, 2001a } \\
\text { Nyboer and Laurin, 2001b }\end{array}$ \\
\hline $\begin{array}{l}295 \\
299 \\
\end{array}$ & $\begin{array}{l}\text { Asphalt paving and roofing materials } \\
\text { Misc. petroleum and coal products }\end{array}$ & & & \\
\hline 20 & Food and kindred products & & & \\
\hline 201 & Meat products & $\begin{array}{l}\text { Energy/tonne } \\
\text { Energy efficiency index }\end{array}$ & & $\begin{array}{l}\text { Institute for Energy Technology, } 1998 \\
\text { Ministry of Economic Affairs, } 1998\end{array}$ \\
\hline 202 & Dairy products & $\begin{array}{l}\text { Energy efficiency index } \\
\text { Energy/liter weighted production } \\
\text { Energy/tonne milk and cream } \\
\text { Energy/\$ gross output } \\
\text { Energy/GDP }\end{array}$ & $\begin{array}{l}\text { GHG/kiloliter milk and cream } \\
\text { GHG/\$ gross output } \\
\text { GHG/GDP }\end{array}$ & $\begin{array}{l}\text { Ministry of Economic Affairs, } 1998 \\
\text { Institute for Energy Technology, } 1998 \\
\text { Nyboer and Laurin, 2001a } \\
\text { Nyboer and Laurin, 2001b }\end{array}$ \\
\hline 203 & Preserved fruits and vegetables & $\begin{array}{l}\text { Energy efficiency index } \\
\text { Energy/\$ gross output } \\
\text { Energy/GDP }\end{array}$ & $\begin{array}{l}\text { GHG/\$ gross output } \\
\text { GHG/GDP }\end{array}$ & $\begin{array}{l}\text { Ministry of Economic Affairs, } 1998 \\
\text { Nyboer and Laurin, 2001a } \\
\text { Nyboer and Laurin, 2001b }\end{array}$ \\
\hline 204 & Grain mill products & & & \\
\hline
\end{tabular}




\begin{tabular}{|c|c|c|c|c|}
\hline SIC Code & Description & Energy Metric & Emissions Metric & \begin{tabular}{|c|} 
Source \\
\end{tabular} \\
\hline 205 & Bakery products & $\begin{array}{l}\text { Energy/kg bread } \\
\text { Energy/\$ gross output } \\
\text { Energy/GDP }\end{array}$ & $\begin{array}{l}\text { GHG/\$ gross output } \\
\text { GHG/GDP }\end{array}$ & $\begin{array}{l}\text { Institute for Energy Technology, } 1998 \\
\text { Nyboer and Laurin, 2001a } \\
\text { Nyboer and Laurin, 2001b }\end{array}$ \\
\hline 206 & Sugar and confectionery products & Energy efficiency index & & Ministry of Economic Affairs, 1998 \\
\hline 207 & Fats and oils & Energy efficiency index & & Ministry of Economic Affairs, 1998 \\
\hline \multirow[t]{3}{*}{208} & Beverages & $\begin{array}{l}\text { Energy/\$ gross output } \\
\text { Energy/GDP }\end{array}$ & $\begin{array}{l}\text { GHG/\$ gross output } \\
\text { GHG/GDP }\end{array}$ & $\begin{array}{l}\text { Nyboer and Laurin, 2001a } \\
\text { Nyboer and Laurin, 2001b }\end{array}$ \\
\hline & Soft Drinks & $\begin{array}{l}\text { Energy efficiency index } \\
\text { Energy/\$ gross output } \\
\text { Energy/GDP }\end{array}$ & $\begin{array}{l}\text { GHG/\$ gross output } \\
\text { GHG/GDP }\end{array}$ & $\begin{array}{l}\text { Ministry of Economic Affairs, } 1998 \\
\text { Nyboer and Laurin, 2001a } \\
\text { Nyboer and Laurin, 2001b }\end{array}$ \\
\hline & Brewery Products & $\begin{array}{l}\text { Energy/hectoliter of beer equiv } \\
\text { Energy/hectoliter of beer } \\
\text { Energy/\$ gross output } \\
\text { Energy/GDP }\end{array}$ & $\begin{array}{l}\text { GHG/hectoliter of beer } \\
\text { GHG/\$ gross output } \\
\text { GHG/GDP }\end{array}$ & $\begin{array}{l}\text { Institute for Energy Technology, } 1998 \\
\text { Nyboer and Laurin, 2001a } \\
\text { Nyboer and Laurin, 2001b }\end{array}$ \\
\hline 209 & Misc. food and kindred products & & & \\
\hline \multirow[t]{2}{*}{32} & Stone, clay, and glass products & & & \\
\hline & Glass and glass products & $\begin{array}{l}\text { Energy efficiency index } \\
\text { Energy/\$ gross output } \\
\text { Energy/GDP }\end{array}$ & $\begin{array}{l}\text { GHG/\$ gross output } \\
\text { GHG/GDP }\end{array}$ & $\begin{array}{l}\text { Ministry of Economic Affairs, } 1998 \\
\text { Nyboer and Laurin, 2001a } \\
\text { Nyboer and Laurin, 2001b }\end{array}$ \\
\hline $\begin{array}{l}321 \\
322 \\
323\end{array}$ & $\begin{array}{l}\text { Flat glass } \\
\text { Glass \& glassware, pressed or blown } \\
\text { Products of purchased glass }\end{array}$ & & & \\
\hline 324 & Cement, hydraulic & $\begin{array}{l}\text { Energy efficiency index } \\
\text { Energy/tonne clinker } \\
\text { Energy/\$ gross output } \\
\text { Energy/GDP }\end{array}$ & $\begin{array}{l}\text { GHG/tonne clinker } \\
\text { GHG/\$ gross output } \\
\text { GHG/GDP }\end{array}$ & $\begin{array}{l}\text { Ministry of Economic Affairs, } 1998 \\
\text { Nyboer and Laurin, 2001a } \\
\text { Nyboer and Laurin, 2001b }\end{array}$ \\
\hline 325 & Structural clay products (bricks, tile) & Energy efficiency index & & Ministry of Economic Affairs, 1998 \\
\hline 326 & Pottery & Energy efficiency index & & Ministry of Economic Affairs, 1998 \\
\hline $\begin{array}{l}327 \\
328 \\
329\end{array}$ & $\begin{array}{l}\text { Concrete, gypsum \& plaster products } \\
\text { Cut stone and stone products } \\
\text { Misc. nonmetallic mineral products }\end{array}$ & & & \\
\hline
\end{tabular}




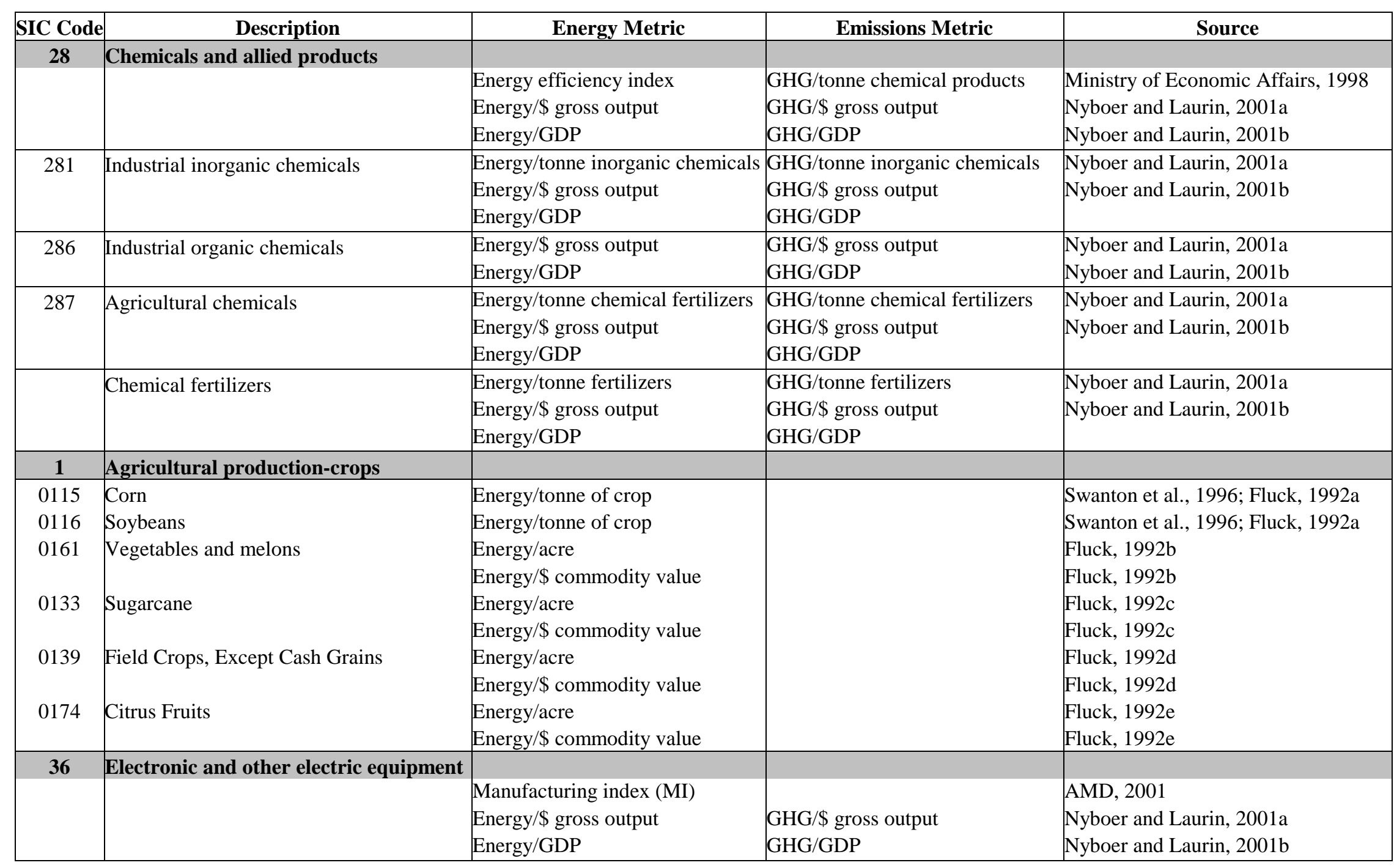




\begin{tabular}{|c|c|c|c|c|}
\hline SIC Code & Description & Energy Metric & Emissions Metric & Source \\
\hline \multirow[t]{3}{*}{33} & Primary metal industries & & & \\
\hline & & Energy/\$ gross output & GHG/\$ gross output & Nyboer and Laurin, 2001a \\
\hline & & Energy/GDP & GHG/GDP & Nyboer and Laurin, 2001b \\
\hline \multirow[t]{4}{*}{331} & Blast furnace and basic steel & Energy efficiency index & GHG/tonne steel & Ministry of Economic Affairs, 1998 \\
\hline & & Energy/tonne steel & GHG/\$ gross output & Nyboer and Laurin, 2001a \\
\hline & & Energy/\$ gross output & GHG/GDP & Nyboer and Laurin, 2001b \\
\hline & & Energy/GDP & & \\
\hline \multirow[t]{10}{*}{332} & Iron and steel foundries & Energy efficiency index & & Ministry of Economic Affairs, 1998 \\
\hline & & Energy $/ \$$ gross output & GHG/\$ gross output & Nyboer and Laurin, 2001a \\
\hline & & Energy/GDP & GHG/GDP & Nyboer and Laurin, 2001b \\
\hline & Non-ferrous Metal Smelters \& Refineries & Energy efficiency index & & Ministry of Economic Affairs, 1998 \\
\hline & & Energy/\$ gross output & GHG/\$ gross output & Nyboer and Laurin, 2001a \\
\hline & & Energy/GDP & GHG/GDP & Nyboer and Laurin, 2001b \\
\hline & & Energy/tonne aluminum & GHG/tonne aluminum & Institute for Energy Technology, \\
\hline & Primary Production of Aluminum & & & 1998 \\
\hline & & & & Nyboer and Laurin, 2001a \\
\hline & & & & Nyboer and Laurin, 2001b \\
\hline \multirow[t]{4}{*}{3335} & Aluminum rolling and drawing & Energy/\$ gross output & GHG/\$ gross output & Nyboer and Laurin, 2001a \\
\hline & & Energy/GDP & GHG/GDP & Nyboer and Laurin, 2001b \\
\hline & Copper/Alloy Roll, Cast \& Extrude & Energy/\$ gross output & GHG/\$ gross output & Nyboer and Laurin, 2001a \\
\hline & & Energy/GDP & GHG/GDP & Nyboer and Laurin, 2001b \\
\hline \multirow[t]{4}{*}{26} & Paper and allied products & & & \\
\hline & & Energy efficiency index & GHG/\$ gross output & Ministry of Economic Affairs, 1998 \\
\hline & & Energy/\$ gross output & GHG/GDP & Nyboer and Laurin, 2001a \\
\hline & & Energy/GDP & & Nyboer and Laurin, 2001b \\
\hline \multirow{6}{*}{261} & Pulp mills & Energy/tonne pulpwood & GHG/tonne market pulp & $\begin{array}{l}\text { Institute for Energy Technology, } \\
1998\end{array}$ \\
\hline & & Energy/tonne thermomechanical & GHG/\$ gross output & Nyboer and Laurin, 2001a \\
\hline & & Energy/tonne chemical pulp & GHG/GDP & Nyboer and Laurin, 2001b \\
\hline & & Energy/tonne market pulp & & \\
\hline & & Energy $/ \$$ gross output & & \\
\hline & & Energy/GDP & & \\
\hline
\end{tabular}




\begin{tabular}{|c|c|c|c|c|}
\hline SIC Code & Description & Energy Metric & Emissions Metric & \begin{tabular}{|c|} 
Source \\
\end{tabular} \\
\hline 262 & Paper mills & $\begin{array}{l}\text { Energy/tonne paper } \\
\text { Energy/tonne pulp and paper } \\
\text { Energy/\$ gross output } \\
\text { Energy/GDP }\end{array}$ & $\begin{array}{l}\text { GHG/tonne pulp and paper } \\
\text { GHG/\$ gross output } \\
\text { GHG/GDP }\end{array}$ & $\begin{array}{l}\text { Institute for Energy Technology, } \\
1998 \\
\text { Nyboer and Laurin, 2001a } \\
\text { Nyboer and Laurin, 2001b }\end{array}$ \\
\hline 263 & Paperboard mills & Energy/tonne paperboard & GHG/tonne paperboard & $\begin{array}{l}\text { Nyboer and Laurin, 2001a } \\
\text { Nyboer and Laurin, 2001b }\end{array}$ \\
\hline 34 & Fabricated metal products & $\begin{array}{l}\text { Energy/\$ gross output } \\
\text { Energy/GDP }\end{array}$ & $\begin{array}{l}\text { GHG/\$ gross output } \\
\text { GHG/GDP }\end{array}$ & $\begin{array}{l}\text { Nyboer and Laurin, 2001a } \\
\text { Nyboer and Laurin, 2001b }\end{array}$ \\
\hline 37 & Transportation equipment & $\begin{array}{l}\text { Energy/\$ gross output } \\
\text { Energy/GDP }\end{array}$ & $\begin{array}{l}\text { GHG/\$ gross output } \\
\text { GHG/GDP }\end{array}$ & $\begin{array}{l}\text { Nyboer and Laurin, 2001a } \\
\text { Nyboer and Laurin, 2001b }\end{array}$ \\
\hline 371 & Motor vehicles and equipment & $\begin{array}{l}\text { Energy/1000 cars and trucks } \\
\text { Energy/\$ gross output } \\
\text { Energy/GDP }\end{array}$ & $\begin{array}{l}\text { GHG/1000 cars and trucks } \\
\text { GHG/\$ gross output } \\
\text { GHG/GDP }\end{array}$ & $\begin{array}{l}\text { Nyboer and Laurin, 2001a } \\
\text { Nyboer and Laurin, 2001b }\end{array}$ \\
\hline 3714 & Motor vehicle parts and accessories & $\begin{array}{l}\text { Energy/\$ gross output } \\
\text { Energy/GDP }\end{array}$ & $\begin{array}{l}\text { GHG/\$ gross output } \\
\text { GHG/GDP }\end{array}$ & $\begin{array}{l}\text { Nyboer and Laurin, 2001a } \\
\text { Nyboer and Laurin, 2001b }\end{array}$ \\
\hline 35 & Industrial machinery and equipment & $\begin{array}{l}\text { Energy/\$ gross output } \\
\text { Energy/GDP }\end{array}$ & $\begin{array}{l}\text { GHG/\$ gross output } \\
\text { GHG/GDP }\end{array}$ & $\begin{array}{l}\text { Nyboer and Laurin, 2001a } \\
\text { Nyboer and Laurin, 2001b }\end{array}$ \\
\hline 30 & Rubber and misc plastics products & $\begin{array}{l}\text { Energy efficiency index } \\
\text { Energy/tonne of rubber products } \\
\text { Energy/\$ gross output } \\
\text { Energy/GDP }\end{array}$ & $\begin{array}{l}\text { GHG/tonne rubber products } \\
\text { GHG/\$ gross output } \\
\text { GHG/GDP }\end{array}$ & $\begin{array}{l}\text { Ministry of Economic Affairs, } 1998 \\
\text { Nyboer and Laurin, 2001a } \\
\text { Nyboer and Laurin, 2001b }\end{array}$ \\
\hline 22 & Textile mill products & $\begin{array}{l}\text { Energy/\$ gross output } \\
\text { Energy/GDP }\end{array}$ & $\begin{array}{l}\text { GHG/\$ gross output } \\
\text { GHG/GDP }\end{array}$ & $\begin{array}{l}\text { Nyboer and Laurin, 2001a } \\
\text { Nyboer and Laurin, 2001b }\end{array}$ \\
\hline 227 & Carpets and rugs & Energy efficiency index & & Ministry of Economic Affairs, 1998 \\
\hline
\end{tabular}




\subsection{Industry-Specific Indices}

Indexing is a means of providing information on a company's energy or emissions intensity (energy use per unit of product produced or emissions per unit of product produced) without revealing the actual underlying data to the public. In establishing an index, the base year intensity value for a company is set at 100 (or zero) and then intensity values for subsequent years are measured from the base year value. The calculation needs to take the company's product mix into account so that year-to-year changes in production will still result in a comparable annual index. (Appendix A provides an example of how such a calculation is made). In this section, we discuss a number of indices that are currently being used in various industries.

\subsubsection{Solomon Associates Index}

Solomon Associates has devised a type of index that is used for benchmarking in a number of industries. Participating companies provide Solomon with very detailed data on production, throughput, energy consumption, installed technology, etc. In return, Solomon offers companies a comparison of their own plant's performance with that of all the other participating plants, which are not identified by name. Plant performance is measured by comparing the plant's actual energy consumption to a reference level of energy consumption, based on the most efficient technology available, using the plant's own configuration, feedstock input, severity, product mix, etc. Specific energy consumption (SEC) is defined as the net energy consumption per unit of product. The energy efficiency is presented as the ratio of the actual SEC to the reference SEC, the energy efficiency index, in which 100 equals the efficiency of the state-of-the-art reference system.

For example, according to Solomon the energy intensity index (EII) of all ethylene production cracking activities in North America (including the U.S., Canada and Mexico) was 175. For comparison, the EII for all countries covered in the study was 164, for Europe was 151, and for Asia was 126 (Solomon Associates 1995).

\subsubsection{Canadian Association of Petroleum Producers}

The Canadian Association of Petroleum Producers (CAPP) has published guidelines for members who are participating in Canada's Voluntary Challenge Registry. The guidelines provide a methodology for calculating a Production Energy Intensity (PEI) and a Carbon Energy Intensity (CEI) (CAPP, 2000). The PEI is expressed as energy use per cubic meter of oil equivalent produced and the $\mathrm{CEI}$ is expressed as $\mathrm{CO}_{2}$ eq. emissions per cubic meter oil equivalent produced. At the request of Natural Resources Canada, the Production Energy Intensity Index (PEII) was developed to enable comparison of the Solomon's EIIs between companies. The PEII represents the industry average and then company PEIIs are calculated that can be compared to this average index value (Archean Energy Limited, 1998).

\subsubsection{Semiconductor Industry Manufacturing Index}

The international semiconductor industry has adopted a metric that normalizes for variations in production capacity and accounts for differences in manufacturing complexity. The metric is used to normalize energy consumption, GHG emissions, and water consumption to varying 
levels of output. This "unit of production" metric is expressed in terms of $\mathrm{kWh}$ per unit of production which is defined as the square inches of wafer starts per year multiplied by the average number of mask layers per wafer processed (Patton and Wiese, 1999).

A recent survey of 14 semiconductor manufacturing facilities around the world reported an average electricity consumption of $0.393 \mathrm{kWh}$ per unit of production, with the plants in the survey ranging from 0.286 to $0.637 \mathrm{kWh}$ per unit of production (Patton and Wiese, 1999). A 1998-1999 study of energy consumption in nine semiconductor fabs in Taiwan found a range of 0.286 to $1.08 \mathrm{kWh}$ per unit of production (Hu and Chuah 2003).

\subsubsection{Netherlands - Industrial Sector Agreements}

The Dutch Long-Term Agreements (LTAs) on Energy Efficiency (described in section 2.2.2.4 above) relied on the calculation of an energy efficiency index (EEI) to both set energy efficiency targets and as a metric to track progress toward realization of those targets. The calculation of the EEI uses physical activity indicators (e.g. ton of product, square meters of building space) in almost all sectors, as this more closely linked to actual energy use. ${ }^{8}$ For industrial companies, the index accounts for both year-to-year changes in products as well as production of new products.

Companies with only buildings use an EEI with climate-corrected energy use per unit of surface area (square meter). ${ }^{9}$ Examples of these types of participants include Schiphol Airport, KLM Airlines, banks, insurance companies, hospitals and colleges. The Netherlands Railway Company participated in the LTAs as well measuring the energy use of buildings (15\%) and trains $(85 \%)$. Energy use in trains is measured in energy used per person-kilometer.

Industrial participants use production-based EEIs. For example, the petroleum refining industry uses an EEI based on the physical production of a number of products, e.g. LPG, naphtha, gasoline, aromatic feedstocks, kerosene, gasoil, diesel, lubricating oil, heavy fuel oil, asphalt and sulfur. For each of the products, an EEI is calculated using 1989 as the base year. The EEI of all the products is aggregated for each company and the sector.

The EEI of an industrial facility is based on the products produced at various production steps within the plant. The relative difference between the actual specific energy consumption (SEC), which is the energy use per ton of product produced, and that of a reference or benchmark technology, is calculated for each of the key products produced by the plant and then aggregated for the entire enterprise. The aggregated EEI is calculated as follows (equation 1):

\footnotetext{
${ }^{8}$ Energy use is measured on a primary energy basis, where electricity is converted to primary energy with a set efficiency of $40 \%$ (lower heating value, LHV). The energy content of feedstocks is not included in the EEI. Renewable energy and biomass are not reported as part of the EEI. This may lead to accounting problems if biomass waste is used for energy purposes, but it was not included on the input side in the EEI as it is a feedstock.

${ }^{9}$ Correction factors are used for climate variations (only for that energy use susceptible to variations in temperature), increased energy use to meet new emission or OSHA standards, changes in feedstocks and product specifications, and capacity utilization. In practice the correction factors (other than climate) have not had much impact on the EEI and were not used much.
} 
$E E I=100 \cdot \frac{\sum_{i=1}^{n} P_{i} \cdot S E C_{i}}{\sum_{i=1}^{n} P_{i} \cdot S E C_{i, r e f}}=100 \cdot \frac{E_{t o t}}{\sum_{i=1}^{n} P_{i} \cdot S E C_{i, r e f}}$

Where:

EEI = energy efficiency index

$\mathrm{n} \quad=$ number of products produced

$\mathrm{SEC}_{\mathrm{i}} \quad=$ actual specific energy consumption for product $\mathrm{i}$

$\mathrm{SEC}_{\mathrm{i}, \mathrm{ref}} \quad=$ benchmark or reference specific energy consumption for product $\mathrm{i}$

$\mathrm{P}_{\mathrm{i}} \quad$ = production quantity for product $\mathrm{i}$.

$\mathrm{E}_{\mathrm{tot}} \quad=$ total actual energy consumption for all products

Once the EEI is calculated it provides an indication of how the actual SEC of the enterprise compares to the reference SEC. By definition a plant that uses the benchmark technology in an efficient manner will have an EEI of 100. In practice, all plants will have an EEI over 100. The gap between actual energy consumption used to produce the products and the reference level energy consumption (EEI - 100) can be viewed as the energy efficiency potential of the plant.

The EEI can also be used to monitor annual progress in energy efficiency improvement by calculating the EEI for each year compared to the performance in the reference year (i.e. the year that company choose to use as reference year for its emission crediting). The level of energy consumption depends to a large extent on the product mix and the production volume. Merely comparing energy efficiency on the basis of the total energy consumption for different years will therefore not provide an accurate picture of the actual achievement. In developing the calculation method for the EEI, both shifts in the product mix and improvements in material efficiency are taken into account.

In this case, the EEI for the reference year is set at 100 and the EEIs for subsequent years are calculated. The EEI is the quotient of the net primary energy consumption in the relevant year and the reference primary energy consumption, multiplied by 100 . Using Equation 1 we can change it to the following equation for calculation of the EEI in year $\mathrm{x}$ :

$E E I=100 \cdot \frac{\sum_{i=1}^{n} P_{i, x} \cdot S E C_{i, x}}{\sum_{i=1}^{n} P_{i, x} \cdot S E C_{i, \text { ref }}}=100 \cdot \frac{E_{\text {total }, x}}{\sum_{i=1}^{n} P_{i, x} \cdot S E C_{i, \text { ref }}}$

Where:

EEI = energy efficiency index

$\mathrm{n} \quad=$ number of products produced

$\mathrm{SEC}_{\mathrm{i}, \mathrm{X}} \quad=$ actual specific energy consumption for product $\mathrm{I}$ in year $\mathrm{X}$

$\mathrm{SEC}_{\mathrm{i}, \mathrm{ref}} \quad=$ benchmark or reference specific energy consumption for product $\mathrm{i}$

$\mathrm{P}_{\mathrm{i}} \quad$ = production quantity for product $\mathrm{I}$ in reference year

$\mathrm{P}_{\mathrm{i}, \mathrm{x}} \quad=$ production quantity for product $\mathrm{I}$ in year $\mathrm{x}$

$\mathrm{E}_{\mathrm{tot}} \quad=$ total actual energy consumption for all products 


\subsubsection{GHG Intensity Index}

Berkeley Lab recommends that the Registry develop a GHG intensity index that measures GHG emissions per unit of physical or economic output. Such an index would provide an industryspecific metric for reporting and tracking GHG emissions trends that could accurately reflect year-to-year changes while protecting proprietary data. A GHG intensity index could be constructed using detailed production and GHG emissions data provided by Registry participants. Only the index, and not the detailed proprietary data, would be reported publicly. Such an index would provide Registry participants with a means for demonstrating improvements in their energy and GHG emissions per unit of production without divulging specific values. 


\section{Establishing Baselines for Calculating Greenhouse Gas Emissions Reductions}

\subsection{Introduction}

Accounting for actions to reduce GHGs can be done on a project-by-project basis or on an entity basis. Establishing project-related baselines for mitigation efforts has been widely discussed in the context of two of the so-called "flexible mechanisms" of the Kyoto Protocol to the United Nations Framework Convention on Climate Change (Kyoto Protocol) - Joint Implementation (JI) and the Clean Development Mechanism (CDM). Issues regarding the development of entityspecific baselines, which can be used by such entities as companies, municipalities, and organizations, have been explored in the context of baseline protection, emissions trading, credit for early action initiatives, and climate change registries.

\subsection{Survey of baseline types}

Table 11 provides an overview of the various baseline types that are discussed further below. For all types of baselines, there is the issue of whether they should be static or dynamic. Static baselines are constant throughout the lifetime of the project while dynamic baselines are revised sometime during the project lifetime.

\subsubsection{Project-related baselines}

Project-related baselines are needed to account for the GHG emissions that are reduced through specific mitigation projects. For the Kyoto Protocol, projects under both JI and CDM are required to demonstrate that their emissions reductions are "additional to any that would otherwise occur" (United Nations, 1997). The UNFCCC defines a baseline for a CDM project as "the scenario that reasonably represents the anthropogenic emissions by sources of greenhouse gases that would occur in the absence of the proposed project activity." This requirement to prove "additionality" leads to the need for a baseline that estimates what would have happened in the absence of the project.

For JI and CDM projects, the UNFCCC has proposed three methodologies to be used to determine emissions reductions for a project activity using project-related baselines: "(a) Existing actual or historical emissions, as applicable; or (b) Emissions from a technology that represents an economically attractive course of action, taking into account barriers to investment; or (c) The average emissions of similar project activities undertaken in the previous five years, in similar social, economic, environmental and technological circumstances, and whose performance is among the top 20 per cent of their category." In addition, the baseline can be static or dynamic. That is, the project participants can choose to use a baseline that is valid for "(a) A maximum of seven years which may be renewed at most two times, provided that, for each renewal, a designated operational entity determines and informs the Executive Board that the original project baseline is still valid or has been updated taking account of new data where applicable; or (b) A maximum of ten years with no option of renewal" (UNFCCC, 2002a). 
Table 11. Characteristics of Various Baselines Used to Calculate Energy Use or GHG Emissions Reductions.

\begin{tabular}{|c|c|c|c|c|}
\hline $\begin{array}{l}\text { Baseline } \\
\text { Focus }\end{array}$ & Type of Baseline & Baseline Used For: & $\begin{array}{l}\text { Use of Industry-Specific } \\
\text { Metrics }\end{array}$ & Notes \\
\hline $\begin{array}{l}\text { Project- } \\
\text { related }\end{array}$ & Project-specific & $\begin{array}{l}\mathrm{JI} / \mathrm{CDM} \\
\text { Emissions trading (credits) } \\
\text { Registries }\end{array}$ & - Varies on a case-by-case basis & $\begin{array}{l}\text { High transaction costs, high uncertainties } \\
\text { (Begg et al., 1999; Ellis and Bosi, 1999; } \\
\text { Parkinson et al., 2001) }\end{array}$ \\
\hline $\begin{array}{l}\text { Project- } \\
\text { related }\end{array}$ & $\begin{array}{l}\text { Multi-project } \\
\text { (standardized) }\end{array}$ & $\mathrm{JI} / \mathrm{CDM}$ & $\begin{array}{l}\text { - Energy use or GHG } \\
\text { emissions/unit of output }\end{array}$ & $\begin{array}{l}\text { Has been evaluated for the electricity, } \\
\text { cement, steel sectors (Bosi, 2000; Bode et } \\
\text { al., 2000; Ellis, 2000; Sathaye et al., } \\
\text { 2001) }\end{array}$ \\
\hline $\begin{array}{l}\text { Project- } \\
\text { related }\end{array}$ & Benchmark value & $\mathrm{JI} / \mathrm{CDM}$ & $\begin{array}{l}\text { - Energy use or GHG } \\
\text { emissions/unit of output } \\
\text { - Absolute energy use or GHG } \\
\text { emissions/year }\end{array}$ & $\begin{array}{l}\text { Ellis et al., 2001; Ministry of Economic } \\
\text { Affairs, } 2000\end{array}$ \\
\hline $\begin{array}{l}\text { Entity- } \\
\text { specific }\end{array}$ & Historical frozen & $\begin{array}{l}\text { Absolute targets or } \\
\text { reductions } \\
\text { Registries } \\
\text { Credit for early action } \\
\text { Emissions trading (credits) }\end{array}$ & Not used & \\
\hline $\begin{array}{l}\text { Entity- } \\
\text { specific }\end{array}$ & $\begin{array}{l}\text { Business-as-usual } \\
\text { projected } \\
\text { Growth baselines }\end{array}$ & $\begin{array}{l}\text { Credit for early action } \\
\text { Emissions trading (credits) }\end{array}$ & $\begin{array}{l}\text { - Energy use or GHG } \\
\text { emissions/unit of economic } \\
\text { output } \\
\text { - Energy use or GHG emissions/ } \\
\text { unit of product produced }\end{array}$ & CCAP, 1998; Nordhaus et al., 1998 \\
\hline $\begin{array}{l}\text { Entity- } \\
\text { specific }\end{array}$ & Future target & Credit for early action & $\begin{array}{l}\text { - GHG emissions/year adjusted in } \\
\text { a straight line downward from a } \\
\text { base year to a designated } \\
\text { reduction target in a future year }\end{array}$ & Nordhaus et al., 1998 \\
\hline $\begin{array}{l}\text { Entity- } \\
\text { specific }\end{array}$ & $\begin{array}{l}\text { Ex-post } \\
\text { reconstructed }\end{array}$ & $\begin{array}{l}\text { Credit for early action } \\
\text { Emissions trading (credits) }\end{array}$ & Not used & BPI, 2002 \\
\hline
\end{tabular}


Baselines for calculating GHG emissions reductions from mitigation projects can be projectspecific, multi-project, or can be based on the use of benchmark values. Project-specific baselines are determined on a project-by-project basis using specific measurements or assumptions. Multi-project, or standardized, baselines use existing or estimated emissions levels from a defined set of actual or projected projects to derive a baseline level (Ellis and Bosi, 1999). Benchmark value baselines define business-as-usual or best-practice benchmark metrics that are used to set the baseline (Ellis et al., 2001).

\subsubsection{Project-specific baselines}

Project-specific baselines are constructed for a particular project using data related to that project to make a judgment of what energy consumption or GHG emissions would have been without the project. Project-specific baselines were commonly used for analysis of the UNFCCC Activities Implemented Jointly (AIJ) pilot projects and are often assumed to be more accurate that other types of baselines. However, one evaluation of the use of project-specific baselines for energy production retrofit projects found uncertainties of $\pm 80 \%$ (Begg et al., 1999) while another found uncertainties of $\pm 35 \%$ for demand-side projects, $\pm 45 \%$ for heat supply projects, \pm $55 \%$ for cogeneration projects, and $\pm 60 \%$ for electricity supply projects (Parkinson et al., 2001). ${ }^{10}$

Data requirements and costs for preparation of project-specific baselines are considered to be high and their transparency is considered to be low (Ellis and Bosi, 1999; Vine and Sathaye, 1999). Specifically, projects related to the Activities Implemented Jointly (AIJ) pilot phase were initiated at the first United Nations Framework Convention on Climate Change (UNFCCC) Conference of the Parties to test the impact of implementing emissions reductions projects in some countries (developing countries or countries with economies in transition). An evaluation of a number World Bank-managed Prototype Carbon Fund projects found that the costs associated with preparing a project-specific baseline study and presenting a case for environmental additionality are about US\$20,000 per project (World Bank, 2000a). Even so, project-specific baselines are applicable to many sectors and all types of projects and they are currently preferred both in the description of JI and CDM in the Kyoto Protocol as well as within implementation schemes such as the World Bank's Prototype Carbon Fund (World Bank, 2000b) and the project-level reporting of the U.S. Voluntary Reporting of Greenhouse Gases Program (U.S. EIA, 2002).

Project-specific analyses use a variety of methods for calculating the "without project" baseline including the use of industry-specific metrics. In such cases, the types of metrics used are similar to those discussed in Section 4 on entity-specific baselines.

\subsubsection{Multi-project (standardized) baselines}

Multi-project, or standardized, baselines are seen as an alternative to project-specific baselines, striking a balance between ensuring environmental integrity and minimizing transaction costs

\footnotetext{
${ }^{10}$ For example, an analysis of an AIJ horticultural project that used 5 project-specific baselines with different assumptions about fuel use, technologies, and project boundaries found that per unit emissions reductions varied by more than a factor of two between the different baselines (Ellis and Bosi, 1999).
} 
while encouraging emissions reduction projects. Multi-project baselines across many projects, for particular sectors or given technologies have been proposed because project-specific baselines may have higher transaction costs, reducing the number of projects that attract investment. These multi-project baselines can be used as an alternative to project-specific baselines depending upon the preference of the developer and/or the host country government.

Multi-project baselines are constructed to derive a weighted average, percentile, or best practice energy and carbon intensity metric from similar projects to which the energy and carbon intensity of the proposed project is compared (Bosi, 2000, Bode et al., 2000; Ellis, 2000; Sathaye et al., 2001). For example, one approach for constructing multi-project baselines is to use carbon intensity values for recently-constructed plants to calculate the baseline, assuming that these represent the best available technology. An advantage of this approach is that the data for such plants are observable. Another approach is to use a "forward-looking" baseline that includes near-future plants, making assumptions about which plants would most likely be built. A forward-looking baseline has the advantage that it can consider new, more efficient technologies. Arguably this type of baseline is more realistic regarding what new technologies are likely to be used. However, there is no guarantee that the planned plants will actually be built. While a "forward-looking" baseline could be methodologically more accurate, one based on "recentlyconstructed" units is likely to have more accurate data (Sathaye et al., 2001).

\subsubsection{Benchmark value baselines}

Benchmark value baselines define metrics in the form of energy consumption or GHG emissions rates per unit of activity, which are then multiplied by expected activity levels to calculate a baseline. For example, for industrial project baselines, benchmark values representing the average or best practice could be defined in terms of $\mathrm{GJ} /$ ton output or $\mathrm{kg} \mathrm{CO}_{2} /$ ton output. Energy consumption benchmark values would then need to be converted to GHG values using fuelspecific emissions factors (Ellis et al., 2001). Similar benchmarks could be developed on an annual basis, e.g. absolute energy use per year or absolute GHG emissions per year based on standard values for specific facility types.

The Dutch Emissions Reduction Unit Procurement Tender (ERUPT) program, which purchases carbon credits from JI projects requires that the baseline be set up using expected baseline emissions factors that are then multiplied by the expected baseline activity levels. The baseline emissions factors are static for the crediting period (through 2012), but the baseline activity levels can be dynamic, allowing for changes depending upon the monitored activity levels of the project (Ministry of Economic Affairs, 2000).

\subsubsection{Entity-specific baselines}

Entity-specific baselines cover GHG emissions for an entire entity (e.g. corporation, municipality, organization) for a given period of time, typically yearly. Such baselines are developed in order to have a starting point for calculating GHG emissions reductions attributable to actions of the entity. Entity-specific reporting protocols have been developed by the World Resources Institute/World Business Council for Sustainable Development (WRI/WBCSD, 2001) and for specific GHG emissions registries, such as the California Climate Action Registry 
(California Climate Action Registry, 2002b). ${ }^{11}$ Entities are interested in accounting for their GHG emissions reduction activities in light of potential national (or state) GHG emissions reduction commitments or for use within emissions trading regimes. ${ }^{12}$ Entity-related baselines can be historical frozen baselines, business-as-usual projected baselines, future target baselines, or ex-post reconstructed baselines.

\subsubsection{Historical frozen baseline}

The historical frozen baseline approach uses an entity's historic energy use or emissions as the baseline. The historic values can either be from one year or averaged over a series of years. While this type of baseline is the least subjective, the least costly, and most easily implemented, it does not account for growth or changes in the structure of the entity (Credit for Early Action Table, 1999). Sectoral or industry-specific metrics are not used for calculating this type of baseline.

\subsection{Single year historical frozen baseline}

A single year historical frozen baseline identifies one year from which to measure all future reductions against. Examples of the use of this type of baseline include the Kyoto Protocol, the U.S. Voluntary Reporting of Greenhouse Gases Program, the Canadian Voluntary Challenge and Registry, and the California Climate Action Registry.

- Kyoto Protocol

National GHG emissions reduction commitments have been made by 25 Annex I countries in the context of the Kyoto Protocol (UNFCCC, 2002b). These commitments are all based on historical frozen baselines defined as national GHG emissions in 1990 and are expressed as percentages above or below the baseline level. The commitments must be met during the 2008-2012 period (United Nations, 1997).

- U.S. Voluntary Reporting of Greenhouse Gases Program

The U.S. Voluntary Reporting of Greenhouse Gases Program, also called the 1605(b) program, has entity-level and project-level reporting components. Most of the participants use the entity-level reporting forms, but also report project-level emissions. For both the entity-level and project-level reports, participants can use a "basic" reference case for reporting GHG emissions reduction in which reductions are the difference between actual GHG emissions in a given year and the actual emissions in a baseline year, typically 1990 (U.S. EIA, 2002).

\footnotetext{
${ }^{11}$ In this section, we do not address the issue of modifying the baseline to account for ownership changes or changes in production within the entity.

12 Emissions trading is a system in which participants can buy or sell GHG emissions allowances or credits. Emissions allowances are derived within a "cap and trade system" where there is an overall limit to emissions for a particular region or country and emissions allowances are distributed to participants. Emissions credits are generated through actions by entities that reduce their emissions below an established threshold. Entity-specific baselines are required in order to calculate these emissions credits (National Round Table on the Environment and the Economy, 2002.)
} 
- Canadian Voluntary Challenge and Registry

The Canadian Voluntary Challenge and Registry (VCR) was established in October 1997 as a private-public partnership with the Canadian government. The purpose of the VCR is to "encourage organizations from all sectors of the economy to accept greater accountability for greenhouse gas (GHG) emissions, serving as a catalyst to ensure that Canada's overall climate change objectives are addressed by both private and public sectors through voluntary actions." The VCR records the actions planned and undertaken by members. As such, the preferred baseline for the VCR is defined as 1990 emissions, but members are allowed to use another base year or to adjust the 1990 data if they provide an explanation for the reason that the 1990 emissions are not the most adequate baseline (VCR-MVR, Inc., 2002a).

- California Climate Action Registry

The California Climate Action Registry, which began operation in October 2002, allows participants to choose any year from 1990 forward as the baseline from which to measure GHG emissions performance over time. This baseline is typically static, but can be revised if there are significant structural changes in the organization, a shift in emissions sources, or if there are fundamental changes in the generally accepted GHG emissions accounting methodologies (California Climate Action Registry, 2002b).

\subsection{Multiple year historical frozen baseline}

A multiple year historical frozen baseline defines a series of years from which to measure future reduction against. The use of multiple years is viewed as preferable to a single year as a means to smooth out annual fluctuations while still providing a historic baseline. Examples of the use of this type of baseline include the Wisconsin Voluntary Emission Reduction Registry and the United Kingdom's Emissions Trading Scheme.

- Wisconsin Voluntary Emission Reduction Registry

The Wisconsin Voluntary Emission Reduction Registry uses a baseline that is the average annual emissions, emissions rates, or energy consumption for the two years immediately prior to the year in which the emission reduction or energy efficiency action took place (Wisconsin Department of Natural Resources, 2002).

- U.S. Voluntary Reporting of Greenhouse Gases Program

The U.S. Voluntary Reporting of Greenhouse Gases Program also allows participating entities to report emissions reductions using a "basic" reference case that is "an average of a range of years" (U.S. EIA, 2002).

- United Kingdom Emissions Trading Scheme

The United Kingdom began its Emissions Trading Scheme (ETS), the world's first economy-wide GHG emissions trading scheme, on April 2, 2002. The UK ETS is a key component of the Government's Climate Change Programme that provides guidance for the UK to meet its Kyoto Protocol Commitment of a $12.5 \%$ reduction all GHGs by 2008-12 relative to 1990 . The UK also has a domestic goal of a $20 \%$ reduction in emissions of $\mathrm{CO}_{2}$, the main GHG. Participation in the scheme is 
voluntary and there are three categories of participants: direct participants, companies that have emissions or energy targets set through the UK Climate Change Agreements, or companies that will undertake UK-specific emissions reduction projects in order to sell the credits to the UK ETS (DEFRA, 2001a). The UK ETS is based on the use of a frozen baseline constructed of the average annual emissions in 1998, 1999, and 2000. Data from only 1999 and 2000 or from only 2000 can be used if earlier data are not available (DEFRA, 2001b).

\subsubsection{Business-as-usual projected baseline}

A business-as-usual projected baseline combines historic trends with projected emissions estimates based on assumptions about growth and entity changes. This type of baseline is more subjective than either a historical frozen baseline or an ex-post reconstructed baseline (Credit for Early Action Table, 1999).

\subsection{Business-as-usual emissions reduction baselines}

\section{- U.S. Credit for Early Action Proposals}

A number of schemes to give entities "credit for early action" were proposed in the late 1990s in the U.S., prior to its withdrawal from the Kyoto Protocol. In 1997, the President's Council on Sustainable Development established a Climate Task Force on Principles for Early Action. Subsequent proposals outlining various credit for early action schemes were made by the Environmental Defense Fund, the Center for Clean Air Policy, and the Coalition to Advance Sustainable Technology (CCAP, 1999; CAST, 1999). Under these schemes, an entity would generate emissions credits when its GHG emissions were reduced below a certain baseline. The CAST proposal for early action credits would establish such a baseline by first calculating a baseline rate, expressed as $\mathrm{CO}_{2}$ equivalent per dollar of company sales, in a baseline year. The business-as-usual baseline would then be projected by adjusting the rate downward by $1 \%$ per year to reflect business-as-usual efficiency improvements. In order to get credits for early action, companies would have to achieve annual efficiency improvements greater than those indicated by the calculated business-as-usual baseline (Nordhaus et al., 1998).

\subsection{Business-as-usual emissions growth baselines}

In discussions related to the inclusion of developing countries in an international GHG emissions reduction scheme such as the Kyoto Protocol or post-Kyoto schemes, the concept of "growth baselines" has emerged as a method for accounting for expected economic growth while also encouraging reductions in emissions intensity.

The Center for Clear Air Policy (CCAP) growth baselines proposal is that emissions targets for developing countries be established by tying emissions to improvements in the ratio of carbon emissions to gross domestic product (C/GDP). CCAP identifies 13 developing countries that account for over $90 \%$ of developing country emissions and advocates that growth baselines be set for these countries only (CCAP, 1998). Like CCAP, the World Resources Institute has also 
advocated a growth baseline for developing countries using a "greenhouse gas intensity indicator" based on country's emissions per unit of economic output (Baumert et al., 1999).

\subsubsection{Future target baseline}

The Center for Clean Air Policy proposal related to credit for early action uses a baseline, expressed in tons of GHG emissions per year, that starts in 1998 and is reduced in a straight line until reaching a $7 \%$ reduction target in $2007 .{ }^{13}$ Companies would earn credit for early action by reducing emissions below the declining baseline (Nordhaus et al., 1998). A variation of this proposal uses a declining generation performance standard in carbon emissions per $\mathrm{kWh}$ for the electric sector. As with the previous proposal, the baseline would be established by drawing a straight line from the actual generation emissions intensity in 1998 to a "desired national performance rate" in 2007. Credits would be calculated by multiplying the difference between the target baseline value and actual performance by the amount of kilowatt-hours (kWhs) generated for each year (Nordhaus et al., 1998).

\subsubsection{Ex-post reconstructed baseline}

An ex-post, or reconstructed, baseline tracks energy use or emissions from a starting year and is then determined on an annual basis by accounting for verifiable reductions attributed to specific mitigation actions. This approach is most accurate because actual emissions are known and reductions can be verified by a third party. However, it can be more complex and costly (Credit for Early Action Table, 1999).

\section{- Canadian Baseline Protection Initiative}

The Baseline Protection Initiative (BPI) in Canada began in March 2001 and is a voluntary program that "ensures that organizations that act early to reduce greenhouse gas emissions are not disadvantaged should potential climate change policies based on emissions levels be implemented." Entities that want to participate in BPI must report their total GHG emissions and register their GHG emissions reduction actions and associated emissions reductions with the BPI Registry (VCR-MRV, Inc, 2002b; BPI, 2002). In the BPI program, participant baselines are reconstructed after emissions reduction projects have been completed. After reporting their actual total annual GHG emissions, participant emissions reductions actions and associated emissions reductions are validated by a validation service to determine if they meet the BPI eligibility criteria and rules. Once these implemented projects have been validated, participant baselines are adjusted by BPI Program Managers to reflect the reduction actions that they have taken since January 1, 1990. The adjusted baseline is then used as an estimate of what the participant's GHG emissions would have been without the implemented mitigation actions (BPI, 2002).

\footnotetext{
${ }^{13}$ The $7 \%$ reduction is based on the reduction in GHG emissions that was calculated to be the U.S. target under the Kyoto Protocol.
} 


\subsection{Baseline Typology}

As can be seen from the above discussion, many different baseline methods have been proposed, and some are currently in use by various registries or trading schemes. Table 12 provides an overall typology for a number of baseline methods, categorizing them according to the way the baselines are calculated. First, the methods are divided into three major categories according to the basic approach used to calculate the baselines, and within these categories, variations of the methods are listed. Each of these variations is then rated on its complexity and robustness. "Complexity" is an indication of whether many calculations are necessary to establish the particular baseline. Baselines that are highly complex may necessitate the use of expertise outside of the Registry and will, therefore, be more costly to implement. "Robustness" is a measure of the likelihood that the method is rigorous enough to be accepted for early action credit or other tradeable credits.

\subsubsection{Absolute Baselines}

The first major group of baseline methods listed in Table 12 are absolute baselines, which are those that extrapolate a total level of emissions into the future. These methods are said to be static because they are not adjusted year to year to reflect an entity's output. While this type of baseline is the least subjective, the least costly, and most easily implemented, it does not account for an entity's growth (Credit for Early Action Table, 1999). Once these baselines are determined, they remain unchanged, unless they are adjusted to correct for a structural change, such as an acquisition or divestiture.

A participating entity's own emissions in some base year or years are used to determine absolute baselines. There are several ways that these future levels of emissions can be calculated. The simplest is a fixed base year baseline that identifies one year against which to measure all future emissions. Examples of the use of this type of baseline include the U.S. Voluntary Reporting of Greenhouse Gases Program, the Canadian Voluntary Challenge and Registry, and the California Climate Action Registry. As an alternative to holding only base year emissions constant, an average can be taken over several years. This fixed multiyear average baseline may be preferred to a single year baseline as a means to smooth out an unrepresentative number due to anomalous circumstances (such as an unusually high or low level of production) that may have affected emissions in any single year. Examples of the use of this type of baseline include the Wisconsin Voluntary Emission Reduction Registry and the United Kingdom's Emissions Trading Scheme.

Future target baselines are calculated by extrapolating a straight line from base year emissions to a future target. This is the type of baseline used in the Kyoto Protocol. On the basis of the U.S. target in the Kyoto Protocol, the Center for Clean Air Policy proposed a credit for early action baseline that starts in 1998 and is reduced in a straight line until reaching a 7\% reduction target in 2007. Companies would earn credit for early action by reducing emissions below the declining baseline (Nordhaus et al., 1998). Future target baselines are interesting because while they are not complex to apply, they may be "robust" in terms of generating potential GHG offset credits if there is a national target or cap in place. However, with no statutory target in force, it is unlikely that a trading scheme would recognize estimated credits from a participant's emissions below a "future target" baseline set by the Registry. 
Finally, the entity's own historical trend may be used to extrapolate future emissions targets. This may be done using either linear or nonlinear methods, and commonly available spreadsheet applications can be used to perform these calculations. However, determining the number of years of data needed to establish a trend is rather arbitrary. Using only three or four years data does not yield a trend with much statistical confidence, but data limitations will prevent many participants from providing a reliable time series that goes back much further than that.

\subsubsection{Intensity Baselines}

In contrast to absolute emissions baselines, intensity baselines estimate GHG savings according the emissions rate at which an entity produces its output. Thus, participants' early actions to reduce GHG emissions may be recognized even if growth in production causes overall emissions to rise, despite any improvements in emissions intensity that have occurred. These baselines are said to be dynamic because the estimated business-as-usual emissions to which the entity is compared depend on the entity's annual production and must be calculated from year to year. Intensity derived baselines are linked to metrics since a participant's rate of emissions for the base year(s) must be known in order to order calculate future base case emissions. The emissions rate may be determined for one or more years in order to establish the baseline rate, or it may need to be monitored over several years in order to determine historic trends.

A fixed base year intensity baseline, similar to the analogous fixed base year absolute baseline, holds the entity's emissions rate from the base year constant. This rate is then multiplied by the entity's own output from year to year. For a fixed multiyear average intensity baseline, similar to the multiyear average absolute baseline, the rate may also be calculated as an average of several years in order to smooth over an anomalous single year. However, fixed rate methods, whether single year or multiyear, are unlikely to result in credits because some autonomous level of intensity decline is expected due to improvements in energy conversion and production technologies.

Alternative methods that use arbitrary rates of decline to calculate emissions rate include a scheme where a baseline rate is first calculated, expressed as $\mathrm{CO}_{2}$ equivalent per dollar of company sales, in a baseline year. Then the rate is adjusted downward by X\% per year to reflect business-as-usual efficiency improvements (Nordhaus et al., 1998). The proposal by Nordhaus et al. (1998) arbitrarily suggests $1 \%$ per year as an expected business-as-usual rate of change. Similar baselines schemes have also been proposed by the Center for Clear Air Policy and the World Resources Institute (CCAP, 1998; Baumert et al., 1999). These approaches recognize that growth in production may outpace improvements in intensity, resulting in increasing emissions overall.

The annual rate of improvement can be determined in several ways. First, this rate may be chosen somewhat arbitrarily by carbon trading program administrators based upon a reasonable estimate of what a given industry should be able to attain. Second, the rate may be based on the participant's own historic rates of change of carbon intensity, which can be used to construct an entity-specific historical trend baseline. Third, if data on the GHG intensities of several participants within the same sector are available, then historic industry-wide rates of change may be used for all participants in that sector and an industry-wide historical trend baseline can be constructed. Finally, an in-depth assessment of the economically feasible technical potential for 
reducing GHG intensity may be performed in order to support construction of an expert judgment baseline.

\subsubsection{Reconstructed Baselines}

An ex-post project-based baseline tracks energy use or emissions from a starting year and is then determined on an annual basis by accounting for verifiable reductions attributed to specific mitigation actions. These are not truly baselines per se, but are simply the sum of an entity's actual emissions in a given year and the savings from specified mitigation actions. This approach is most accurate because actual emissions are known and reductions can be verified by a third party, but it can be more complex and costly (Credit for Early Action Table, 1999). This type of baseline is used by the Baseline Protection Initiative (BPI) in Canada (BPI, 2002). 
Table 12. Typology and Qualitative Assessment of Baselines for Estimating Entity-Wide GHG Savings

\begin{tabular}{|c|c|c|c|c|}
\hline Type of Baseline $^{\mathrm{a}}$ & Calculation Method & Complexity $^{b}$ & Robustness $^{c}$ & Notes \\
\hline \multicolumn{5}{|l|}{ Absolute: Static } \\
\hline Fixed Base Year & $\begin{array}{l}\text { Frozen base year absolute emissions } \\
\text { projected into future }\end{array}$ & Low & Low & $\begin{array}{l}\text { Used by the California Climate } \\
\text { Action Registry }\end{array}$ \\
\hline $\begin{array}{l}\text { Fixed Multiyear } \\
\text { Average }\end{array}$ & $\begin{array}{l}\text { Multiyear average absolute emissions } \\
\text { projected into future }\end{array}$ & Low & Low & $\begin{array}{l}\text { Eliminates savings for all years used } \\
\text { to construct the multiyear baseline }\end{array}$ \\
\hline Future Target & $\begin{array}{l}\text { Absolute emissions projected as a } \\
\text { straight line between base year and } \\
\text { future target }\end{array}$ & Low & Low/High & $\begin{array}{l}\text { Robustness will be low with an } \\
\text { arbitrary target and high if there is a } \\
\text { national target }\end{array}$ \\
\hline Historical Trend & $\begin{array}{l}\text { Absolute emissions projected as a } \\
\text { straight line based on historical trends }\end{array}$ & Low & Low & $\begin{array}{l}\text { Will need to establish how many } \\
\text { years are needed to constitute a trend }\end{array}$ \\
\hline \multicolumn{5}{|l|}{ Intensity: Dynamic } \\
\hline Fixed Base Year & $\begin{array}{l}\text { Frozen base year intensity multiplied } \\
\text { by actual production }\end{array}$ & Low & Low & $\begin{array}{l}\text { Could be more complex and robust if } \\
\text { structural changes are included }\end{array}$ \\
\hline $\begin{array}{l}\text { Fixed Multiyear } \\
\text { Average }\end{array}$ & $\begin{array}{l}\text { Multiyear average intensity } \\
\text { multiplied by actual production }\end{array}$ & Low & Low & \\
\hline $\begin{array}{l}\text { Arbitrary Rate of } \\
\text { Decline }\end{array}$ & $\begin{array}{l}\text { Intensity declining at an arbitrary rate } \\
\text { multiplied by actual production }\end{array}$ & Low & Low & $\begin{array}{l}\text { Rates of decline may need to be } \\
\text { negotiated. }\end{array}$ \\
\hline Historical Trend - Entity & $\begin{array}{l}\text { Entity historical intensity rate } \\
\text { multiplied by actual production }\end{array}$ & Low & Mid & \\
\hline $\begin{array}{l}\text { Historical Trend - } \\
\text { Industry }\end{array}$ & $\begin{array}{l}\text { Industry-wide historical intensity rate } \\
\text { multiplied by actual production }\end{array}$ & Low/High & Mid & $\begin{array}{l}\text { Complexity is a function of the } \\
\text { availability of regularly updated data } \\
\text { on historical trends }\end{array}$ \\
\hline Expert Judgment & $\begin{array}{l}\text { Intensity rate decline based on expert } \\
\text { judgment regarding industry } \\
\text { multiplied by actual production }\end{array}$ & High & Mid & Expert judgment may be contested \\
\hline \multicolumn{5}{|l|}{ Reconstructed: Dynamic } \\
\hline Ex-Post Project-Based & $\begin{array}{l}\text { Verified GHG emissions reduction } \\
\text { project savings are added to actual } \\
\text { GHG emissions trends to reconstruct } \\
\text { the baseline }\end{array}$ & Mid/High & High & $\begin{array}{l}\text { Project savings will need to be } \\
\text { verified. Used by the Baseline } \\
\text { Protection Initiative in Canada }\end{array}$ \\
\hline
\end{tabular}


Note: Baselines covered in this table are for existing facilities. Development of baselines for newly-constructed (greenfield) plants would require information on existing trends in the industry.

${ }^{a}$ Static or dynamic refers to whether total baseline emissions are projected into future years or are adjusted annually to reflect a participating entity's actual output.

${ }^{\mathrm{b}}$ Complexity is an indication of how transparent a method is and to what extent outside expertise will probably be needed to calculate the baselines.

${ }^{c}$ Robustness indicates whether the resulting GHG emissions reductions are calculated using a methodology that could be strict enough to qualify for carbon credits under a cap and trade or other emissions trading scheme. 


\section{Case Studies}

\subsection{Introduction}

In order to fully explore the issues surrounding the use of industry-specific metrics and to begin to understand the implications of using one type of baseline over another, Berkeley Lab conducted three case studies with entities representing a wide spectrum of activities that could be included in the California Climate Action Registry. These case studies were done for Advanced Micro Devices (AMD), Fetzer Vineyards, and the City of Berkeley.

\subsection{Electronics Manufacturing: Advanced Micro Devices Case Study}

\subsubsection{Sector Background}

Electronics manufacturing includes the production of electricity distribution equipment, electrical industrial apparatus, household appliances, electrical lighting and wiring equipment, radio and television receiving equipment, communications equipment, electronic components and accessories, and other electrical equipment and supplies (U.S. Department of Labor 2003).

The U.S. has the largest electronics manufacturing labor force in the world, although Japan, South Korea, and other Asian nations are experiencing rapid growth in this industry. The electronics industry provides more jobs than any other manufacturing sector in the U.S., three times as many jobs as automotive manufacturing, and nine times more than the steel industry.

Electronics manufacturing consumes significant amounts of energy; in California this industry is the second largest industrial sector consumer of electricity. In a recent report, the California Energy Commission identified electronics and computers manufacturing as the fastest growing energy users in the industrial sector (California Energy Commission, 1998).

Electronic components include the production of semiconductors by manufacturers such as Advanced Micro Devices, Inc. (AMD), the subject of this case study. The U.S. semiconductor industry is concentrated in California, New York, Arizona, and Texas, close to primary users, transportation routes, utility and telecommunication infrastructures, and engineering experts. Semiconductors, while accounting for only a small portion of electronics industry sales, are crucial to all electronic products. Semiconductors are used in computers, consumer electronic products, telecommunication equipment, industrial machinery, transportation equipment, and military hardware (U.S. EPA, 1995).

The largest energy end use in the semiconductor industry is clean rooms for chip manufacture. Clean rooms are extremely energy-intensive, averaging 4 to 100 times more energy-intensive than average commercial buildings (U.S. EPA 1995). Energy consumption in clean rooms is primarily for heating, ventilating, and air conditioning (HVAC) systems (Sartor et al. 1999). A recent study of energy consumption by semiconductor fabrication facilities (fabs) in Taiwan found that over 56 percent of power at the fabs in the study was consumed by the clean room facilities while another 40 percent of the total was used for process tools (Hu and Chuah 2003). 


\subsubsection{Overview of AMD}

AMD is a global supplier of microprocessors and other integrated circuit products. AMD was founded in 1969 and is headquartered in Sunnyvale, California. In addition to the Sunnyvale campus, AMD owns two chip manufacturing facilities (one in Austin, Texas, the other in Dresden, Germany) and several test and assembly facilities located in various countries in Asia (AMD 2002a). Since the California Climate Action Registry requires participants to report all emissions from activities in California and encourages them to report emissions from activities in other states, this case study focuses on the facilities in Sunnyvale and Austin.

In 2002, the Austin AMD site consisted of two wafer manufacturing areas and other testing, engineering design, and administrative support units, housed in four AMD-owned buildings and several leased spaces. Approximately 3,000 people are employed at the site. AMD implemented several energy conservation projects at the site during 2001. These projects included a reduced lighting project as well as optimization of airflow and the centralization of chillers, boilers, and condensers (AMD 2002b). In addition, AMD purchased 12 million kWh of electricity produced by renewable energy sources in 2001, about three percent of the electricity consumed there that year. ${ }^{14}$ AMD increased its commitment to purchasing 24 million $\mathrm{kWh}$ of renewable electricity in 2002 and subsequent years (AMD 2002b).

Although fewer people (about 2,000) are employed by AMD at the Sunnyvale site, it is the home of a more diverse range of activities than the Austin site. The Sunnyvale campus consists of eight AMD-owned buildings and other leased spaces that contain AMD's primary research and development center, as well as the corporate headquarters and other design and research centers.

By far, the primary energy source used at both the Sunnyvale and Austin facilities is electricity. From 1997 to 2001 electricity consumption at the Austin site averaged approximately 330 million kWhs per year. Electricity consumption at the Sunnyvale site was much lower, averaging approximately 84 million $\mathrm{kWh}$ per year (AMD 2002a). While exact figures were not made available, consumption of natural gas was reported to produce approximately $5 \%$ of energyrelated GHG emissions in Austin and 25\% in Sunnyvale (Seif 2003). Thus, total energy-related GHG emissions were estimated given the reported electricity values and the approximate share of emissions from natural gas in total emissions. AMD has established an internal goal of reducing its normalized energy-related GHG emissions by 15 percent of the 2000 level by 2005 at its two manufacturing sites (AMD 2002b). This goal was derived from historical performance of normalized emissions, incorporating future operational projections and a reasonable improvement over a 5-year period (Seif 2003). The major energy end uses at these AMD facilities consist of machinery used for chip manufacturing, HVAC, and lighting. At the corporate headquarters, a significant share of electricity is also used by office equipment such as copiers, faxes, computers, and printers.

In addition to energy-related GHG emissions, semiconductor manufacturing results in the release of perfluorocarbons (PFCs), synthetic gases with a very large global warming forcing potential

\footnotetext{
${ }^{14}$ The actual total may have been somewhat less since the subscription to the renewable electricity did not begin until March of 2001 (Seif 2003).
} 
(GWP). ${ }^{15}$ Between 1997 and 2001, the Sunnyvale site averaged emissions of approximately 5,300 metric tons carbon equivalent per year of PFCs ${ }^{16}$, and the Austin site averaged 61,800 metric tons per year (AMD 2002a). ${ }^{17}$ AMD co-founded the PFC Leadership Group with other semiconductor manufacturers in 1995 to encourage suppliers of semiconductor manufacturing equipment to work with manufacturers to achieve the industry's PFC reduction goals. AMD was also one of the first companies to join the EPA's voluntary "PFC Reduction Partnership for the Semiconductor Industry" (AMD 2002b). AMD has been aggressively pursuing improvement of its production processes and emissions recovery to lower PFC emissions. It has established a goal to reduce total PFC emissions by 50 percent of the 1995 level by 2010. The PFC goal was created to support the World Semiconductor Council's (WSC) 10\% absolute reduction goal by 2010 against the 1995 baseline. The same baseline years are employed in the AMD goal, but a reduction goal of $50 \%$ was chosen because it is recognized that companies would have varied ability to reach or surpass a $10 \%$ reduction based upon their manufacturing technology. Those semiconductor companies manufacturing with state-of-the-art technology, like AMD, would have a greater ability to reduce emissions via new process and equipment incorporation (Seif 2003).

\subsubsection{Analysis of Possible Metrics}

As with all manufacturing industries, energy consumption and GHG emissions related to semiconductor manufacturing can be reported at various levels of aggregation. The appropriate level of aggregation will depend on factors such as data availability, practicality, and accuracy of the resulting metric in tracking improvements over time. For example, energy use could be tracked at the level of specific process steps, but this would be cumbersome for reporting and companies will be reluctant to release such detailed data. At the other extreme, all energy or emissions can be indexed to one measure of output for each site. However, since many factors may influence total energy consumption, such aggregated measures may not accurately reflect real changes in efficiency. Alternatively, energy use can be indexed for select categories of energy end uses such as manufacturing, lighting, or HVAC.

Although the Registry enabling legislation specifically refers to the use of economic metrics, such as emissions per dollar of revenue, previous analyses have found that physical measures of output are preferable, since physical metrics are more consistent over time (Farla et al., 1997; Freeman et al., 1996; Nanduri et al., 2002; Phylipsen et al., 1996; Phylipsen et al., 1997; Worrell et al., 1997). Economic measures of output, such as value added and gross output can be erratic compared to actual physical production in a given year, even for extremely mature industries such as iron and steel (Worrell et al. 1997). Thus, physical measures of production should be used for the construction of metrics when possible, although non-manufacturing building-related energy use is commonly normalized for building area and sometimes corrected for weather.

\footnotetext{
${ }^{15}$ The 100-year global warming potential of PFCs is 6,500 to 23,900 according to the Intergovernmental Panel on Climate Change's Second Assessment Report. These values were updated to 5,700 to 22,000 in the IPCC's Third Assessment Report. EPA Memorandum of Understanding (MOU) reporting companies have used the Second Assessment Report, although indications are that the Third Assessment Report factors will be used starting in 2003 (2002 reporting). Global warming potential is the ratio of radiative forcing (both direct and indirect) from one kilogram of a greenhouse gas to one kilogram of $\mathrm{CO}_{2}$ over a period of time (U.S. EPA, 2003b).

${ }^{16}$ All GHG emissions in this report are given in metric tons, or million metric tons, of carbon equivalent (not $\mathrm{CO}_{2}$ ).

${ }^{17} \mathrm{PFC}$ emissions from these sites are from $\mathrm{SF}_{6}, \mathrm{CF}_{4}, \mathrm{C}_{2} \mathrm{~F}_{6}, \mathrm{C}_{3} \mathrm{~F}_{8}, \mathrm{c}-\mathrm{C}_{4} \mathrm{~F}_{8}, \mathrm{CHF}_{3}$, and $\mathrm{NF}_{3}$ (Seif, 2003).
} 


\subsubsection{Semiconductor Industry Metrics}

The production efficiency index, which measures electricity usage per square inch or per square centimeter, is commonly used by the U.S. semiconductor industry. This index is used in the Semiconductor Industry Association's National Technology Roadmap for Semiconductors, which based its proposed target of $4 \mathrm{kWh}$ per inch ${ }^{2}$ by 2003 on this metric (Semiconductor Industry Association, 1998). In 1997, the U.S. average semiconductor electricity consumption was $11.4 \mathrm{kWh} / \mathrm{inch}^{2}$ (U.S. EPA, 1998).

In 1999, International SEMATECH introduced a new metric for the semiconductor industry that normalizes for variations in production capacity and accounts for differences in manufacturing complexity (Patton and Wiese, 1999). AMD refers to this index as the Manufacturing Index (MI) and uses it for its Austin and Dresden fabs. This MI is used to normalize energy consumption, GHG emissions, and water consumption to varying levels of output.

This "unit of production" metric is expressed in terms of $\mathrm{kWh}$ per unit of production which is defined as the square inches of wafer starts per year multiplied by the average number of mask layers per wafer processed (Patton and Wiese, 1999).

$$
\text { MI = Wafer starts } \mathrm{x} \text { Photolithographic Masking Steps } \mathrm{x} \text { Wafer area }\left(\mathrm{in}^{2}\right)
$$

"Wafer starts" refers to the actual number of semiconductor wafers entered into the production line. While AMD uses wafer starts, some other industry groups and companies prefer "wafer outs" which represents the number of wafers that undergo full processing (Seif 2003). "Masking steps" is a measure of each wafer's complexity/functionality. Device functionality often scales closely with microelectronic complexity. The shrinking and increased functionality of mobile phones provides a prime example. The number of microelectronic devices has continually decreased while functionality has increased, both occurring via processing advances. The few devices in modern mobile phones are many times more functional than the many individual devices in the mobile phone models of 10 years ago. The wafer area is simply the surface area of one side of a given wafer. The MI is thus equivalent to the total surface area of wafers processed (accounting for multiple layers) and reasonably represents both the number and the functionality of the final product.

SEMATECH's 1999 survey of 14 semiconductor manufacturing facilities around the world reported an average production efficiency of $7.45 \mathrm{kWh}$ per inch ${ }^{2}$ and an average consumption of $0.393 \mathrm{kWh}$ per unit of production, with the plants in the survey ranging from 5.36 to $10.23 \mathrm{kWh}$ per inch ${ }^{2}$ and from 0.286 to $0.637 \mathrm{kWh}$ per unit of production (Patton and Wiese, 1999). A 19981999 study of energy consumption in nine semiconductor fabs in Taiwan found a range of 0.286 to $1.08 \mathrm{kWh}$ per unit of production (Hu and Chuah 2003) ${ }^{18}$ The two indices may produce significantly different results. For example, in the Hu and Chuah (2003) study, "Fab D" was the

\footnotetext{
${ }^{18}$ This metric has been criticized, though, as an ineffective metric for evaluating overall energy performance because it is quite possible to increase production and continue to operate building systems inefficiently. For example, one company claimed that if they could process two wafers simultaneously they would double their energy efficiency, ignoring the opportunity to improve the real performance of the tool through improved vacuum pumps, sizing and layout, etc. (Tschudi, 2003).
} 
fourth least intensive plant of the nine plants when ranked by $\mathrm{kWh} / \mathrm{cm}^{2}$. However, when ranked by $\mathrm{kWh} / \mathrm{unit}$ of production, it was next to last. This would indicate that Fab D produces wafers of lower complexity, which lowers its energy consumption per $\mathrm{cm}^{2}$ of wafer produced. Similarly, Patton and Wiese found that of the three most "efficient" fabs in their study when ranked by the production efficiency index $\left(\mathrm{in}^{2}\right)$ only one was among the top three when ranked by the unit of production index.

Since AMD's publicly available data provide manufacturing energy, water consumption, and hazardous waste generation normalized to the MI (AMD 2002a), and this index is commonly used in the semiconductor industry, we have used it in this report. It is important to note that the MI reported by AMD for its Sunnyvale site is not equivalent to the "unit of production" index. The R\&D wafer starts in Sunnyvale go through varying degrees of processing and rarely go through all the photolithographic steps that are used to produce a full flow, product wafer; thus, the MI is calculated differently for this site and represents the number of process steps, or "activities," that have taken place in the facility. Thus, the two normalization factors used by AMD at the Austin and Sunnyvale sites, although both called MI, are not directly comparable.

\subsubsection{Energy-Related Metrics}

AMD reports total electricity consumption for each site, as well as electricity consumption normalized to the MI. ${ }^{19}$ Table 13 provides the electricity consumption for the Sunnyvale and Austin sites for 1997 through 2001 as reported by AMD. ${ }^{20}$ We used these values to calculate the MI for each site. ${ }^{21}$ Figure 1 shows total electricity use for the two sites indicating that total electricity consumed declined after 1998 at the Sunnyvale site and after 1999 in Austin. Figure 2 provides indexed electricity use showing that even though total electricity was declining after 1998 in Sunnyvale, electricity use per MI increased, an unexpected trend. Similarly, at the Austin site, even though electricity use declined between 2000 and 2001, electricity use per MI increased. It appears, then, that the electricity use per MI metric is sensitive to capacity utilization of facilities. Note that the normalized electricity consumption at both the Sunnyvale and Austin facilities rose sharply when production levels (measured by the MI) fell in 2000 and 2001, respectively. Hu and Chuah (2003) report a similar finding for one of the fabs in their study. This could be due to fixed levels of energy consumption for activities such as lighting and HVAC, which are relatively insensitive to production levels. This may be exacerbated for the Sunnyvale site where electricity used for the corporate headquarters is included in normalized totals. Approximately 35\% of electrical power use in Sunnyvale occurs in buildings used primarily for administrative activities, and the remainder occurs in equipment-intensive buildings that have testing and processing equipment (Seif 2003).

\footnotetext{
${ }^{19}$ Data at more detailed levels of disaggregation were not provided to LBNL for use in this report.

${ }^{20}$ Data for this report were taken primarily from the 2001 Sustainability Progress Report (AMD, 2002a), with some supplemental information from personal communications with Daniel Seif of AMD's Environmental, Health, and Safety Department (Seif, 2003).

${ }^{21}$ MI derived by dividing the electricity consumed at each site by the normalized electricity consumption.
} 
Table 13. Electricity Use Data for AMD, 1997 - 2001

\begin{tabular}{l|c|r|r|r|r|r}
\hline Sunnyvale & Unit & \multicolumn{1}{|c|}{$\mathbf{1 9 9 7}$} & \multicolumn{1}{c|}{$\mathbf{1 9 9 8}$} & \multicolumn{1}{|c|}{$\mathbf{1 9 9 9}$} & \multicolumn{1}{c|}{$\mathbf{2 0 0 0}$} & \multicolumn{1}{c}{$\mathbf{2 0 0 1}$} \\
\hline Electricity use & $\mathrm{GWh}$ & 86.70 & 87.77 & 84.30 & 81.67 & 79.08 \\
Manufacturing Index (MI) & $10^{\wedge} 6$ activities & 5.7 & 7.4 & 6.3 & 4.3 & 4.3 \\
Indexed electricity use & $\mathrm{kWh}$ per MI & 15.14 & 11.85 & 13.44 & 19.00 & 18.49 \\
\hline Austin & & & & & & \\
\hline Electricity use & $\mathrm{GWh}$ & 307.6 & 330.3 & 345.4 & 340.6 & 334.4 \\
Manufacturing Index (MI) & $10^{\wedge} 6 \mathrm{in}^{2}$ & 334 & 371 & 443 & 480 & 363 \\
Indexed electricity use & $\mathrm{kWh}$ per MI & 0.92 & 0.89 & 0.78 & 0.71 & 0.92 \\
\hline
\end{tabular}

Source: AMD 2002a
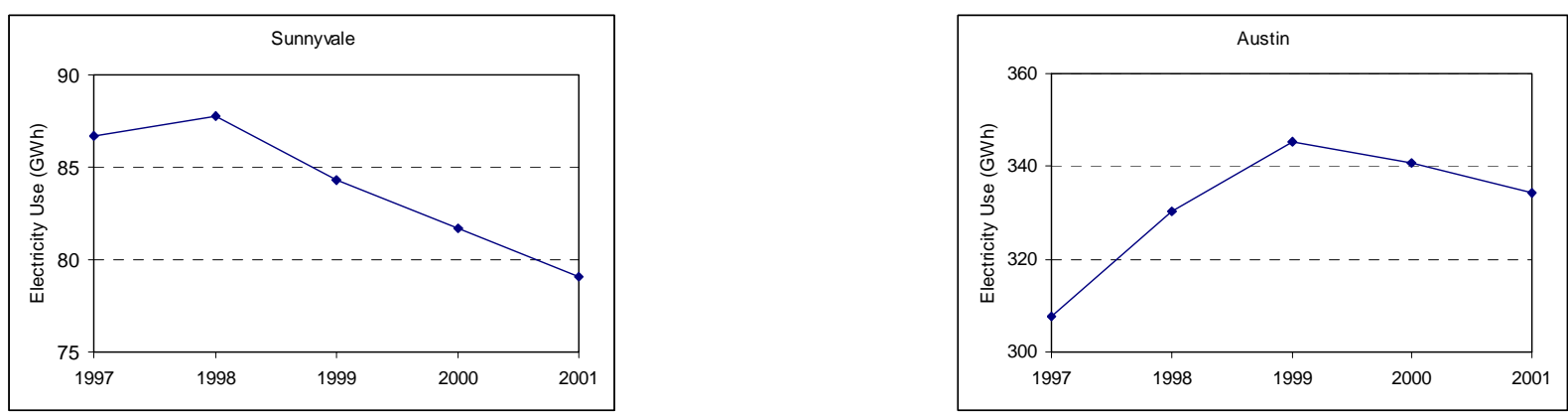

Figure 1. Total Electricity Consumption at AMD's Sunnyvale and Austin Sites, 1997-2001.
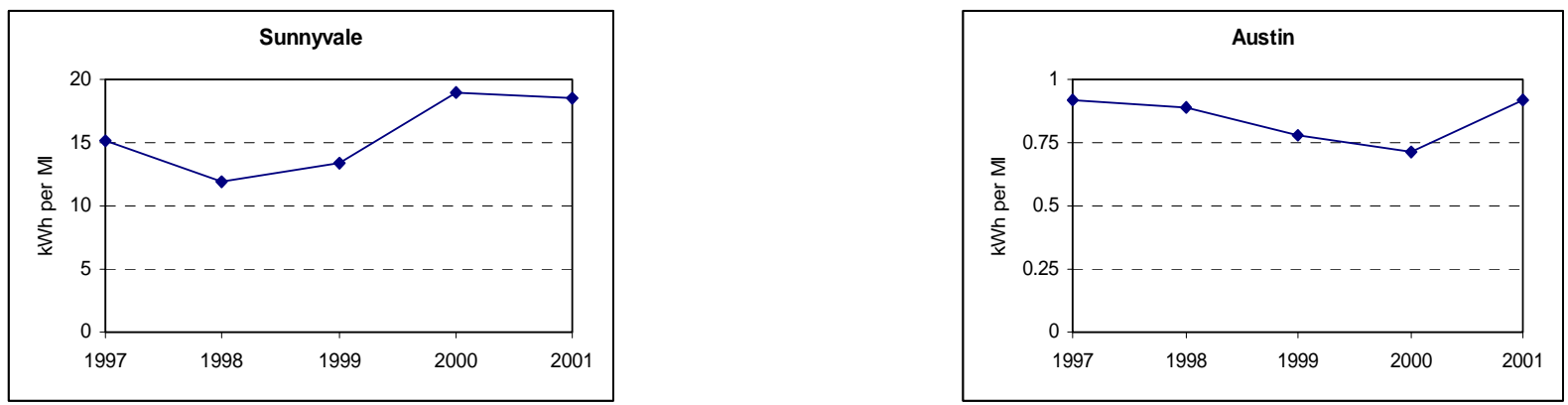

Figure 2. Electricity Consumption Metrics for AMD's Sunnyvale and Austin Sites, 1997-2001.

\subsubsection{Emissions-Related Metrics}

To further evaluate possible metrics for use by this industry, we converted AMD's reported electricity consumption to equivalent $\mathrm{CO}_{2}$ emissions using an average emissions factor for Pacific Gas and Electric Company (PG\&E), the utility serving Sunnyvale (Marnay et al., 2002).

We then estimated natural gas emissions for both sites, given that they were approximately 5\% of energy-related emissions in Austin and 25\% of energy-related emissions in Sunnyvale during the period (Seif 2003). Total electricity-related emissions and the estimated natural gas emissions were then added to the reported PFC emissions to derive a plant-total emissions value for the two sites (see Table 14). 
Figure 3 illustrates the trends in actual emissions for both sites. As can be seen, total GHG emissions at the Sunnyvale site dropped continuously from 1998 to 2001, almost completely attributable to the drop in PFC emissions during that period. Total GHG emissions at the Austin site rose slightly between 1997 and 1998 and then were relatively stable until they dropped in 2001, also reflecting trends in PFC emissions. Figure 4 provides indexed emissions on an individual basis as well as total indexed emissions for both sites. The disaggregated indexed emissions are helpful in explaining the trends in total emissions per MI in the figure.

An additional GHG emissions metric that can be used to mask proprietary data is the GHG intensity index. This metric indexes current annual GHG emissions to a base year, accounting for changes in production. For AMD, the index is calculated by multiplying the actual current year MI by the current year emissions rate $(\mathrm{kgCeq} / \mathrm{MI})$ and then dividing that value by the current year MI multiplied by the base year emissions rate. This provides an indication of what emissions would be in the current year, given current year production values, if the base year emissions rate had not changed. Figure 5 shows the GHG intensity index for both the Sunnyvale and Austin sites, illustrating that while both sites had indices around 84 in 2001 (the base year is set at 100), they both experienced wide fluctuations in the years between 1997 and 2001. 
Table 14. GHG Emissions Data for AMD, 1997 - 2001

\begin{tabular}{|c|c|c|c|c|c|c|}
\hline Sunnyvale & Unit & 1997 & 1998 & 1999 & 2000 & 2001 \\
\hline Electricity-related emissions & MtCeq. & 0.0055 & 0.0056 & 0.0054 & 0.0052 & 0.0050 \\
\hline Natural gas-related emissions & MtCeq. & 0.0014 & 0.0014 & 0.0013 & 0.0013 & 0.0013 \\
\hline Total energy-related emissions & MtCeq. & 0.0069 & 0.0070 & 0.0067 & 0.0065 & 0.0063 \\
\hline PFC emissions & MtCeq. & 0.0068 & 0.0070 & 0.0055 & 0.0045 & 0.0027 \\
\hline Total GHG emissions & MtCeq. & 0.0137 & 0.0140 & 0.0122 & 0.0110 & 0.0090 \\
\hline Manufacturing Index (MI) & $10^{\wedge} 6$ process steps & 5.7 & 7.4 & 6.3 & 4.3 & 4.3 \\
\hline Indexed electricity-related emissions & kgCeq./MI & 0.9659 & 0.7532 & 0.8497 & 1.2061 & 1.1678 \\
\hline Indexed natural gas-related emissions & kgCeq./MI & 0.2415 & 0.1883 & 0.2124 & 0.3015 & 0.2920 \\
\hline Indexed total energy-related emissions & kgCeq./MI & 1.2073 & 0.9415 & 1.0621 & 1.5076 & 1.4598 \\
\hline Indexed PFC emissions & kgCeq./MI & 1.1930 & 0.9459 & 0.8730 & 1.0465 & 0.6279 \\
\hline Indexed total GHG emissions & KgCeq./MI & 2.4003 & 1.8874 & 1.9351 & 2.5541 & 2.0877 \\
\hline Austin & Unit & 1997 & 1998 & 1999 & 2000 & 2001 \\
\hline Electricity-related emissions & MtCeq. & 0.0443 & 0.0476 & 0.0497 & 0.0490 & $0.0464 *$ \\
\hline Natural gas-related emissions & MtCeq. & 0.0022 & 0.0024 & 0.0025 & 0.0025 & 0.0023 \\
\hline Total energy-related emissions & MtCeq. & 0.0465 & 0.0499 & 0.0522 & 0.0515 & 0.0487 \\
\hline PFC emissions & MtCeq. & 0.0634 & 0.0712 & 0.0648 & 0.0697 & 0.0516 \\
\hline Total GHG emissions & MtCeq. & 0.1099 & 0.1211 & 0.1170 & 0.1212 & 0.1003 \\
\hline Manufacturing Index (MI) & $10^{\wedge} 6 \mathrm{in}^{2}$ & 334 & 371 & 443 & 480 & 363 \\
\hline Indexed electricity-related emissions & kgCeq./MI & 0.1326 & 0.1282 & 0.1123 & 0.1022 & 0.1279 \\
\hline Indexed natural gas-related emissions & $\mathrm{kgCeq} . / \mathrm{MI}$ & 0.0066 & 0.0064 & 0.0056 & 0.0051 & 0.0064 \\
\hline Indexed total energy-related emissions & kgCeq./MI & 0.1392 & 0.1346 & 0.1179 & 0.1073 & 0.1343 \\
\hline Indexed PFC emissions & kgCeq./MI & 0.1898 & 0.1919 & 0.1463 & 0.1452 & 0.1421 \\
\hline Indexed total GHG emissions & $\mathrm{kgCeq} . / \mathrm{MI}$ & 0.3291 & 0.3265 & 0.2642 & 0.2525 & 0.2764 \\
\hline
\end{tabular}

"Assuming that the $12 \mathrm{GWh}$ of green power purchased from Austin Energy is 100 percent renewable.

Notes: Electricity-related emissions calculated by multiplying reported electricity consumption (AMD, 2002a) by electricity emissions factors for the local utility company. For the Sunnyvale site, the electricity emissions factor for Pacific Gas \& Electric Company $(0.0635 \mathrm{kgC} / \mathrm{kWh})$ was used (Marnay et al., 2002). For the Austin site, the electricity emissions factor for Austin Energy $(0.144 \mathrm{kgC} / \mathrm{kWh})$ was used (Seif, 2003). Natural gas-related emissions calculated given the fact that consumption of natural gas was reported to be approximately $5 \%$ of energyrelated GHG emissions in Austin and 25\% in Sunnyvale (Seif 2003). PFC emissions and normalized electricity use $(\mathrm{kWh} / \mathrm{MI})$ provided by AMD (AMD, 2002a). MI derived by dividing the electricity consumed at each site by the normalized electricity consumption. 

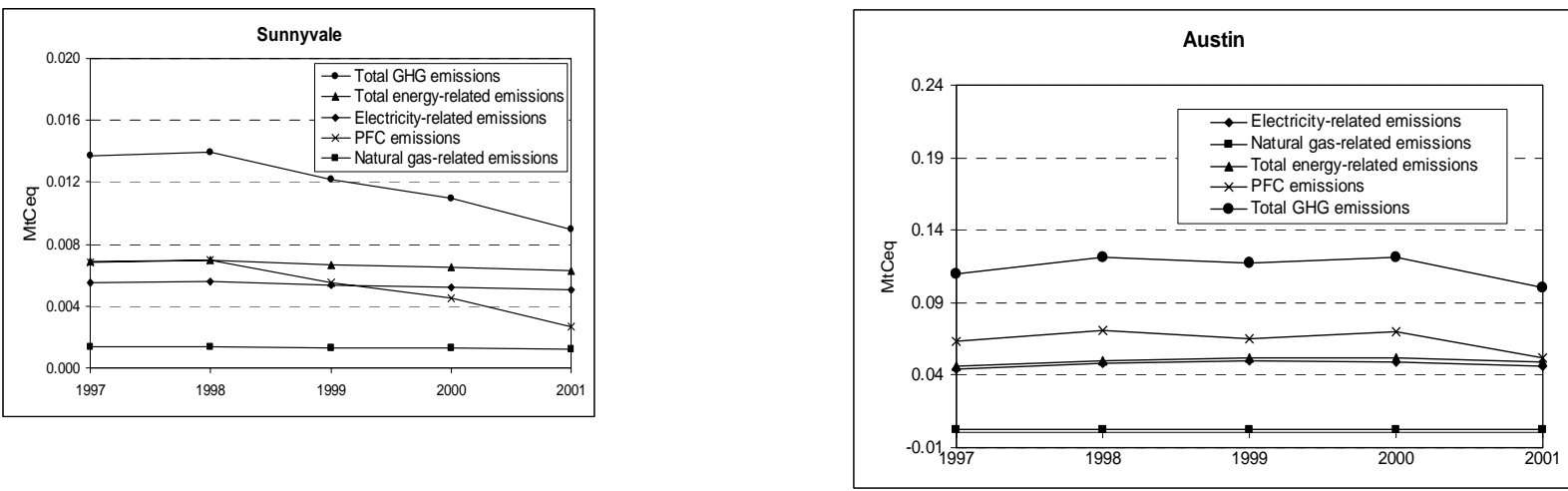

Figure 3. Total GHG Emissions of AMD's Sunnyvale and Austin Sites, 1997-2001.
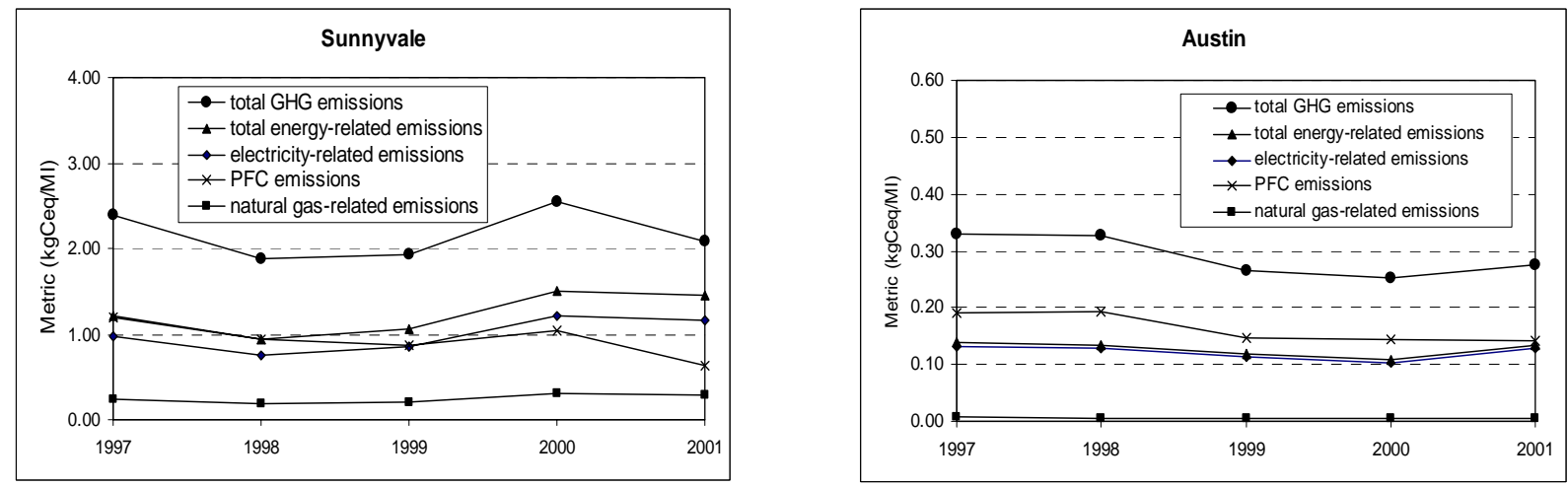

Figure 4. GHG Emissions Metrics for AMD's Sunnyvale and Austin Sites, 1997-2001.

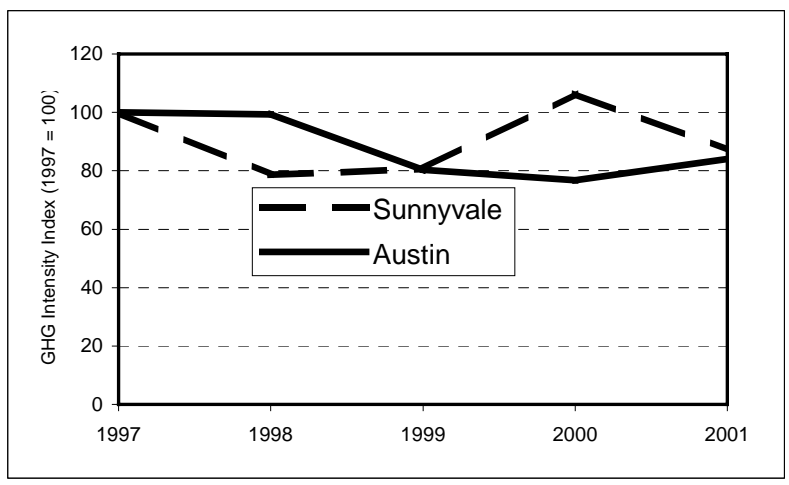

Figure 5. GHG Intensity Index for AMD's Sunnyvale and Austin Sites, 1997-2001.

\subsubsection{Findings}

The energy-related GHG metrics reported in AMD's Sustainability Progress Report are subject to large fluctuations due changes in capacity utilization. This undermines the purpose of the metrics, which is to track progress in reducing emissions per unit of output. Moreover, baselines derived from these metrics may be prone to unduly penalizing or rewarding manufacturers for 
factors beyond their control. The sensitivity to changes in capacity utilization may be due to the level of aggregation of energy data, where the more constant non-manufacturing energy consumption required to move air in the cleanroom and remove heat from the process tools is coupled with manufacturing-related energy consumption.

PFC emissions, however, seem to be more closely correlated to production, and AMD has achieved relatively steady improvements in the emissions of PFCs per MI. Since the Registry's goal is to track real changes in GHG or energy intensity, this would argue for reporting the PFC and energy-related emissions metrics separately, as AMD currently does, but reporting the energy-related emissions at a more disaggregated level of end-use.

A suggested disaggregation that would not be too burdensome for Registry participants in this industrial sector might include the following metrics:

- Energy-related emissions from building energy use per square foot or square meter

- Energy-related emissions from clean room HVAC facilities per square foot or square meter

- Energy-related emissions from process tools and other productive end-uses per MI

- Non-energy-related emissions from manufacturing per MI

Separating the production-related emissions from the non-production-related emissions can be important for participants like AMD that have facilities with large fixed energy consumption requirements. Such metrics would allow the participants to clearly show the effect of energyefficiency measures taken within the non-manufacturing facilities, such as offices and warehouses, separately from those taken within the manufacturing facilities. Within the manufacturing facilities, disaggregating the clean room HVAC from other end-uses will prevent changes in capacity utilization from masking the improvements in process efficiencies. Since the GWP-weighted emissions of PFCs can equal or exceed all the energy-related emissions combined, reporting them separately is imperative to account for the underlying reasons for changes in the GHG emissions.

If other electronics manufacturers participate in the Registry and the Registry would like to maintain comparability among participants in similar industries, it will be important to work with the manufacturers to ensure that the normalization factors are defined consistently. For semiconductor manufacturing facilities, the Manufacturing Index described in this report is commonly employed in the industry. For R\&D activities, however, this may be more complicated as each manufacturer may have defined a normalization factor differently.

\subsubsection{Baseline Issues}

The State of California has pledged to use its "best efforts" to ensure that entities that establish GHG emissions baselines and register their emissions will receive "appropriate consideration under any future international, federal, or state regulatory scheme relating to greenhouse gas emissions" (California Senate, 2001). LBNL has been asked by the California Energy Commission to evaluate the use of various types of baselines to assist the State in analyzing possible approaches for fulfilling its pledge. In this section, we evaluate the use of several different types of baselines that could be used to calculate GHG emissions reductions (or increases) for AMD. 


\subsubsection{Absolute Baselines for AMD}

Figure 6 illustrates three types of absolute baselines that could be constructed for the two AMD sites and compares them to actual emissions for 1997 through $2001 .{ }^{22}$ The first baseline is the fixed base year baseline. For the Sunnyvale site, the use of this type of baseline would result in significant emissions reductions from 1999 to 2001. The opposite trend is seen at the Austin site, where emissions grew between 1997 and 2000 and then dropped in 2001. Even with the decline in 2001, the cumulative total emissions are significantly higher than those projected by the fixed base year baseline.

The average emissions from the period 1997 through 1999 were used to project a fixed multiyear average baseline. For the Sunnyvale site, the use of this baseline results in only a slightly different baseline value and overall emissions reductions for the 1997 to 2001 period are below the projected baseline. The multiyear baseline changes the picture significantly, though, for the Austin site where the use of the fixed multiyear average baseline is much higher than the 1997 fixed base year value. One issue to consider regarding the use of fixed multiyear average baselines is that during the multiple year period that is used to set the baseline (e.g. 1997-1999 in this example), the reporting entity will not show any emissions reductions.

The figure also illustrates the use of a future target baseline using a target of a $10 \%$ reduction in GHG emissions below 1997 levels by 2010. In this case, the actual GHG emissions between 1997 and 2001 from the Sunnyvale site are below the projected baseline, while for the Austin site, actual GHG emissions were higher than the $10 \%$ future target baseline.

\footnotetext{
${ }^{22}$ An absolute baseline using historical GHG emissions trends could theoretically be constructed for these sites, but has not been done for this case study due to lack of availability of historical data.
} 

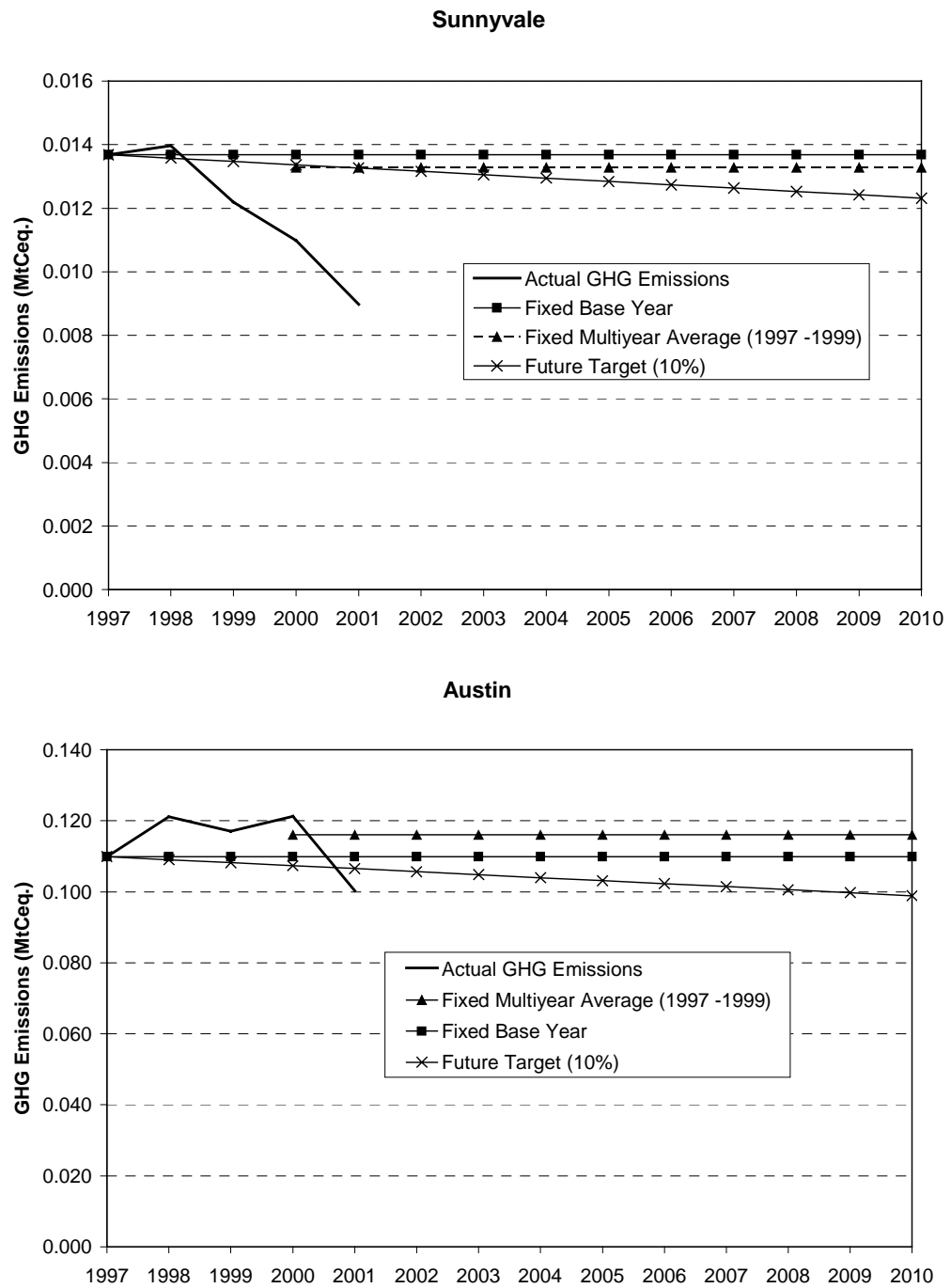

Figure 6. Absolute Baselines for AMD's Sunnyvale and Austin Sites

\subsubsection{Intensity Baselines for AMD}

Figure 7 illustrates four intensity-based baselines for the two AMD sites. ${ }^{23}$ The first, the fixed base year rate baseline, multiplies each year's actual MI by the 1997 intensity rate to generate the baseline. For this example, the 2001 MI was used to generate the baseline for 2002 through 2010. The second, the fixed multiyear average baseline, multiplies each year's actual MI by the average intensity rate for 1997 through 1999. As can be seen from the figure, both of these baselines result in estimated GHG emissions that are greater than actual emissions for both AMD sites for the period 1997 through 1999. The arbitrary rate of decline baseline show in this figure uses a $1 \%$ per year decline in the intensity value and multiplies that by the actual MI each year. The entity historical trend baseline projects future baseline GHG emissions by multiplying each

\footnotetext{
${ }^{23}$ The other types of intensity baselines - historical trend of the industry and expert judgment baselines - were not calculated for this case study.
} 
year's actual MI by the projected intensity value that is calculated based on the actual rate of decline in intensity between 1997 and 1999.
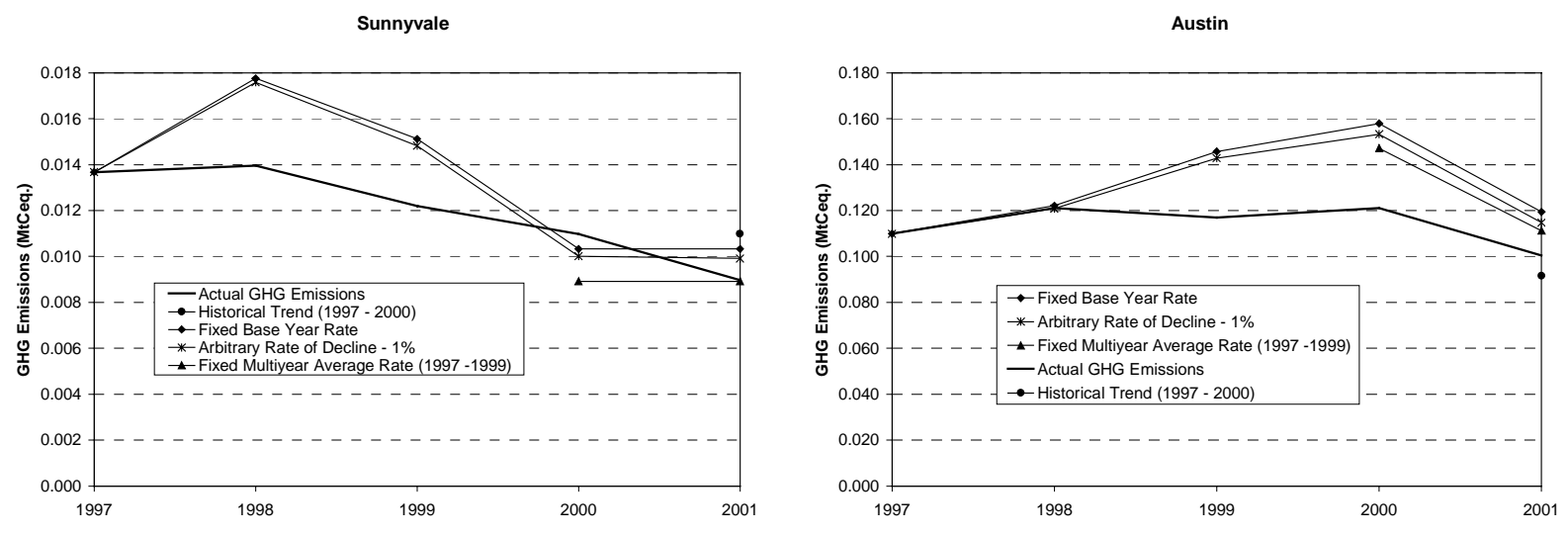

Figure 7. Intensity Baselines for AMD's Sunnyvale and Austin Sites

\subsubsection{Reconstructed Baselines}

AMD has undertaken a number of energy-efficiency and GHG emissions reduction projects at both the Sunnyvale and Austin sites during the past few years. Due to better availability of data and information for the Austin site regarding these efforts, we only developed an ex-post reconstructed baseline for that site for the year 2001 .

In 2001, AMD's Austin site purchased $12 \mathrm{GWh}$ of electricity produced by renewable energy sources (AMD, 2002b), reducing emissions by 0.0017 MtCeq. Also during 2001, AMD completed three energy conservation projects at the Austin site. A utility cross-connection project improved the system efficiency of chiller, boiler, condenser, and air drier units, saving an estimated $1600 \mathrm{MWh}$ of electricity and 8000 million Btus (MBtus) in natural gas annually. AMD engineers optimized an air humidification system by relocating it to another spot in the air conditioning system, achieving annual reductions of $370 \mathrm{MWh}$ in electricity and $100 \mathrm{MBtus}$ in natural gas. Over 2300 non-essential lights were removed and thermostat settings were increased in two buildings to new levels still comfortable for employees. The energy reduction estimate for the lighting reduction alone is over $1000 \mathrm{MWh} /$ year (AMD, 2002b). All of these actions reduced GHG emissions by a total of $0.0023 \mathrm{MtCeq}$ below what emissions would have been without the energy conservation measures. The total savings were added to the 2001 actual emissions to show what total emissions would have been had AMD not undertaken the actions described above (see Figure 8). 


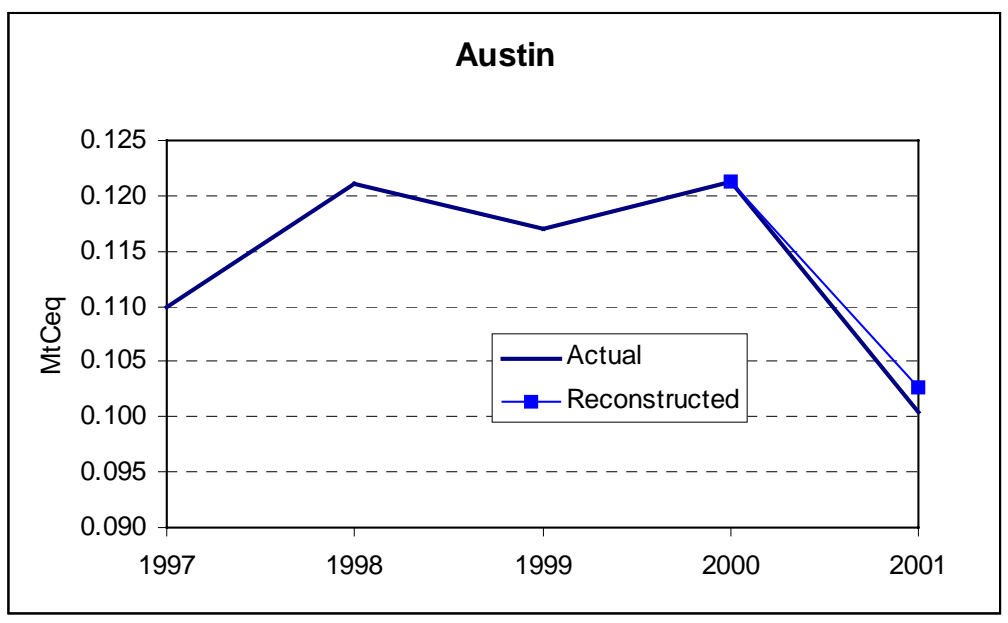

Figure 8. Ex Post Reconstructed Baseline for Austin Site, 2001.

\subsubsection{Findings}

Table 15 provides a comparison of the actual GHG emissions and those emissions projected by the various baselines in 2001 for AMD's Sunnyvale and Austin sites. In almost all cases, actual emissions are below the baselines. The only exceptions are for the fixed multiyear average rate baseline in the case of Sunnyvale and the historical trend baseline in the case of Austin where actual emissions are above the baseline values. For the Sunnyvale site, the three absolute baselines are very similar and as a result show very similar GHG emissions savings when compared to actual emissions in 2001. The intensity-based baselines provide a greater variation in projected 2001 values, none of which are similar to the absolute baseline values for that year. For the Austin site, the baselines and resulting GHG emissions reductions calculations vary widely.

Overall, these examples show that it is difficult to clearly identify any one baseline that is preferable to another based on the limited number of years projected but also due to the wide variation in the differences between the baselines and actual GHG emissions. Thus, these case studies indicate that while there are many types of baselines that can possibly be used to determine GHG emissions reductions attributable to the early actions of a company, the decision on which baseline to choose can be best made by considering the baseline complexity and robustness as outlined in Table 12 in terms of the ultimate desired use of the baseline. 
Table 15. Comparison of the Use of Various Baselines for AMD Sunnyvale and Austin Sites (MtCeq.).

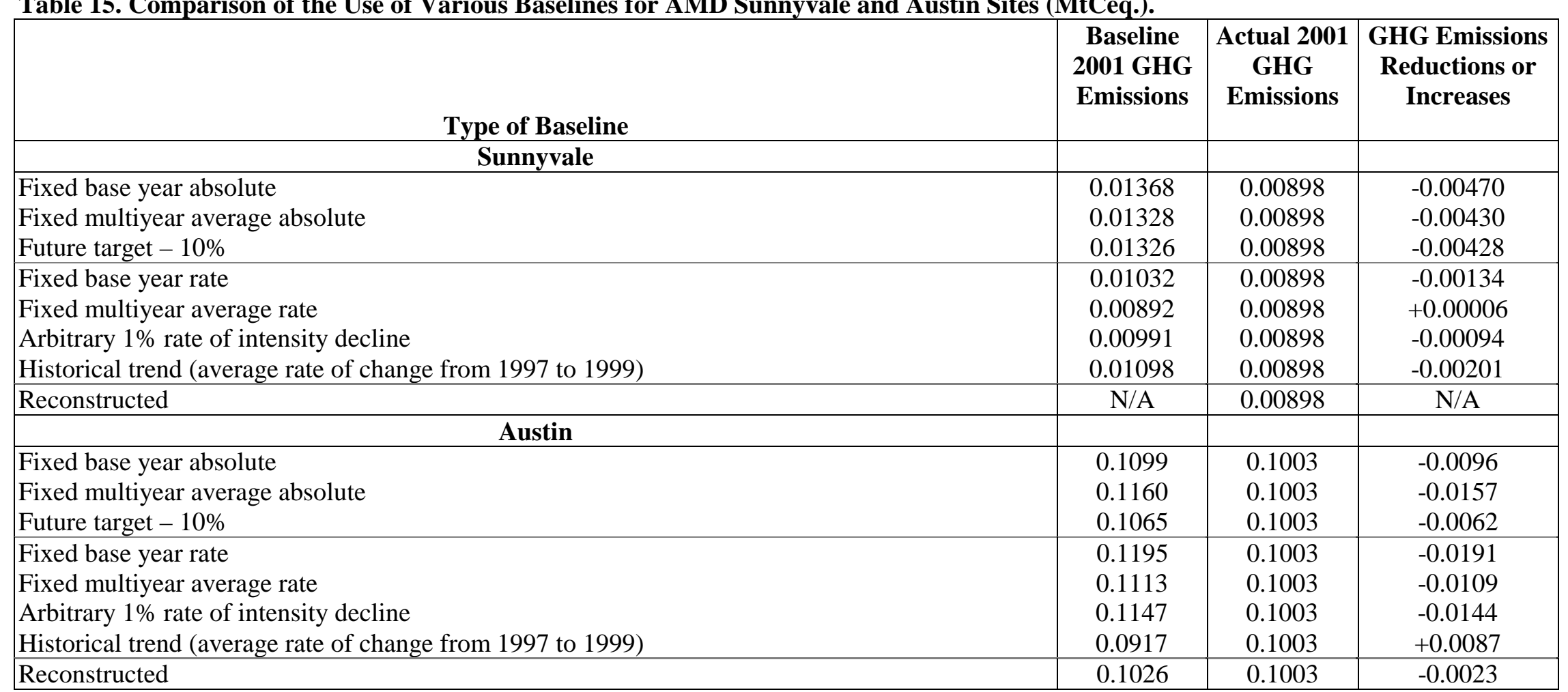




\subsection{Agricultural Crop Production and Food Processing: Fetzer Vineyards Case Study}

\subsubsection{Sector Background}

Although this case study was originally intended to focus on metrics and baselines for the agricultural sector, the case study participant, Fetzer Vineyards, represents two distinct, but closely affiliated industries. First, Fetzer grows and harvests grapes, an activity akin to other types of crop production. Second, there is the process of transforming grapes into a beverage, a food processing activity similar to beer brewing or other types of beverage production. The data supplied by Fetzer Vineyards presented us with the opportunity to perform case studies of both industries.

The two activities, and their associated energy consumption and GHG emissions, need to be analyzed separately because wineries commonly purchase grapes from other growers for use in their wines. Indeed, a few wineries operate more like breweries, with no self-grown grapes. Thus, the ratio of wine produced to grapes grown may vary considerably among wineries or from year to year for the same winery. A single metric based solely on wine production may not provide a meaningful comparison among wineries or accurately track efficiency improvement for any given winery. For this report, we have separated the end uses into these two activities as accurately as possible.

Agriculture and food processing are important industries for California's economy. California is by far the leading agricultural state in the country, with a total 2001 gross cash income of over $\$ 27$ billion, and a net contribution of over $\$ 13$ billion to California's Gross State Product in 2000 (NASS 2002; BEA 2003). Production of crops is also the sixth largest industrial sector consumer of electricity and natural gas in California. Food processing contributed another $\$ 16$ billion to the 2000 GSP and was the third largest industrial sector consumer of electricity and natural gas (BEA 2003).

The wine industry is particularly important for California. The retail value of wine produced in California is the largest of any finished agricultural product and winegrapes are the second largest primary agricultural product in California, behind milk and cream (Wine Institute 2002a; NASS 2002). This industry has been growing rapidly, with the reported acreage of winegrapes in California increasing nearly 50 percent between 1991 and 2001, from 333,500 acres to 489,579 acres (Wine Institute 2002b).

\subsubsection{Overview of Fetzer Vineyards}

Fetzer Vineyards, headquartered in Hopland, California, was established in 1968. Currently, it is the sixth largest vineyard by total sales in the United States. Fetzer cultivates over 1,000 acres of grapes and produces approximately 200,000 cases of wine per year. Fetzer also engages in various service sector activities through its on-site restaurant and tasting facility, events center, and bed and breakfast operation (Fetzer 2001a).

The main agricultural end uses of energy are water pumps, tractors and other field vehicles, and on-site housing for the family and laborers. End uses for food processing are more varied. They 
include the production machinery, refrigeration, process heat, pumps, and wastewater treatment needed for wine production. On an annual basis over the past several years, Fetzer has been averaging consumption of about $6.3 \mathrm{GWh}$ of purchased electricity. Fetzer also uses about 100,000 therms of natural gas; 4,000 million Btu (MMBtu) of propane; 140,000 gallons of diesel; and 33,000 gallons of gasoline per year (Healy 2002).

Fetzer has proactively mitigated its environmental impact since it first began to systematically develop sustainable business practices in the mid-1980s. In 1985, Fetzer committed to growing all of its grapes organically and is now one of the largest growers of organic grapes in the world (Fetzer Vineyards 2001b; Fetzer Vineyards 2001c). Fetzer has also taken several actions to reduce GHG emissions. With the advent of competition for retail electricity in 1998, Fetzer became the first winery to purchase $100 \%$ renewable power. In addition to numerous projects to reduce electricity consumption, roughly $50,000 \mathrm{kWh}$ are produced on site by solar photovoltaic panels. In 2002, Fetzer also substituted approximately 9,000 gallons of diesel with $100 \%$ biodiesel from soybean oil (Healy 2002). Recently, Fetzer has also undertaken energy efficiency measures that have significantly reduced its consumption of natural gas (Healy 2002). Fetzer estimates that with improved waste management practices and reduced waste going to landfill that emissions from solid waste have been reduced 92\% (Fetzer Vineyeards 2001b).

\subsubsection{Analysis of Possible Metrics}

As with all industries, energy consumption and GHG emissions related to agricultural crop production and food processing can be reported and indexed at various levels of aggregation. The appropriate level of aggregation will depend on factors such as data availability, practicality, and accuracy of the resulting metric in tracking improvements over time. For example, energy use could be tracked at the level of specific process steps, but this would be cumbersome for reporting, and companies will be reluctant to release such detailed data. At the other extreme, all energy or emissions can be indexed to one measure of output for each entity. However, since many factors may influence total energy consumption, such aggregated measures may not accurately reflect real changes in efficiency. Alternatively, energy use can be indexed for select categories of energy end uses such as manufacturing processes, lighting, or HVAC.

Although SB 1771 specifically refers to the use of economic metrics, such as emissions per dollar of revenue, previous analyses have found that physical measures of output are preferable, since physical metrics are more consistent over time. Economic measures of output, such as value added and gross output can be erratic compared to actual physical production in a given year, even for extremely mature industries such as iron and steel (Worrell et al. 1997). Using economic metrics for agricultural or mineral commodities is particularly problematic since commodity prices are especially volatile and tend to fall rapidly in real terms (Murtishaw et al. 2001). Thus, physical measures of production should be used for the construction of metrics when possible.

\subsubsection{Energy, GHG Emissions, and Production Data for Agricultural Crop Production and Food Processing}

Previous efforts to index agricultural energy consumption have used tons of crops produced, acres, or commodity value. While acreage is not a measure of production per se, it can be used to 
normalize emissions when production volumes do not depend heavily on energy use. This may be appropriate for perennial crops such as grapes, tree fruits, and nuts. Since Fetzer provided data on both tons of grapes grown by Fetzer and acres owned or farmed by Fetzer, both were used for this case study. ${ }^{24}$

Previous work on indexing energy consumption and GHG emissions in the food processing industries have either used physical production or economic value as the indexing metric. Metrics used for studies on energy use and GHG emissions from brewing, for example, have included barrels of beer, hectoliters of beer, gross output, and value added as metrics (Galitsky et al., 2003; Institute for Energy Technology 1998; Nyboer and Laurin 2001a; Nyboer and Laurin $2001 b$ ). Fetzer provided production data on cases produced, gallons moved, and gallons racked, all of which were evaluated for use as metrics. ${ }^{25}$

Table 16 lists the energy and production data for this case study, broken down by economic activity and end use. Other possible sources of GHG emissions and other possible normalization factors that were not available for this case study are listed. Development of differentiated agricultural and food processing metrics for Fetzer's energy consumption and GHG emissions requires separation of annual energy consumption and GHG emissions into agricultural and food processing activities. We have categorized the energy end uses and other GHG emissions at Fetzer Vineyards as either agricultural, food processing, or other (buildings and transportation).

Agricultural crop production includes the energy consumed by tractors, field vehicles, and agricultural pumps, along with the energy used for onsite residences for the Fetzer family, other managers, and laborers since on-site housing is common in the agricultural sector. Food processing energy includes the energy used for bottling machinery, winery machinery, refrigeration units, pumps, wastewater treatment, forklifts, process heat, barrel washing, the administrative office, and the operations and maintenance facility. ${ }^{26}$ Energy used by the main administration building was allocated to food processing since most of the activity occurring there is related to managing the wine business. Those end-uses not allocated to either agricultural or food processing activity consist of haulage of empty and filled bottles and electricity consumed in buildings used for guest lodging and the visitor center.

\footnotetext{
${ }^{24}$ Fetzer farms a significant share of its total acreage under contract with other vineyards. While these sites are not owned by Fetzer, the trucks and tractors used to tend the vines and harvest the grapes are. In some cases, Fetzer is also responsible for paying the electric bills of the pumps used for irrigating these sites. Thus, these acres have been included in the inventories and metrics for this report.

25 "Gallons moved" refers to the quantity of unfinished wine moved in and out of the facility and "gallons racked" refers to the quantity of wine filled into barrels.

${ }^{26}$ Electricity use at Fetzer is monitored by over 50 meters, most of which measure electricity for individual pumps. There are also several meters for the various residential and administrative buildings. Unfortunately, two facilities that use a large portion of the energy at Fetzer, the winery and the bottling plant, are each served by only one meter, limiting the opportunity for tracking energy consumption for specific process steps.
} 
Table 16. Energy End-Uses, Non-Energy GHG Sources, and Production Metrics at Fetzer Vineyards by Economic Activity

\begin{tabular}{|c|c|c|c|}
\hline \multicolumn{4}{|l|}{ Agricultural } \\
\hline Data Type & End Use, Source, Activity & Fuel Type & $\begin{array}{l}\text { Data } \\
\text { Availability }\end{array}$ \\
\hline Energy End Use & $\begin{array}{l}\text { Pumps } \\
\text { Tractors and field vehicles } \\
\text { HVAC/lighting for residences }\end{array}$ & $\begin{array}{l}\text { Electricity } \\
\text { Diesel }^{\mathrm{a}} \\
\text { Electricity }^{\text {a }}\end{array}$ & $\begin{array}{l}1999-2002 \\
2001-2002 \\
1999-2002\end{array}$ \\
\hline Other GHG Emissions & Nitrous oxide emissions from fertilizer & & N/A \\
\hline Production Metrics & $\begin{array}{l}\text { Tons of grapes grown by Fetzer } \\
\text { Acres owned or farmed by Fetzer }\end{array}$ & & $\begin{array}{l}1999-2002 \\
1999-2002\end{array}$ \\
\hline \multicolumn{4}{|l|}{ Food Processing } \\
\hline Data Type & End Use, Source, Activity & Fuel Type & $\begin{array}{l}\text { Data } \\
\text { Availability }\end{array}$ \\
\hline Energy End Use & $\begin{array}{l}\text { Winery machinery } \\
\text { Refrigeration units in winery } \\
\text { Winery pumps } \\
\text { Barrel washing in winery } \\
\text { Bottling machinery } \\
\text { Wastewater treatment }{ }^{b} \\
\text { Process heat for winery \& bottling plant } \\
\text { Process heat for winery } \\
\text { Forklifts } \\
\text { HVAC/lighting for winery \& bottling plant } \\
\text { HVAC/lighting for Administrative Office } \\
\text { HVAC/lighting for Operations \& Maintenance }\end{array}$ & $\begin{array}{l}\text { Electricity } \\
\text { Electricity } \\
\text { Electricity } \\
\text { Electricity } \\
\text { Electricity } \\
\text { Electricity } \\
\text { Natural Gas } \\
\text { Propane } \\
\text { Electricity/Propane } \\
\text { Electricity } \\
\text { Electricity } \\
\text { Electricity }\end{array}$ & $\begin{array}{l}1999-2002 \\
1999-2002 \\
1999-2002 \\
1999-2002 \\
1999-2002 \\
1999-2002 \\
1999-2002 \\
1999-2002 \\
1999-2002 \\
1999-2002 \\
1999-2002\end{array}$ \\
\hline Other GHG Emissions & R22 Refrigerant (HCFC-22) & & N/A \\
\hline Production Metrics & $\begin{array}{l}\text { Cases produced (Bottling and Total) } \\
\text { Gallons moved (Winery only) }^{\mathrm{d}} \\
\text { Gallons racked (Winery only) }^{\mathrm{d}}\end{array}$ & & $\begin{array}{l}1999-2002 \\
1999-2002 \\
1999-2002\end{array}$ \\
\hline \multicolumn{4}{|l|}{ Other: Buildings } \\
\hline Data Type & End Use, Source, Activity & Fuel Type & $\begin{array}{l}\text { Data } \\
\text { Availability }\end{array}$ \\
\hline Energy End Use & $\begin{array}{l}\text { HVAC/lighting: guest suites } \\
\text { HVAC/lighting: restaurant/visitor center } \\
\text { Cooking energy: restaurant }\end{array}$ & $\begin{array}{l}\text { Electricity } \\
\text { Electricity } \\
\text { Electricity }\end{array}$ & $\begin{array}{l}1999-2002 \\
1999-2002 \\
1999-2002\end{array}$ \\
\hline Production Metrics & Floor area & & N/A \\
\hline \multicolumn{4}{|l|}{ Other: Transportation } \\
\hline Data Type & End Use, Source, Activity & Fuel Type & $\begin{array}{l}\text { Data } \\
\text { Availability }\end{array}$ \\
\hline Energy End Use & Haulage of empty and filled bottles ${ }^{\mathrm{e}}$ & Diesel, Gasoline & $2001-2002$ \\
\hline Production Metrics & $\begin{array}{l}\text { Vehicle miles traveled } \\
\text { Ton-miles hauled }\end{array}$ & & $\begin{array}{l}\text { N/A } \\
\text { N/A }\end{array}$ \\
\hline
\end{tabular}

${ }^{a}$ Estimated for 1999 and 2000 based on the 2001 intensity of fuel used per acre.

b Energy for wastewater treatment was attributed 80 percent to winery operations and 20 percent to the bottling facility as suggested by Fetzer (Healy 2002).

${ }^{c}$ A case is nine liters.

d "Gallons moved" refers to the quantity of unfinished wine moved in and out of the facility and "gallons racked" refers to the quantity of wine filled into barrels.

${ }^{\mathrm{e}}$ Although related to the food processing activities, we have separated the fuel consumed for hauling bottles from the other food processing activities. For the sake of consistency, end-uses that are frequently outsourced should be excluded from the agricultural and food processing categories, and many vineyards would not use their own trucks for bringing bottles to their facilities or for delivering full bottles. 


\subsubsection{Energy-Related Metrics}

Table 17 provides information on energy use, GHG emissions, metrics for agricultural crop production, food processing, and other end-uses at Fetzer Vineyards. The energy data are shown both in the original units as reported by Fetzer and in MMBtu equivalents.

Although we did not include the energy from the "other" end-uses in this case study, there are various ways that the Registry could incorporate them. For example, Figure 9 shows clearly that electricity consumed by "other" buildings constitutes a very small share of total energy consumption (about 2\% overall or 3\% not counting the liquid fuels used for transportation). Similar to the "de minimis" criterion for total reporting, some emissions sources that are not closely linked to an entity's main economic activity could be disregarded for purposes of indexing. As an alternative to excluding these end uses, the energy could be lumped in with the food processing energy. Since the "other" buildings do not contribute much to the food processing total, it would have little effect on the metrics.

Usually, when building energy consumption is indexed for studies of the commercial sector, square footage, number of employees, or economic measures are used as normalization factors (Schipper et al. 2001; Krackeler, Schipper, and Sezgen 1998). Additional analysis can employ degree-day statistics to correct energy consumption for annual variation in weather. However, given the small share of energy consumed for service activities, the information gained from this effort does not justify the added reporting requirements and analysis.

Transportation fuels, however, are over a third of the total energy consumed. This energy consumption could have been included in the food processing category, but the energy demand will not necessarily correspond to the cases produced. Moreover, this activity is likely to be outsourced by many wineries. Generally, energy consumed in the transportation sector is indexed to vehicle miles traveled or to ton-miles hauled (Schipper et al. 2001). If the data had been available, this approach would have been used.

Figure 9 depicts Fetzer's energy consumption by economic activity and fuel. Total energy use was relatively stable between 1999 and 2000, increased slightly in 2001, and fell again in 2002. Overall, total energy consumption dropped an average of $-0.8 \%$ per year from 35,748 MMBtu in 1999 to 34,857 MMBtu in 2002 .

There was significant growth in the use of electricity and liquid fuels in the agricultural crop production portion of Fetzer's business. Use of these two energy sources increased an average of $20.9 \%$ and $45.6 \%$ per year, respectively. Average annual growth of $3.6 \%$ was also seen in the electricity used for other end uses (the guest suites, restaurant, and visitor's center). Energy consumption for food processing dropped between 1999 and 2002, with the largest reduction, of $-15.5 \%$ per year, in propane consumption. Natural gas consumption fell at $-8.7 \%$ per year, while use of electricity for food processing grew an average of $1.8 \%$ per year. 
Table 17. Energy Use and Production Data for Fetzer Vineyards, 1999 - 2001

\begin{tabular}{|c|c|c|c|c|c|}
\hline Agricultural Crop Production & Unit & 1999 & 2000 & 2001 & 2002 \\
\hline Electricity use & $\mathrm{kWh}$ & 300,897 & 313,365 & 515,695 & 531,358 \\
\hline Electricity use (non-productive acres excluded) & kWh & 300,897 & 313,365 & 409,563 & 410,754 \\
\hline Fuel use & Gallons & 5,802 & 6,740 & 13,785 & 18,245 \\
\hline Electricity use & MMBtus & 1,027 & 1,069 & 1,760 & 1,813 \\
\hline Electricity use (non-productive acres excluded) & MMBtus & 1,027 & 1,069 & 1,397 & 1,401 \\
\hline Fuel use & MMBtus & 805 & 935 & 1,912 & 2,482 \\
\hline Total energy use & MMBtus & 1,831 & 2,004 & 3,671 & 4,295 \\
\hline Total energy use (non-productive acres excluded) & MMBtus & 1,831 & 2,004 & 3,309 & 3,884 \\
\hline Grapes grown & Short tons & 2,708 & 3,749 & 4,108 & 4,050 \\
\hline Land area used & Acres & 668 & 776 & 1,587 & 1,549 \\
\hline Indexed electricity use & $\mathrm{kWh} /$ short ton & 111.12 & 83.59 & 125.54 & 131.20 \\
\hline Indexed electricity use & kWh/acre & 450.44 & 403.82 & 324.95 & 343.03 \\
\hline Indexed fuel use & Gallons/short ton & 2.14 & 1.80 & 3.36 & 4.51 \\
\hline Indexed fuel use & Gallons/acre & 8.69 & 8.69 & 8.69 & 11.78 \\
\hline Indexed electricity use & MBtus/short ton & 379 & 285 & 428 & 448 \\
\hline Indexed electricity use (non-productive acres excluded) & MBtus/short ton & 379 & 285 & 340 & 346 \\
\hline Indexed electricity use & MBtus/acre & 1,537 & 1,378 & 1,109 & 1,170 \\
\hline Indexed fuel use & MBtus/short ton & 297 & 249 & 465 & 613 \\
\hline Indexed fuel use & MBtus/acre & 1,205 & 1,205 & 1,205 & 1,602 \\
\hline Indexed total energy use & MBtus/short ton & 676 & 535 & 894 & 1,061 \\
\hline $\begin{array}{l}\text { Indexed total energy use (non-productive acres } \\
\text { excluded) }\end{array}$ & MBtus/short ton & 676 & 535 & 806 & 959 \\
\hline Indexed total energy use & MBtus/acre & 2,742 & 2,583 & 2,313 & 2,773 \\
\hline \multicolumn{6}{|l|}{ Food Processing } \\
\hline Winery electricity use & $\mathrm{kWh}$ & $3,602,899$ & $3,851,978$ & $3,803,463$ & $3,808,809$ \\
\hline Bottling electricity use & $\mathrm{kWh}$ & $1,353,669$ & $1,495,886$ & $1,575,741$ & $1,455,136$ \\
\hline Total electricity use & $\mathrm{kWh}$ & $5,138,813$ & $5,524,727$ & $5,530,083$ & $5,426,833$ \\
\hline Winery propane use & MMBtus & 1,777 & 969 & 746 & 735 \\
\hline Bottling propane use & MMBtus & 2,914 & 3,619 & 3,217 & 2,094 \\
\hline Natural gas use & Therms & 107,512 & 87,754 & 110,064 & 81,693 \\
\hline Winery electricity use & MMBtu & 12,293 & 13,143 & 12,977 & 12,996 \\
\hline Bottling electricity use & MMBtu & 4,619 & 5,104 & 5,376 & 4,965 \\
\hline Total electricity use & MMBtus & 17,534 & 18,850 & 18,869 & 18,516 \\
\hline Total propane use & MMBtus & 4,691 & 4,587 & 3,962 & 2,829 \\
\hline Natural gas use & MMBtus & 10,751 & 8,775 & 11,006 & 8,169 \\
\hline Total energy use & MMBtus & 32,975 & 32,213 & 33,838 & 29,515 \\
\hline Cases produced & thousand cases & 3,329 & 3,710 & 3,754 & 3,772 \\
\hline Gallons moved & Thousand gallons & 6,834 & 7,849 & 6,892 & 11,559 \\
\hline Gallons racked & Thousand gallons & 5,395 & 5,558 & 6,412 & 7,178 \\
\hline Indexed winery electricity use & MBtu/1000 gals. moved & 1,799 & 1,675 & 1,883 & 1,124 \\
\hline Indexed winery electricity use & MBtu/1000 gals. racked & 2,279 & 2,365 & 2,024 & 1,811 \\
\hline Indexed winery electricity use & MBtu/1000 cases & 3,693 & 3,543 & 3,457 & 3,445 \\
\hline Indexed bottling electricity use & MBtu/1000 cases & 1,387 & 1,376 & 1,432 & 1,316 \\
\hline Indexed total electricity use & MBtu/1000 cases & 5,267 & 5,081 & 5,027 & 4,909 \\
\hline Indexed total propane use & MBtu/1000 cases & 1,409 & 1,237 & 1,056 & 750 \\
\hline Indexed total natural gas use & MBtu/1000 cases & 3,230 & 2,365 & 2,932 & 2,166 \\
\hline Indexed total energy use & MBtu/1000 cases & 9,906 & 8,683 & 9,015 & 7,824 \\
\hline \multicolumn{6}{|l|}{ Other } \\
\hline Electricity & $\mathrm{kWh}$ & 275,907 & 302,544 & 295,803 & 306,927 \\
\hline Electricity & MMBtu & 941 & 1,032 & 1,009 & 1,047 \\
\hline Total liquid fuel use & Gallons & 158,436 & 158,436 & 158,436 & 161,829 \\
\hline Total liquid fuel use & MMBtus & 21,457 & 21,457 & 21,457 & 21,875 \\
\hline
\end{tabular}

*Beginning in 2001, the natural gas meter was equipped with a timer that has resulted in savings of approximately $40 \%$. However, propane was used for process heat in the winery until 2001, when the winery boiler was retrofitted to use natural gas. The increased need for gas to supply process heat largely offset the savings from the timer, resulting in relatively steady overall consumption of natural gas. Thus, the combined total of natural gas and propane drops significantly in 2002. 


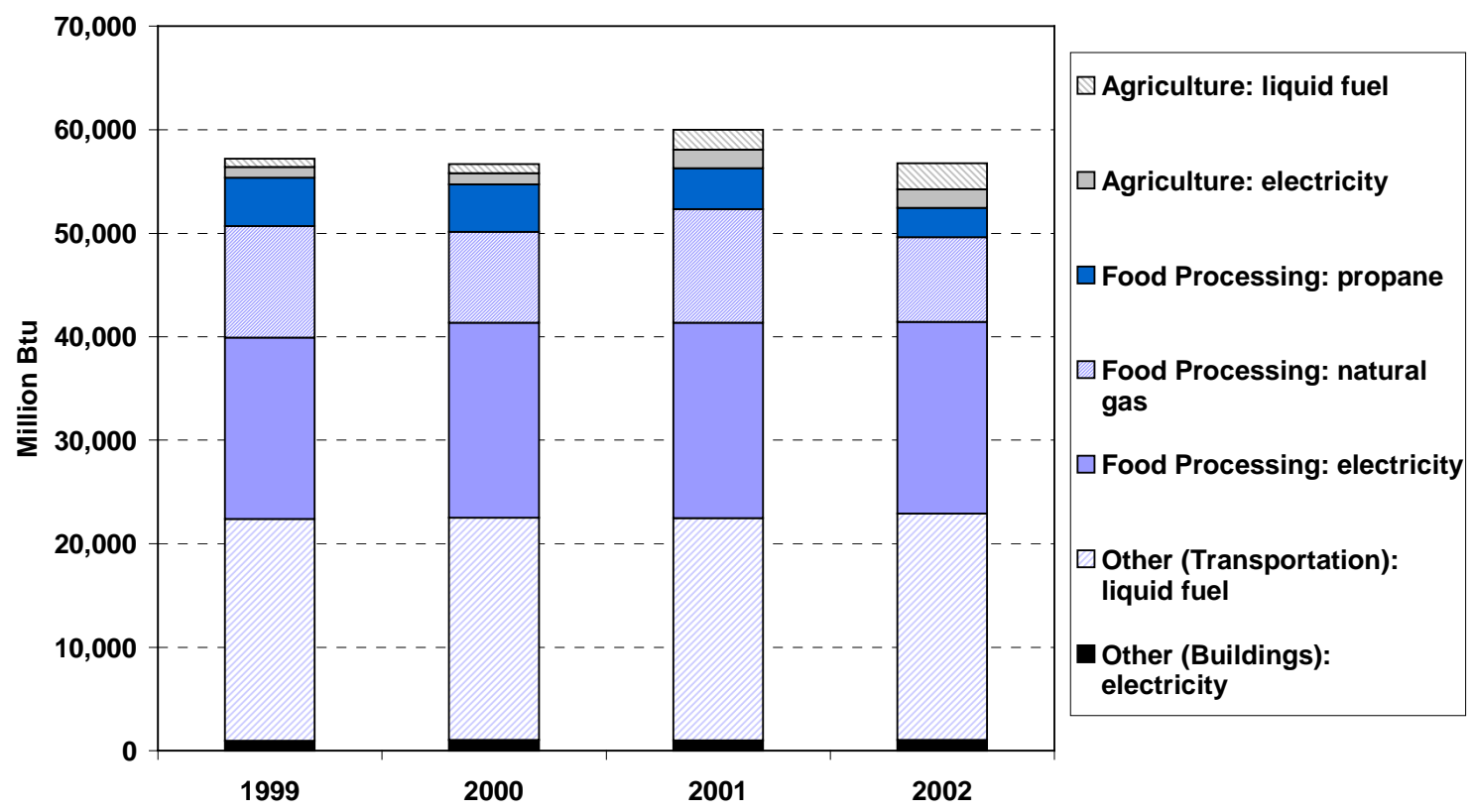

Figure 9. Energy Consumption by Activity (Agricultural Crop Production, Food Processing, Other Transportation, and Other Buildings) and Fuel at Fetzer Vineyards, 1999-2002

\subsection{Agricultural Crop Production Energy-Related Metrics}

Figure 10 shows electricity, fuel, and total energy consumption for agriculture at Fetzer Vineyards indexed to acres owned or farmed by Fetzer. ${ }^{27}$ Indexed total energy use per acre increased after 2001, driven by increases in fuel use per acre between 2001 and 2002. Given the method used to estimate fuel consumption for 1999 and 2000, the fuel use/acre remains constant from 1999 to 2001. Electricity use, however, declines nearly 30\% from 1,537 MBtu/acre in 1999 to 1,109 MBtu/acre in 2001, and then rises slightly in 2002.

${ }^{27}$ Liquid fuel use for 1999 and 2000 estimated based on the 2001 fuel/acre ratio. 
Agricultural Crop Production

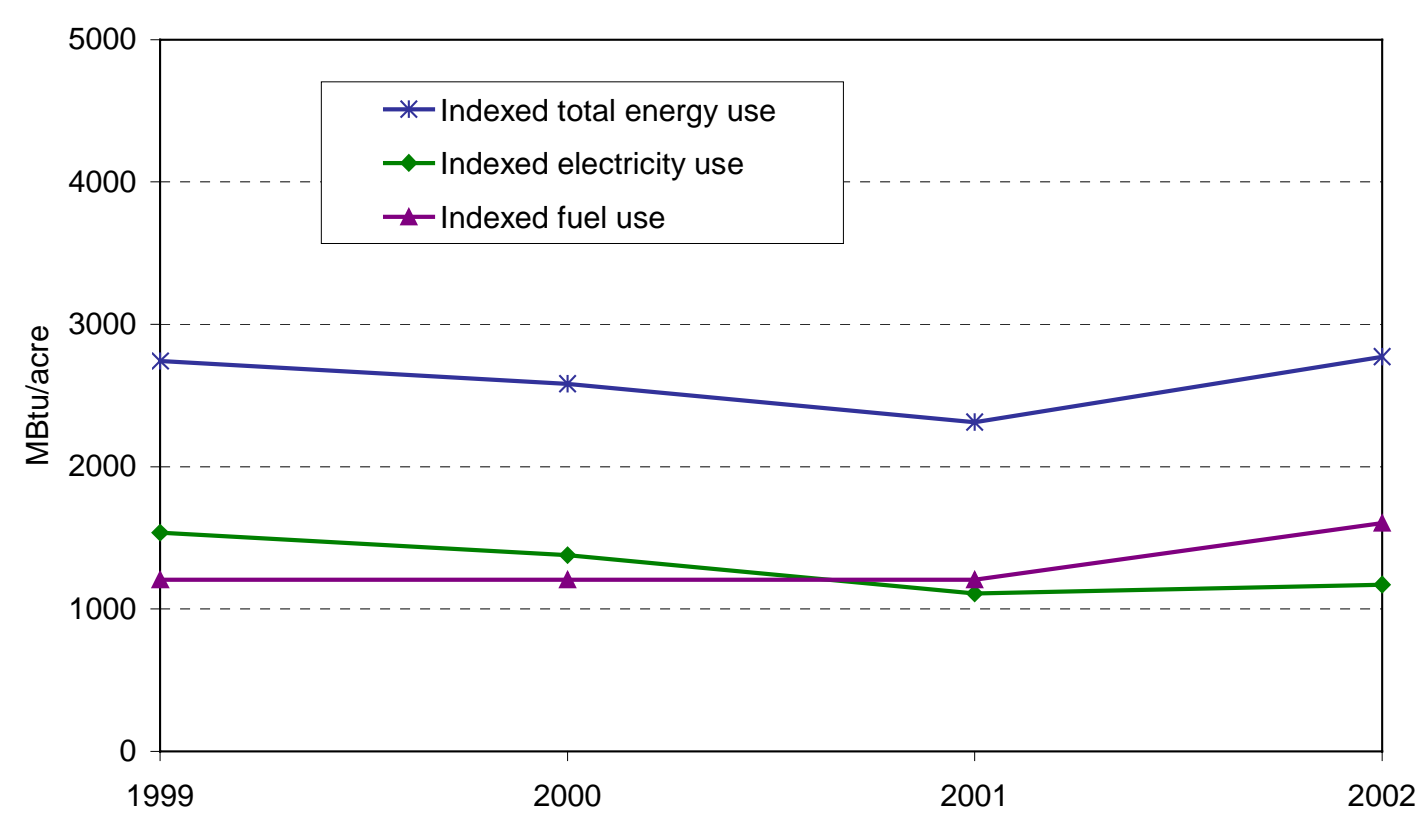

Figure 10. Indexed Energy Consumption for Agricultural Crop Production at Fetzer Vineyards: Energy Use per Acre

Figure 11 shows indexed total energy use per short tons of grapes produced. The 2002 value of $1061 \mathrm{MBtu} / \mathrm{short}$ ton is much higher than the $676 \mathrm{MBtu} /$ short ton in 1999. With the acquisition of new terrains, Fetzer decided to replant some of the acquired grounds. Winegrapes need three to five years before attaining maturity but still need to be watered and tended by field vehicles during this time. Consequently, energy consumption for replanted acres is comparable to productive acres although no grapes are produced. Since the electricity consumption is reported by several different meters, the pumping energy used for non-productive acreage could be excluded. With the non-productive acres removed from the calculation, indexed total energy use in 2002 is slightly lower than the 1999 value, indicating an overall improvement in energy consumed per short ton of grapes produced. ${ }^{28}$

\footnotetext{
${ }^{28}$ According to Fetzer, additional water may be needed to spray vines for frost protection from March to May. Thus, electricity use for pumping may also fluctuate for reasons other than production changes.
} 
Agricultural Crop Production

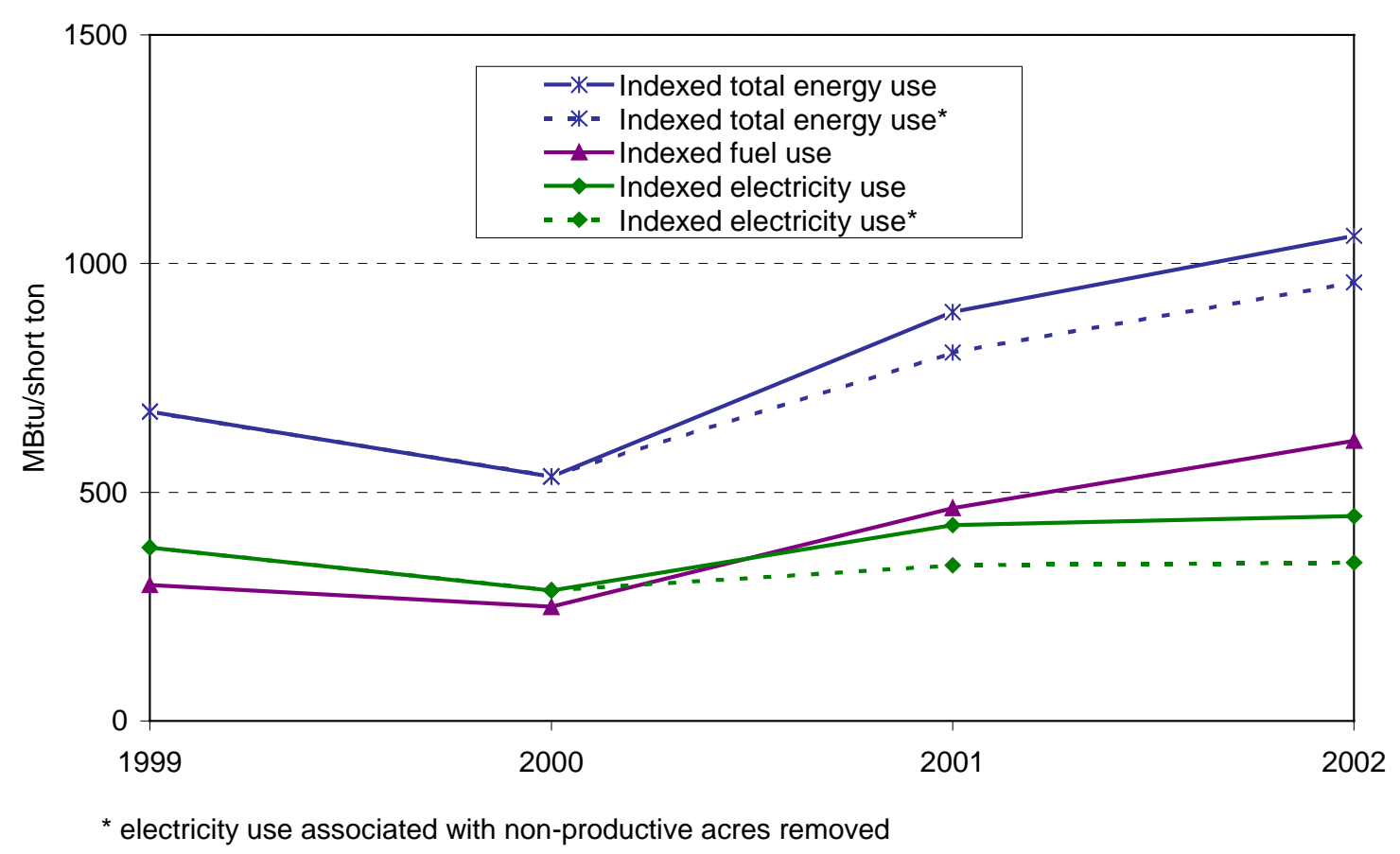

Figure 11. Indexed Energy Consumption for Agricultural Crop Production at Fetzer Vineyards: Energy Use per Short Tons of Grapes Produced

\subsection{Food Processing Energy-Related Metrics}

Data on electricity, propane, and natural gas use for the Fetzer food processing activities are available for 1999 through 2002. Figure 12 shows the trends in the use of these fuels as well as total energy use when indexed to cases produced. Indexed electricity use dropped an average of about 2\% per year, from $5080 \mathrm{MBtu} / 1000$ cases produced in 1999 to $4761 \mathrm{MBtu} / 1000$ cases produced in 2002. The decline in indexed natural gas use was much more significant, dropping an average of $12.5 \%$ per year from $3230 \mathrm{MBtu} / 1000$ cases produced in 1999 to $2166 \mathrm{MBtu} / 1000$ cases produced in 2002. The largest drop occurred in the use of propane, which fell $19 \%$ per year. As a result of these combined savings, indexed total energy use per case produced dropped about $7.6 \%$ per year on average during the period.

The decline in propane use resulted from two actions. First, Fetzer began to switch from propane to electric-powered forklifts. In 2000 , there was a large reduction in natural gas due to a change in sterilization/sanitation procedures at the bottling facility. In 2001, a heat exchanger was installed between the winery and the bottling facility, which replaced the use of propane for process heat in the winery with natural gas from the bottling facility. This resulted in an increase in natural gas use, but large savings from the installation of a timer on the boiler in 2002 more than offset the increased demand for natural gas for process heat in the winery (Zechiel 2003). Finally, several recently completed electrical efficiency projects have steadily reduced the demand for electricity. 
Food Processing

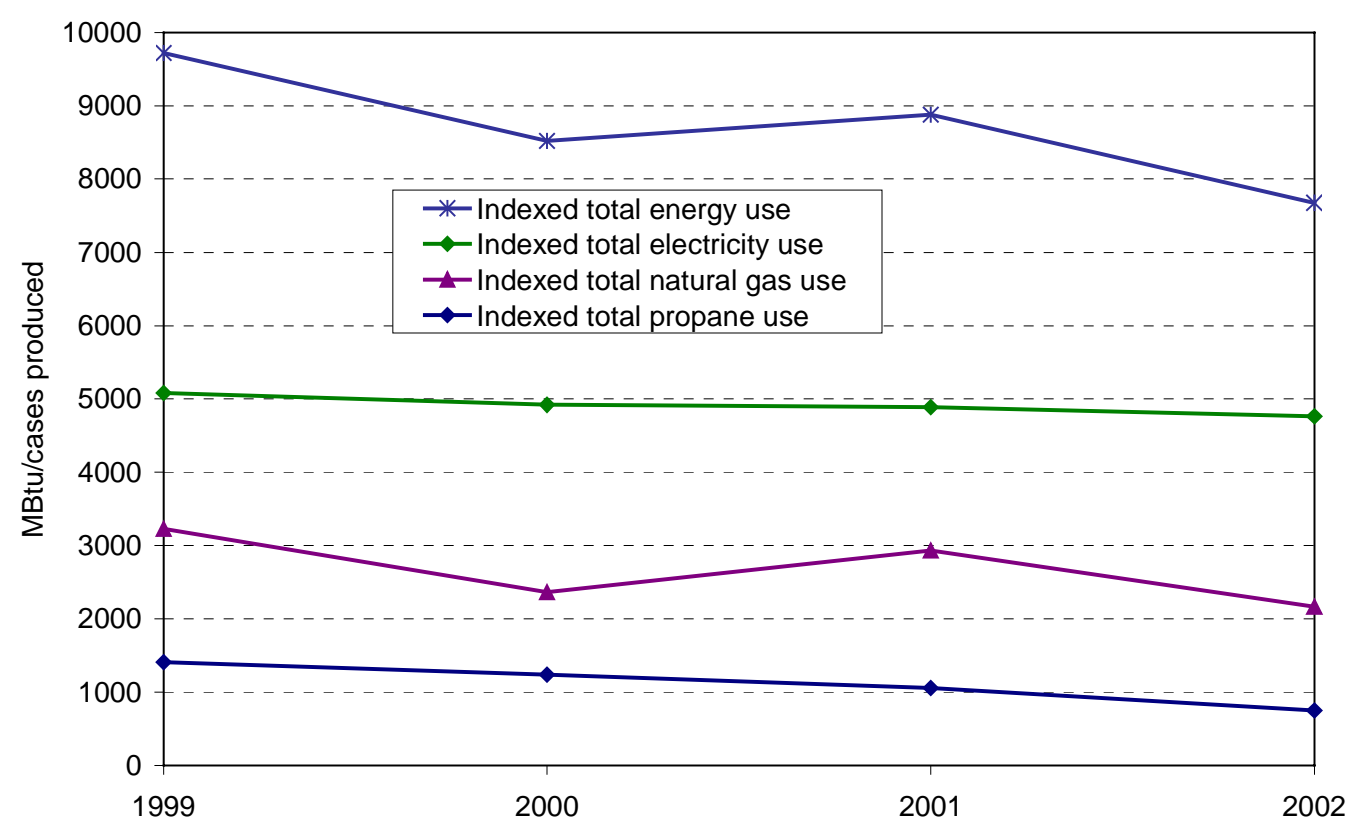

Figure 12. Fetzer Vineyards Energy Use Indexed to Cases Produced, 1999 to 2002

We explored the possibility of creating separate metrics for the winery and the bottling facility. The primary rationale for separating winery activities from bottling activities is that the ratios of grapes pressed to finished product may vary with the procurement of some juice and crushed grapes from outside sources, which would affect the amount of energy needed to produce a case of wine. However, data limitations led us to conclude that this would not be feasible. Although, Fetzer tracks propane consumption separately for the winery and the bottling facility, and there are separate electricity meters each facility, natural gas consumption cannot be disaggregated. Until 2001 natural gas was used only in the bottling facility, but the heat exchanger that was installed to provide process heat to both is fed by only one meter.

There are also problems with using the production data available for the winery (gallons moved and gallons racked) as a normalization factor for winery activities. It was determined that energy used in the winery depends too heavily on other factors for the resulting ratios to be accurate. Electricity use at the winery is influenced by many factors: the total mass of grapes crushed onsite, ambient air temperatures (which affects refrigeration needs), quantities of unfinished wine moved, and quantities of wine racked. ${ }^{29}$

\footnotetext{
${ }^{29}$ Above we note that the common practice of producing some grapes onsite and procuring the rest from other growers renders "cases of wine" inappropriate as a common metric for agricultural crop production and food processing aggregated together. This problem of outsourcing also occurs within wine production since Fetzer, like many vineyards, crushes some grapes at its own facility and purchases some juice from other crushers. The energy for crushing is not negligible; at Fetzer, it constitutes roughly a fifth of the winery electricity demand and about a tenth of total food processing energy. Unfortunately, since the winery is not sub-metered for any processes, this problem cannot be truly resolved.
} 
Figure 13 shows the results of indexing winery electricity to gallons moved and gallons racked. The figure shows that compared to $\mathrm{MBtu} / 1000$ cases produced, these two metrics tend to overstate changes in intensity. This is not surprising since movement and racking of wine only affect part of the electricity use in the winery. The largest single end use, the refrigeration system for white wines, is largely independent of wine movement. This helps to explain the large drop in "gallons moved" metric in 2002, when less than expected sales necessitated the movement of large quantities of wine to off-site storage. However, this did not cause a proportional increase in overall winery energy consumption.

For the bottling facility, "cases produced" was the only metric available. Figure 13 illustrates the use of "cases produced" to normalize electricity consumption in the bottling plant. Indexed electricity use at the bottling facility shows a relatively steady decline from $1387 \mathrm{MBtu} / 1000$ cases produced in 1999 to $1316 \mathrm{MBtu} / 1000$ cases produced in 2002. Electricity consumption at this site seems to correlate strongly to the number of cases produced, resulting in a consistent metric.

Food Processing, Disaggregated Metrics Using Electricity Data

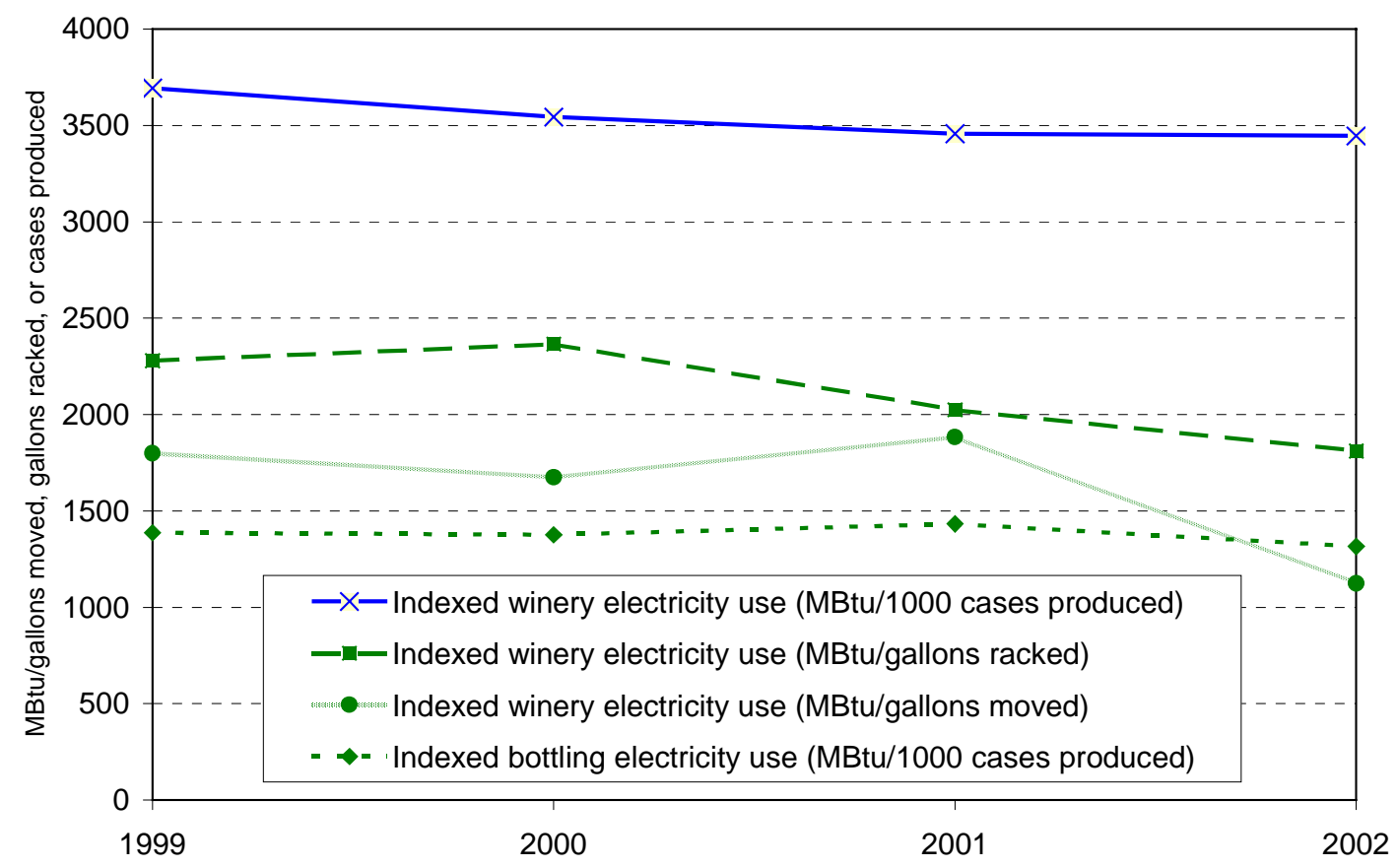

Figure 13. Fetzer Vineyards Winery and Bottling Facility Energy Use Indexed to Gallons Moved, Gallons Racked, and Cases Produced, 1999 to 2002 


\subsubsection{Emissions-Related Metrics}

To evaluate possible GHG emissions metrics for use by this industry, we converted Fetzer's reported electricity consumption for 1999 to equivalent $\mathrm{CO}_{2}$ emissions using an average emissions factor for Pacific Gas and Electric Company (PG\&E), the utility serving Fetzer Vineyards (Marnay et al., 2002) (30 $^{30}$ and then assumed zero emissions for 2000 through 2002 because Fetzer purchased renewable electricity beginning in their fiscal year 2000 (i.e. beginning May 1999).

Figure 14 shows Fetzer's GHG emissions by economic activity and fuel. As can be seen, GHG emissions at Fetzer, which are dominated by the transportation-related consumption of liquid fuels, dropped significantly after 1999 due to the change to renewable electricity in $2000 .^{31}$ Overall, GHG emissions dropped an average of $-2.2 \%$ per year between 1999 and 2002. Of the fuel-consuming activities, emissions dropped $-8.7 \%$ per year on average from natural gas used for food processing, and propane emissions dropped $15.5 \%$ per year. Liquid fuel consumption for agricultural crop production grew an average of $39.2 \%$ per year during this period.

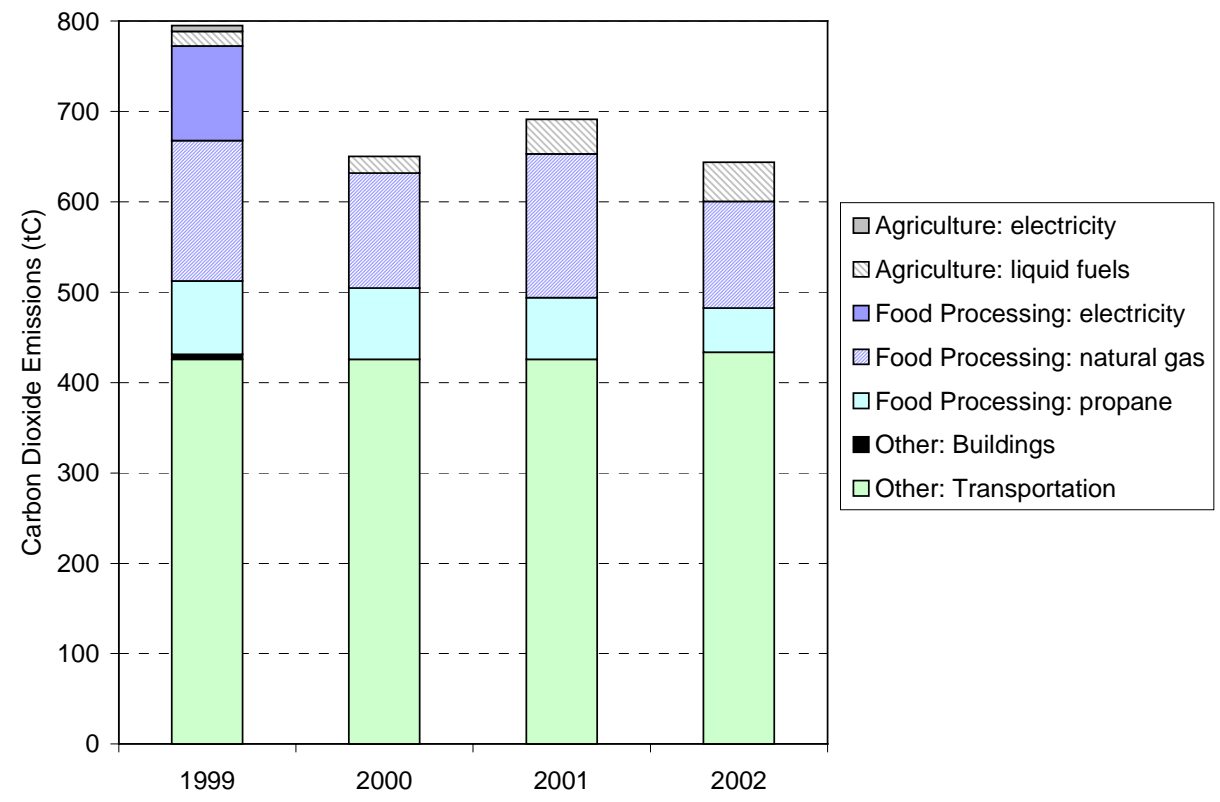

Figure 14. GHG Emissions by Activity (Agricultural Crop Production, Food Processing, and Other) and Fuel at Fetzer Vineyards, 1999 - 2002

\footnotetext{
${ }^{30}$ This value $(0.0635 \mathrm{kgC} / \mathrm{kWh})$ is the PG\&E specific emissions factor reported in Marnay et al. (2002). It differs from the value provided by the U.S. Energy Information Administration for use in reporting within the EIA's Voluntary Reporting of Greenhouse Gas Emissions (1605b) program for the years studied. LBNL analysis has shown, however, that the EIA value only accounts for utility-owned in-state electricity generation and does not include utility-owned out-of-state electricity generation, non-utility electricity generation, or imported electricity (Marnay et al., 2002). Since imported electricity accounts for a disproportionate share of California's electricityrelated emissions, we feel that the EIA value significantly underestimates emissions from electricity consumed in California.

${ }^{31}$ This drop would have been much greater if Fetzer had used the standard PG\&E electricity mix for the full 1999 calendar year.
} 
Figure 17 provides information on GHG emissions and GHG emissions metrics for agricultural crop production, food processing, and other end-uses at Fetzer Vineyards.

Table 18. GHG Emissions Data for Fetzer Vineyards, 1997 - 2001

\begin{tabular}{|c|c|c|c|c|c|}
\hline Agricultural Crop Production & Unit & 1999 & 2000 & 2001 & 2002 \\
\hline Electricity-related emissions & $\mathrm{kgC}$ & 6,369 & 0 & 0 & 0 \\
\hline Fuel-related emissions & $\mathrm{kgC}$ & 16,054 & 18,650 & 38,141 & 43,326 \\
\hline Total energy-related emissions & $\mathrm{kgC}$ & 22,423 & 18,650 & 38,141 & 43,326 \\
\hline Grapes grown & Short tons & 2,708 & 3,749 & 4,108 & 4,050 \\
\hline Land area used & Acres & 668 & 776 & 1,587 & 1,549 \\
\hline Indexed electricity-related emissions & $\mathrm{kgC} /$ short ton & 2.35 & 0.00 & 0.00 & 0.00 \\
\hline Indexed electricity-related emissions & kgC/acre & 9.53 & 0.00 & 0.00 & 0.00 \\
\hline Indexed fuel-related emissions & $\mathrm{kgC} / \mathrm{short}$ ton & 5.93 & 4.97 & 9.29 & 10.70 \\
\hline Indexed fuel-related emissions & $\mathrm{kgC/acre}$ & 24.03 & 24.03 & 24.03 & 27.97 \\
\hline Indexed total energy-related emissions & $\mathrm{kgC} /$ short ton & 8.28 & 4.97 & 9.29 & 10.70 \\
\hline Indexed total energy-related emissions & $\mathrm{kgC/acre}$ & 33.57 & 24.03 & 24.03 & 27.97 \\
\hline \multicolumn{6}{|l|}{ Food Processing } \\
\hline Winery electricity-related emissions & $\mathrm{kgC}$ & 76,261 & 0 & 0 & 0 \\
\hline Bottling electricity-related emissions & $\mathrm{kgC}$ & 28,653 & 0 & 0 & 0 \\
\hline Total electricity-related emissions & $\mathrm{kgC}$ & 104,914 & 0 & 0 & 0 \\
\hline Winery propane-related emissions & $\mathrm{kgC}$ & 50,114 & 62,244 & 55,330 & 36,012 \\
\hline Bottling propane-related emissions & $\mathrm{kgC}$ & 30,564 & 16,661 & 12,825 & 12,644 \\
\hline Total propane-related emissions & $\mathrm{kgC}$ & 80,678 & 78,905 & 68,155 & 48,657 \\
\hline Natural gas-related emissions & $\mathrm{kgC}$ & 155,570 & 126,980 & 159,263 & 118,210 \\
\hline Total energy-related emissions & $\mathrm{kgC}$ & 341,162 & 205,885 & 227,418 & 166,866 \\
\hline Cases Produced & Thousand cases & 3,329 & 3,710 & 3,754 & 3,772 \\
\hline Indexed bottling electricity-related emissions & $\mathrm{kgC} / 1000$ cases & 8.6 & 0.0 & 0.0 & 0.0 \\
\hline Indexed total electricity-related emissions & $\mathrm{kgC} / 1000$ cases & 31.5 & 0.0 & 0.0 & 0.0 \\
\hline Indexed total propane-related emissions & $\mathrm{kgC} / 1000$ cases & 24.2 & 21.3 & 18.2 & 12.9 \\
\hline Indexed total natural gas-related emissions & $\mathrm{kgC} / 1000$ cases & 46.7 & 34.2 & 42.4 & 31.3 \\
\hline Indexed total energy-related emissions & $\mathrm{kgC} / 1000$ cases & 102.5 & 55.5 & 60.6 & 44.2 \\
\hline \multicolumn{6}{|l|}{ Other: Buildings } \\
\hline $\begin{array}{l}\text { Electricity-related emissions } \\
\text { Floor area } \\
\text { Indexed electricity-related emissions }\end{array}$ & $\mathrm{kgC}$ & 5,840 & 0 & 0 & 0 \\
\hline \multicolumn{6}{|l|}{ Other: Transportation } \\
\hline $\begin{array}{l}\text { Liquid fuel-related emissions } \\
\text { Indexed liquid fuel use } \\
\text { Indexed liquid fuel use }\end{array}$ & $\mathrm{kgC}$ & 425,692 & 425,692 & 425,692 & 433,790 \\
\hline
\end{tabular}

Note: Transportation liquid fuel use for 1999 and 2000 assumed to be the same as that for 2001. 


\subsection{Agricultural Crop Production Emissions-Related Metrics}

Figure 15 shows total agricultural energy-related GHG emissions as well as disaggregated electricity- and fuel-related GHG emissions indexed to acres used and short tons of grapes produced at Fetzer Vineyards for 1999 through 2002. Total emissions per acre clearly drop between 1999 and 2000 due to the reduction in GHG emissions from electricity and then increase between 2001 and 2002 due to increased fuel consumption. Total emissions per ton of grapes grown rises sharply from 2000 to 2001 with the acquisition of a large number of acres that were replanted.

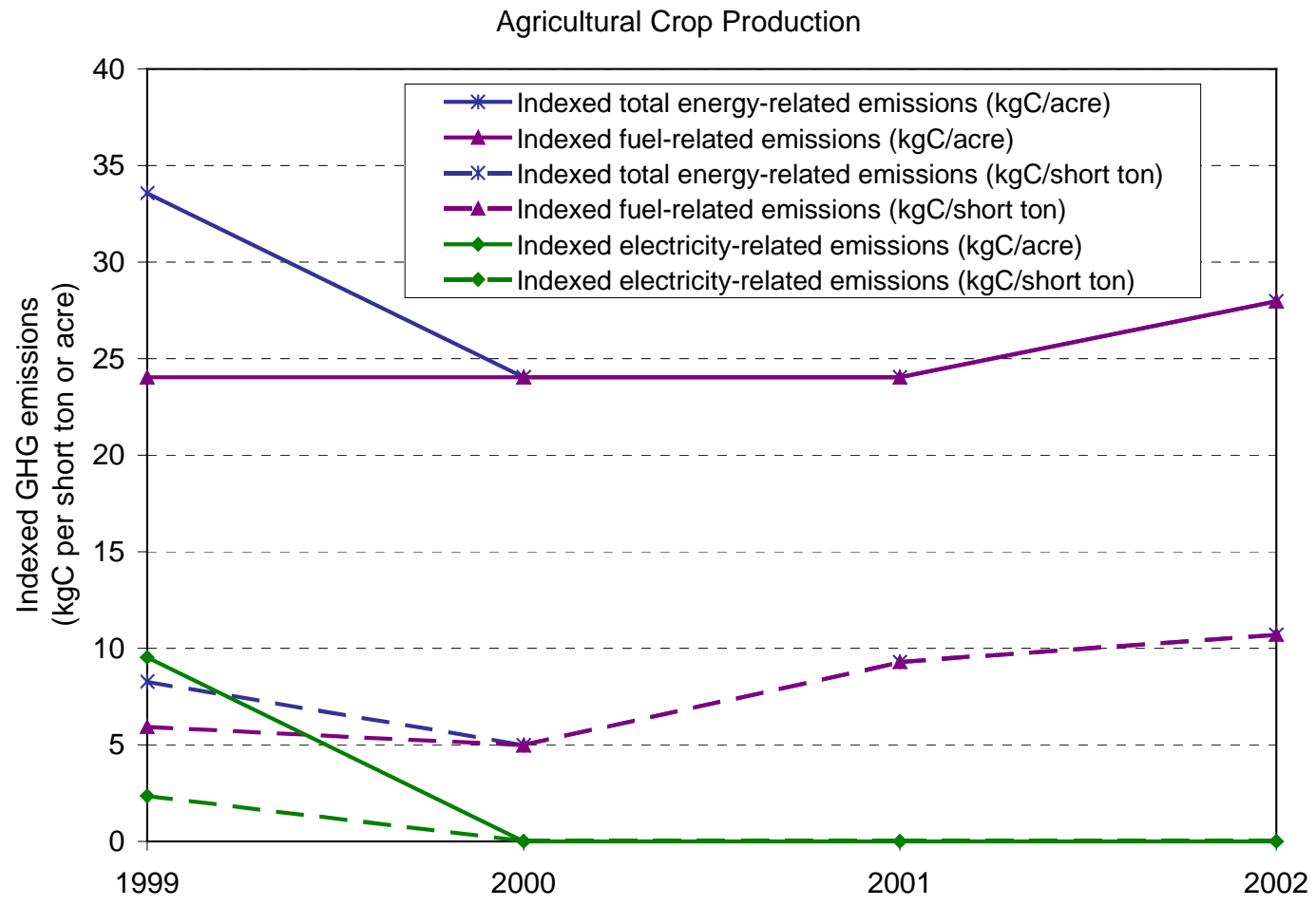

Figure 15. Indexed GHG Emissions for Agricultural Crop Production at Fetzer Vineyards 


\subsection{Food Production Emissions-Related Metrics}

Figure 16 shows GHG emissions indexed to the number of cases produced at Fetzer Vineyards. Total food processing emissions per case of wine fall markedly between 1999 and 2000, from 102 to $56 \mathrm{kgC}$ per 1000 cases. This resulted mostly from the decision to purchase renewable electricity beginning in May 1999. The increase in emissions in 2001 is due to a 25 percent increase in the use of natural gas that year. However, this increase in emissions is largely offset by the decrease in propane emissions.

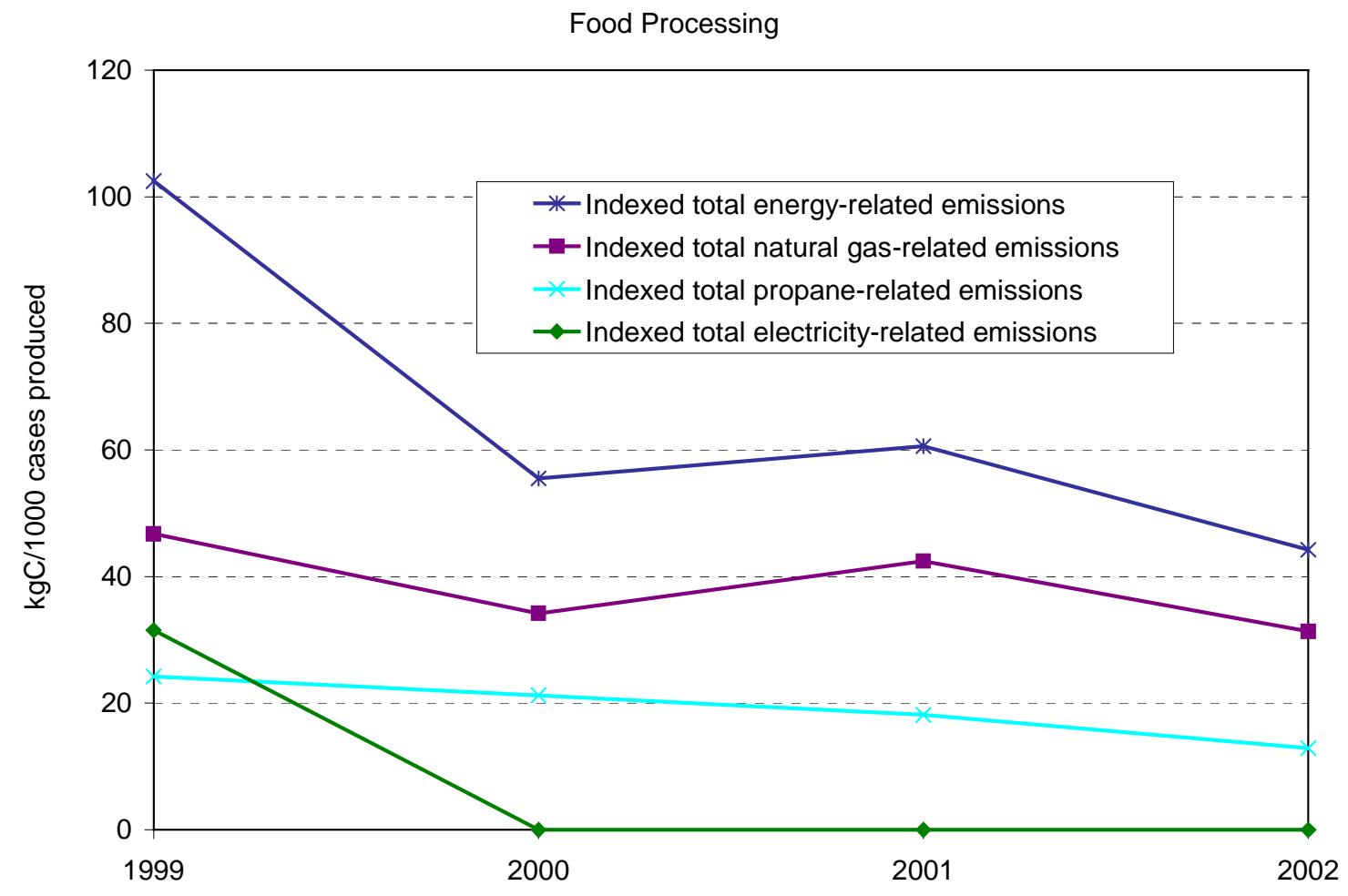

Figure 16. Fetzer Vineyards GHG Emissions Indexed to Cases Produced, 1999 to 2002 


\subsubsection{Baseline Issues}

In this section, we evaluate the use of several different types of baselines that could be used to calculate GHG emissions reductions (or increases) for Fetzer.

\subsubsection{Absolute Baselines for Fetzer}

This section examines the use of absolute baseline methods for Fetzer. Fetzer presents an interesting case with regard to baselines because of its decision to switch to renewable electricity beginning in May 1999. Since data were not available for 1998, baselines that project future emissions based on initial year totals or rates begin in 1999. Thus, the baselines constructed from 1999 GHG emissions already reflect the tremendous reductions arising from the use of renewable electricity. Since these baselines are much lower than they would be if they were based on 1998 or previous year data, the baselines shown do not give Fetzer full credit for its early action to reduce GHG emissions prior to 1999.

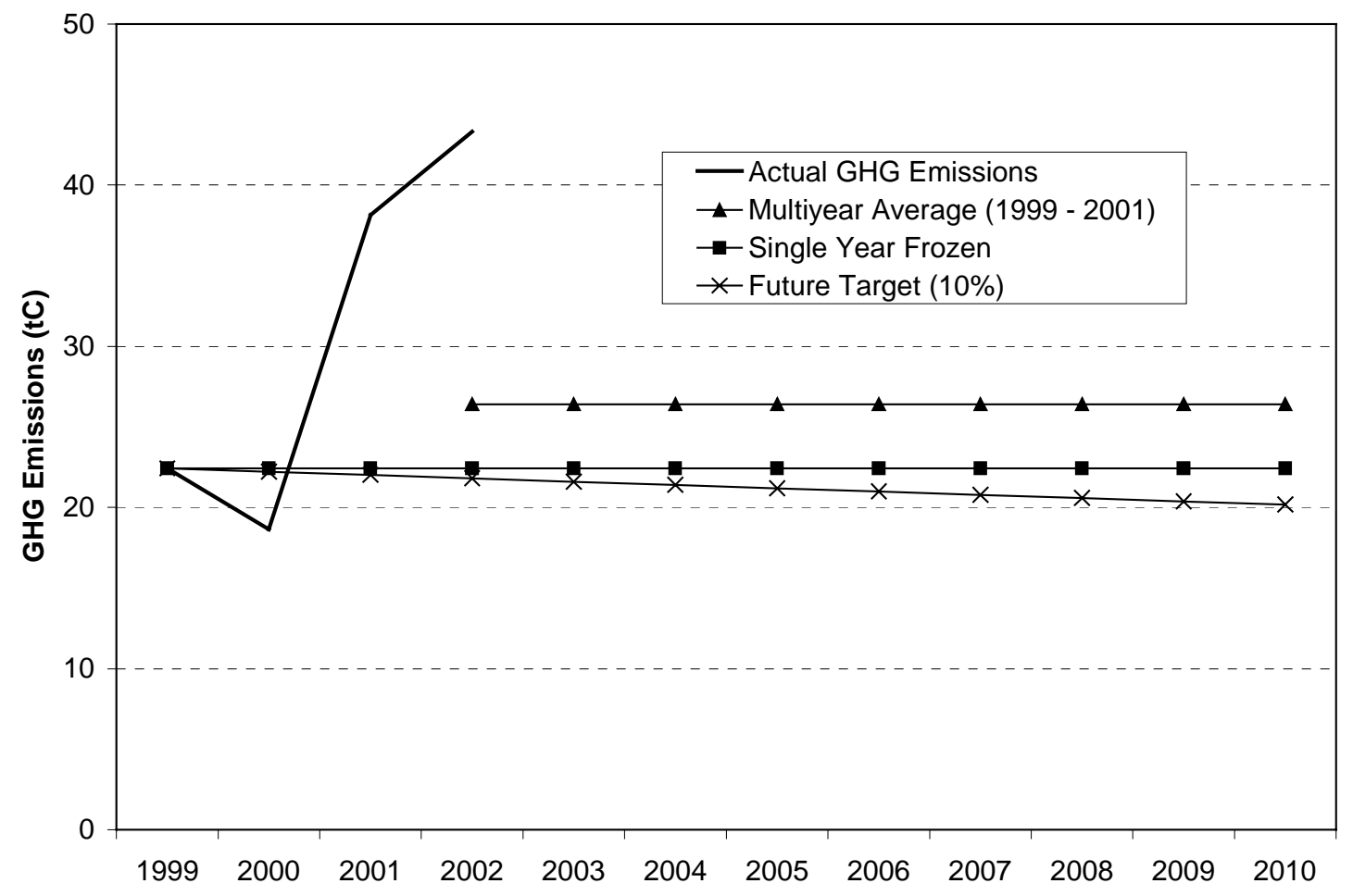

Figure 17. Absolute Emissions Baselines for Agricultural Activity

Figure 17 shows three types of absolute emissions applied to Fetzer's agricultural activity. ${ }^{32}$ Due to the large increase in emissions associated with the new acreage acquired in 2000, actual emissions are well above all of the baselines. The multiyear average reflects the increased

\footnotetext{
${ }^{32}$ An absolute baseline using historical GHG emissions trends could theoretically be constructed, but has not been done for this case study due to lack of availability of historical data.
} 
emissions in 2001 but is still significantly below the actual 2002 emissions level. ${ }^{33}$ This chart clearly demonstrates the need to adjust the baselines for the acreage acquisitions. However, energy consumption data for the acquired properties were not available from the previous years, and thus it was not possible to reset the baseline data for 1999 and 2000.

Figure 18 depicts the same absolute baselines applied to Fetzer's food processing activities. ${ }^{34}$ Actual emissions are substantially less than those in the baselines, due to the fact that electricity constitutes a much larger share of food processing energy consumption. Thus, the switch to renewable electricity had a larger impact on emissions from food processing activity. The fixed multiyear average baseline captures the effect of the lower emissions in 2000 and 2001, but does not give Fetzer adequate credit for its early action by holding future emissions to this lower baseline.

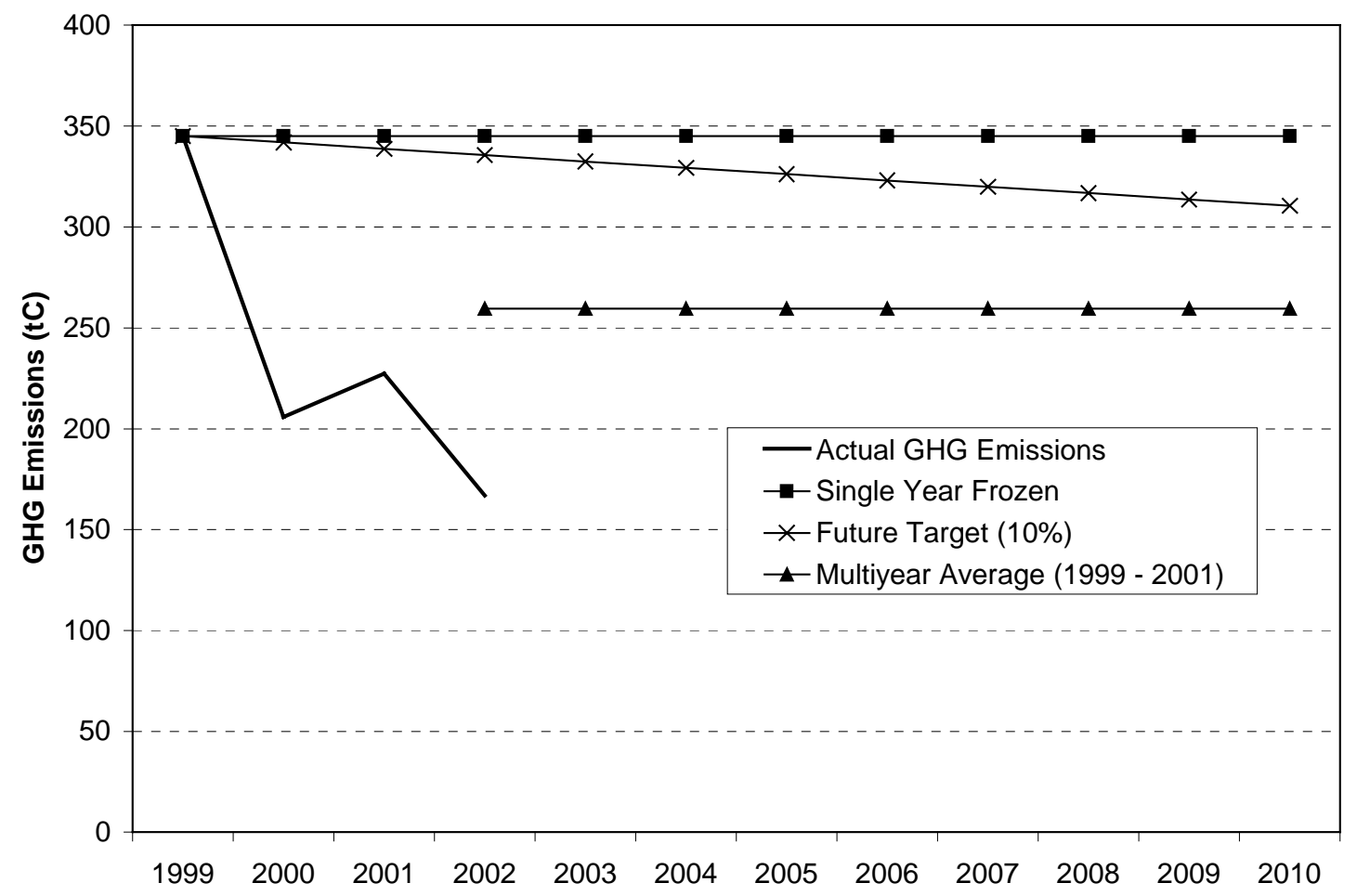

Figure 18. Absolute Emissions Baselines for Food Processing

\subsubsection{Intensity Baselines for Fetzer}

The following intensity baselines from Table $\mathbf{1 2}$ are applied to both agriculture and food processing activities at Fetzer: fixed base year intensity, fixed multiyear average intensity,

\footnotetext{
${ }^{33}$ Note that the multiyear baseline begins in 2002 because baselines calculated from multiyear averages can only be used for years after the base years.

${ }^{34}$ Again, the historical trend baseline was inappropriate since the rapid decline in emissions results in a trend in which emissions quickly reach zero. Similar to the agricultural sector, there are not enough data to establish a more realistic trend from earlier years.
} 
arbitrary $1 \%$ rate of decline, and Fetzer's own historical trends. The historical trend rate was defined as the average annual rate of growth from 1999 to 2001. Although these rates are best used for calculating the baselines with each year's actual production data, for the purposes of depicting possible baselines for future years, we froze the production values at the 2002 levels and then extrapolated using the baseline rates. We did not find any studies of industry-wide rates of energy or GHG intensity changes for the wine industry, and development of an expert judgment baseline for these two industries was beyond the scope of this report.

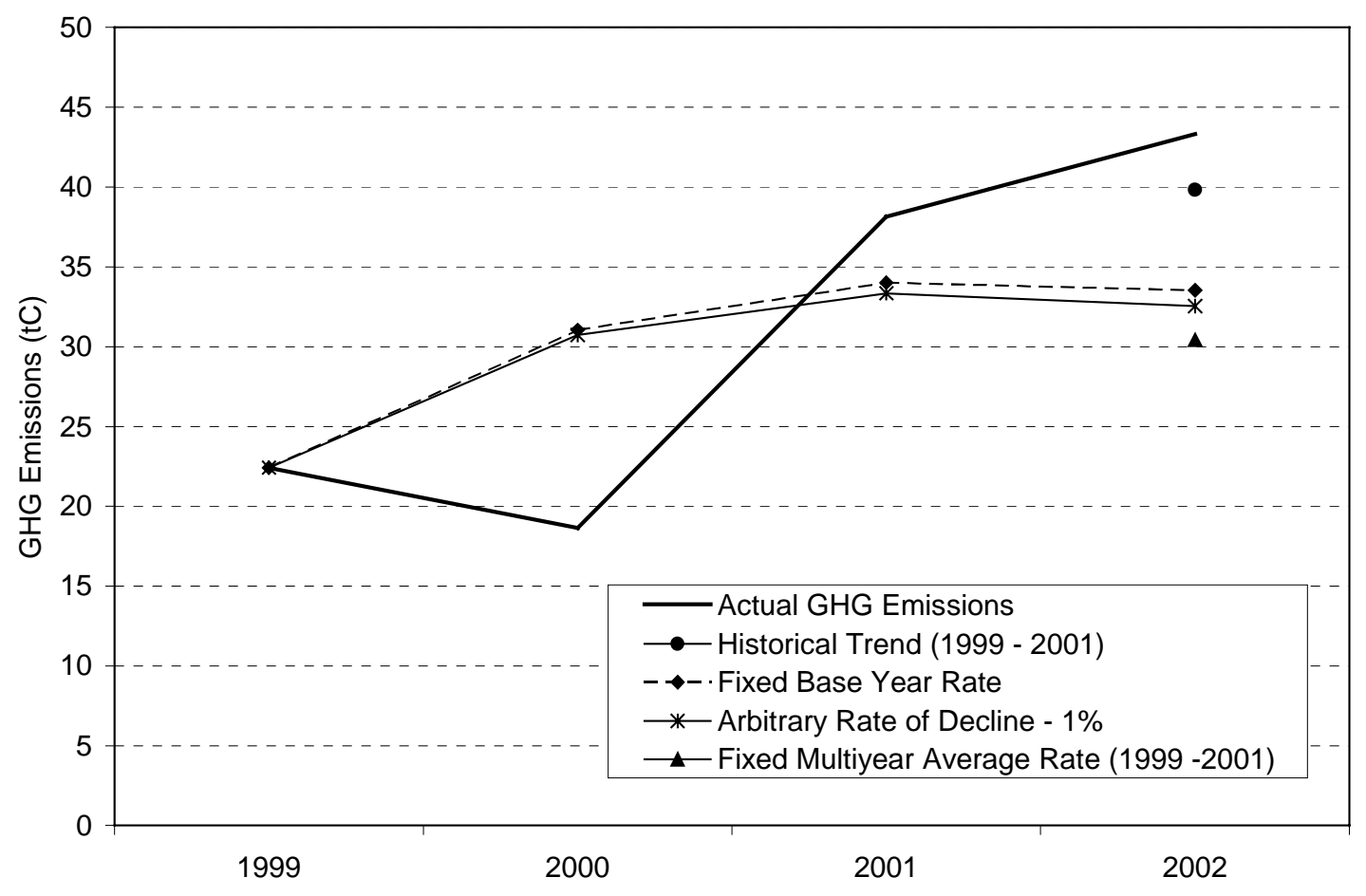

Figure 19. Intensity-Derived Agricultural Crop Production Baselines Using "Tons of Grapes" Metric

Since there are two metrics for agricultural production, there are two ways of calculating the intensity-derived baselines. Figure 19 shows the four intensity baselines applied to agricultural activity, using the GHG emissions per ton of grapes grown metric. Since the fixed base year rate baseline is equal to a fixed rate times the actual production, this line indicates how the production metric changed from 1999 to 2002. GHG intensity per ton of grapes increased from 1999 to 2001 (see Figure 15) although a large drop in intensity in 2000 causes the multiyear average to be lower than the base year rate $(7.5 \mathrm{kgC} /$ short ton compared to $8.3 \mathrm{kgC} / \mathrm{short}$ ton in 1999). However, since the 2001 rate $(9.3 \mathrm{kgC} / \mathrm{short}$ ton) is higher than the base year, the rate of change based on historical trends is nearly a $6 \%$ per year increase in emissions intensity due to the acquisition of land that was replanted. This suggests that the baseline rate would need to be corrected for the unproductive land.

The intensity baselines were also generated for Fetzer's agricultural crop production activities using the GHG emissions per acre metric, and the resulting trend differs markedly from the 
baselines generated using the tons of grapes grown metric. In Figure 20, Fetzer's actual emissions are below the baselines that use 1999 emissions per acre intensity to project future emissions. The historical trend baseline projects a declining rate of intensity of over $15 \%$ per year. Obviously, this rate of decline would be unattainable after just a few years, as it would require Fetzer to reduce its total 2002 emissions more than $80 \%$ by 2010 , assuming that acreage remains relatively unchanged.

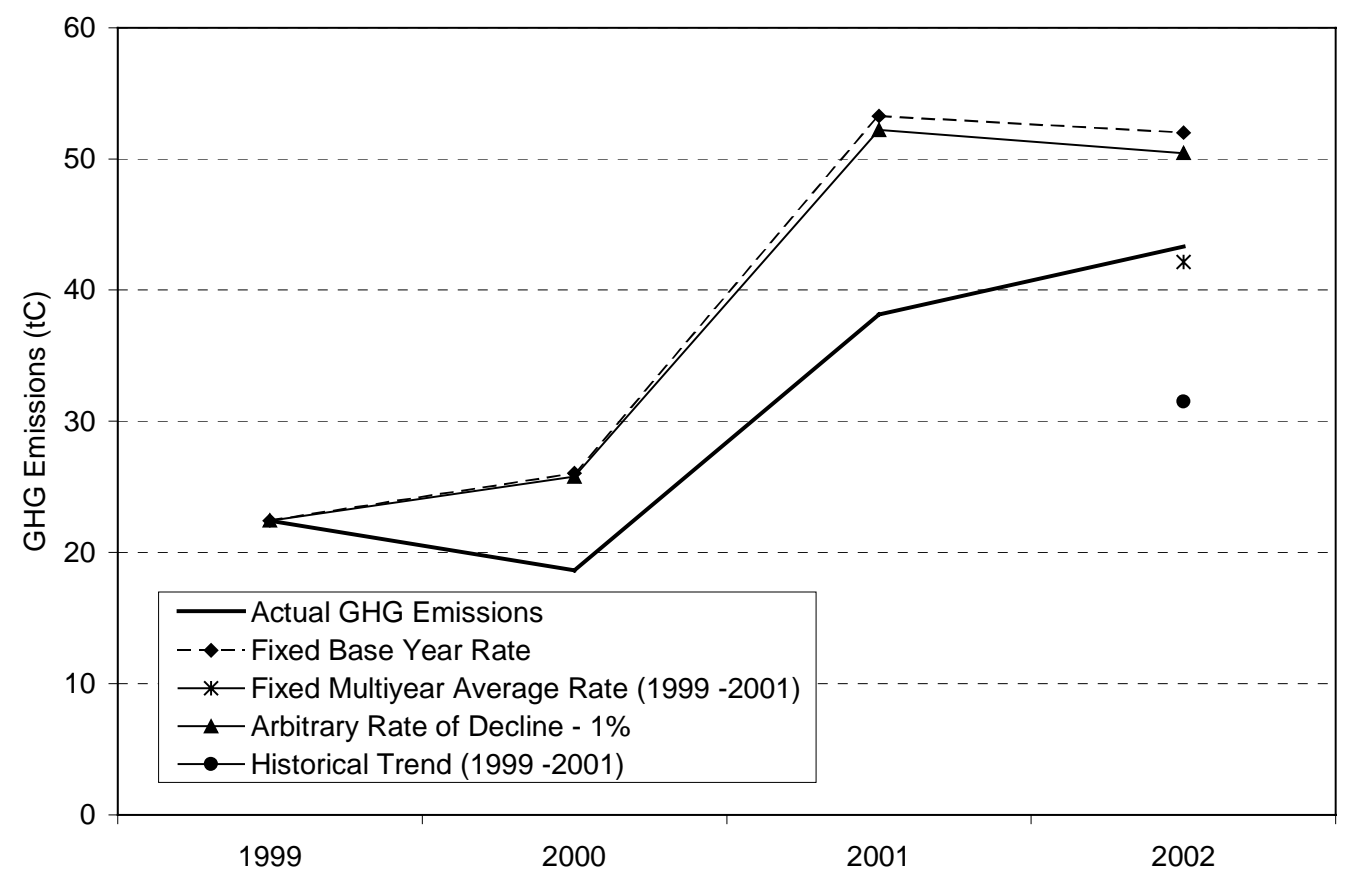

Figure 20. Intensity Based Agricultural Crop Production Baselines Using the Acreage Metric

The intensity baselines for food processing are pictured in Figure 21. For food processing there was no equivalent structural change resulting from acquisitions as there was in the agricultural sector. Although there was an 11 percent increase in production in 2000, production volumes remained stable in the subsequent years. This figure shows that either the fixed base year baseline or the arbitrary rate of decline baseline captures the GHG emissions reductions at Fetzer from the switch to renewable electricity. The multiyear average baseline is more than $200 \mathrm{tC}$ lower than the fixed base year baseline, but Fetzer's 2002 emissions are still 109 tC below the multiyear baseline. As with the agricultural baselines derived from the acreage metric, the sharp drop in emissions due to the use of renewable electricity and the efficiency projects yields an unrealistic historical trend baseline that would require Fetzer to reduce its 2002 emissions nearly 90 percent by 2010 . 


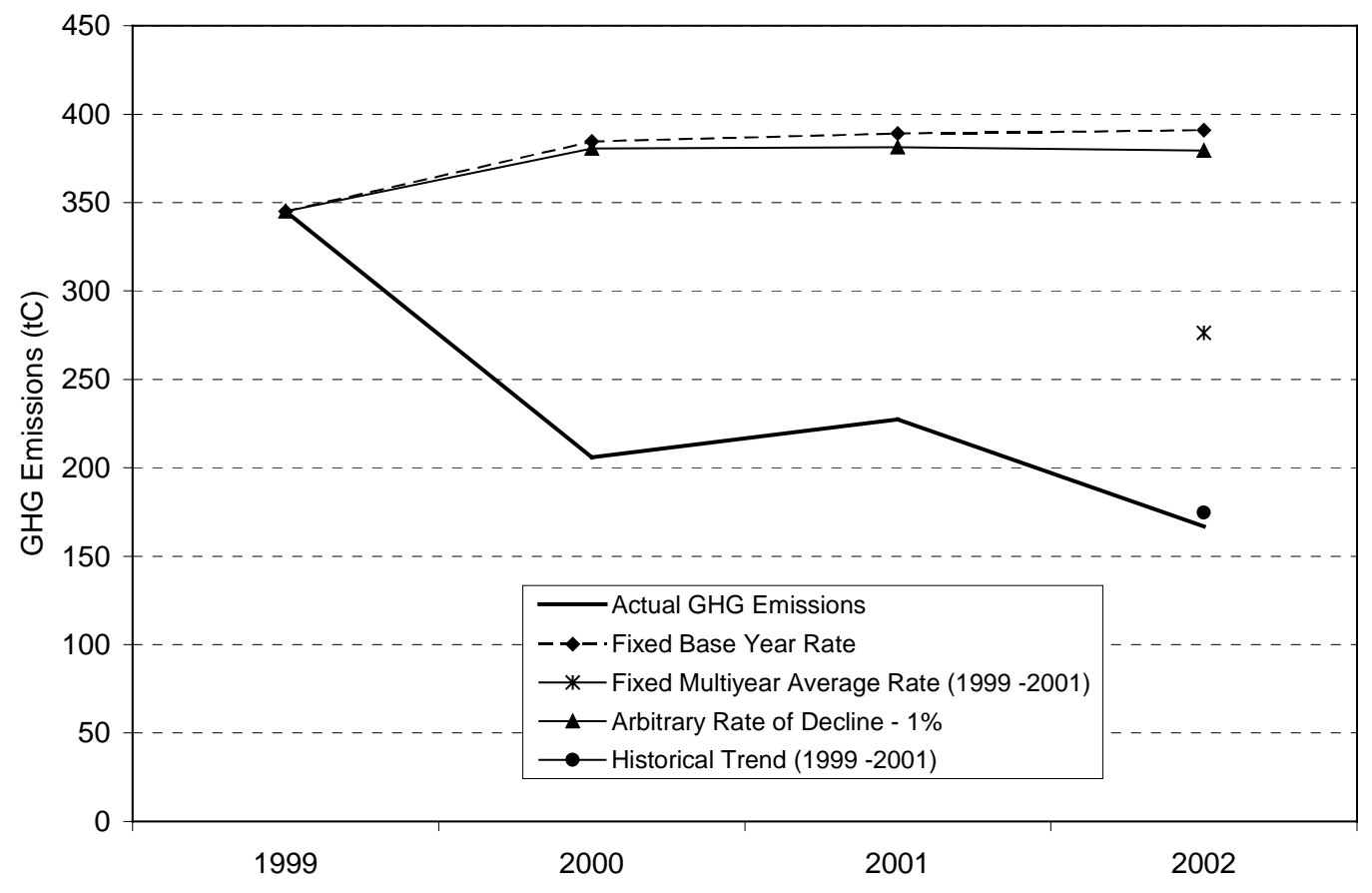

Figure 21. Intensity Based Food Processing Baselines, Using Cases Produced Metric

\subsubsection{Reconstructed Baselines}

In this section, we reconstruct baselines for Fetzer's agricultural crop production and food processing GHG emissions. For the reconstructed agricultural crop production baseline (Figure 22), we assumed that all of the electricity purchased in the business-as-usual case would have come from the standard mix for PG\&E. We used the emissions factor described in footnote 30 to estimate emissions from this electricity. Since no efficiency project savings for agriculture were reported by Fetzer, the only other adjustment to the actual emissions was to assume that Fetzer would have used standard diesel fuel instead of the $310 \mathrm{MMBtu}$ of biodiesel used in 2002. This added another 6.2 tC to the 2002 reconstructed baseline. 


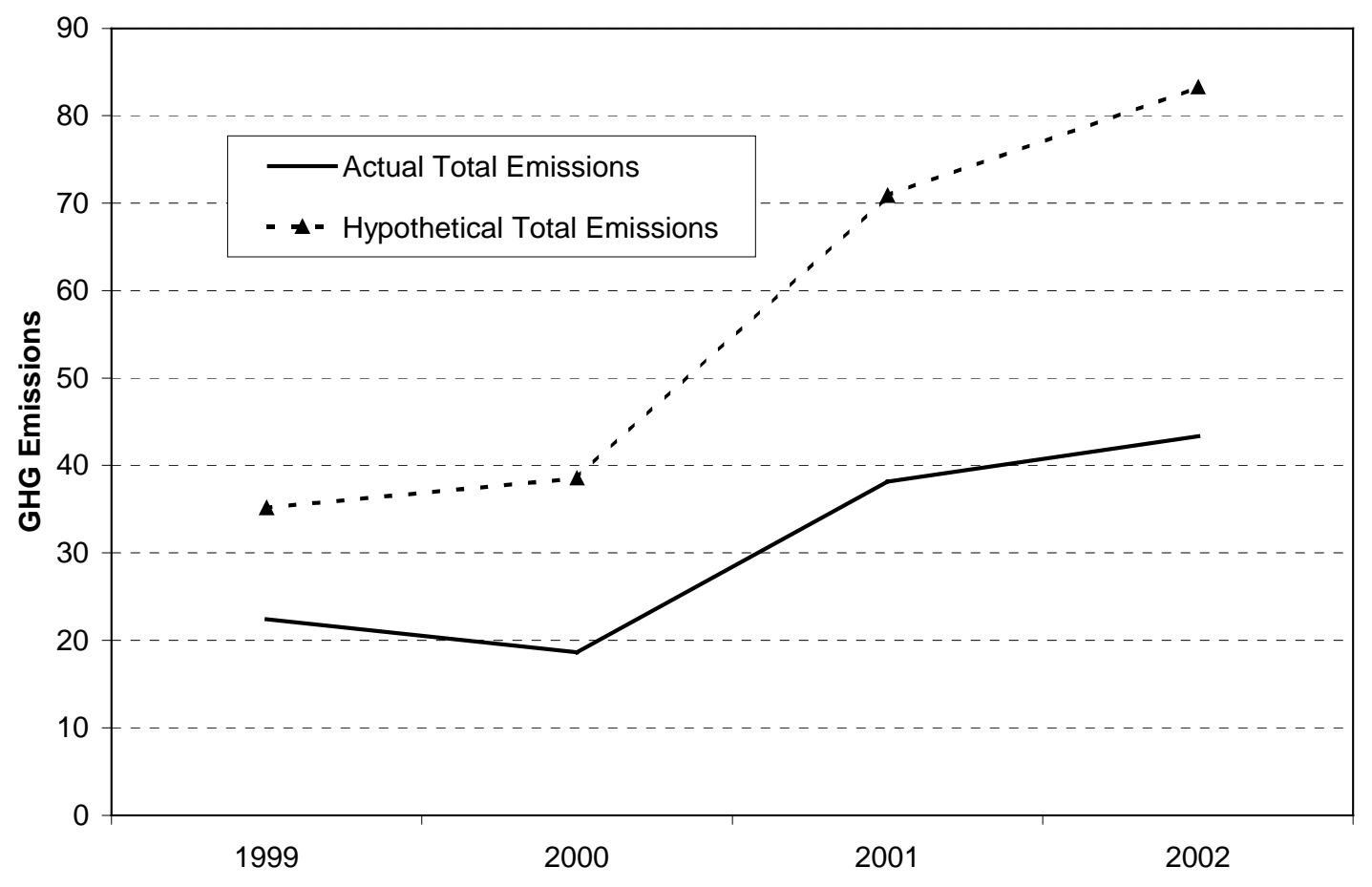

Figure 22. Ex-Post Baseline for Agricultural Crop Production

The reconstructed baseline for food processing is shown in Figure 23. This baseline was calculated by assuming that the reported savings from specific electricity efficiency projects had not occurred and the solar photovoltaic panel had not been installed. Then the sum of the actual electricity consumed and the savings for each year were multiplied by the PG\&E emissions factor. In order to estimate the substantial savings of propane and natural gas from the various efficiency and fuel switching projects that Fetzer completed during the period studied, the 1999 ratios of propane and natural gas per case produced were held constant and multiplied by actual production for the other years. The resulting GHG reductions are estimated at over 1,540 tC from 1999 to 2002. 


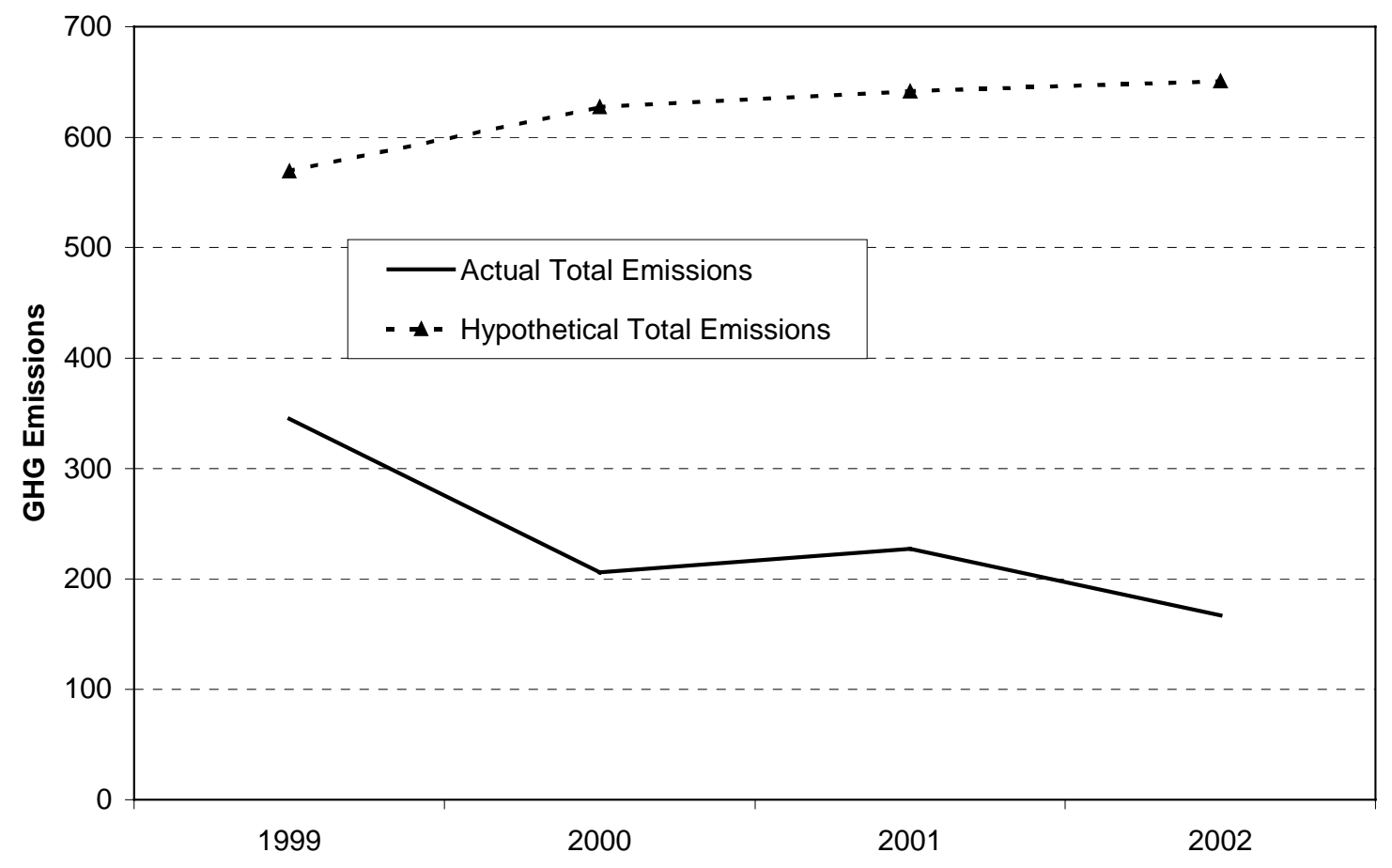

Figure 23. Ex-Post Baseline for Food Processing

\subsubsection{Findings}

Table 19 shows the estimated 2002 savings (or additions) of GHGs using the various baseline methods shown above. The estimates vary widely depending on which baseline is chosen, although it is important to note that the results would not differ so greatly if the absolute and intensity baselines were extrapolated from a year prior to 1999, when the switch to renewable electricity occurred. The figures for emissions from the agricultural sector range from savings of $39.9 \mathrm{tC}$ to an addition of $21.5 \mathrm{tC}$ above the baseline. The range for food processing activities is a reduction between 8 and 484 tC.

In practice, different baselines are useful for different purposes. When choosing among baseline methods, the considerations shown in Table 12 must be taken into account. Frozen baselines simply show whether an entity is contributing more or less to GHG emissions overall. Intensity baselines do not offer the precision to be used as a basis for protecting early action, unless perhaps they are more complex and use highly disaggregated data. Otherwise, "intensity" as defined at more practical levels of detail will be affected by factors that do not reflect true changes in efficiency. Project-based reconstructed baselines are the most defensible for the generation of credits. While total emissions are reported at the entity-wide level, savings must be documented on a project-specific basis. Since the claimed savings are attributable to specific projects, they can be more realistically monitored and verified. 
Table 19. Comparison of the Use of Various Baselines for Estimating 2002 GHG Savings for Agricultural Crop Production and Food Processing at Fetzer Vineyards (tC).

\begin{tabular}{|c|c|c|c|}
\hline 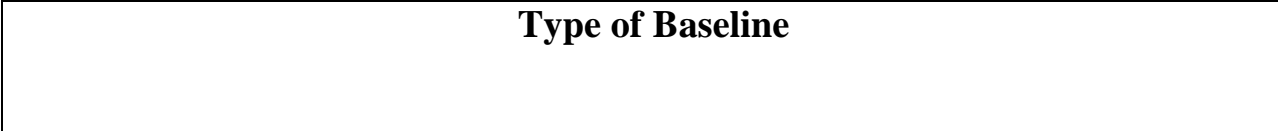 & $\begin{array}{c}\text { Actual } 2002 \text { GHG } \\
\text { Emissions }\end{array}$ & $\begin{array}{c}\text { Baseline 2002 } \\
\text { GHG Emissions }\end{array}$ & $\begin{array}{c}\text { GHG Emissions } \\
\text { Reductions or } \\
\text { Increases }\end{array}$ \\
\hline \multicolumn{4}{|l|}{$\begin{array}{l}\text { Agricultural Crop Production } \\
\end{array}$} \\
\hline Fixed base year absolute & 43.3 & 22.4 & 20.9 \\
\hline Fixed multiyear average absolute & 43.3 & 26.4 & 16.9 \\
\hline Future target $-10 \%$ & 43.3 & 21.8 & 21.5 \\
\hline Fixed base year rate (tons of grapes metric) & 43.3 & 33.5 & 9.8 \\
\hline Fixed multiyear average rate (tons of grapes metric) & 43.3 & 30.4 & 12.9 \\
\hline Arbitrary $1 \%$ rate of intensity decline (from 1999, tons of grapes metric) & 43.3 & 32.5 & 10.8 \\
\hline Historical trend (average rate of change from 1999 to 2002 , tons of grapes metric) & 43.3 & 39.8 & 3.5 \\
\hline Fixed base year rate (acreage metric) & 43.3 & 52.0 & -8.7 \\
\hline Fixed multiyear average rate (acreage metric) & 43.3 & 42.2 & 1.2 \\
\hline Arbitrary $1 \%$ rate of intensity decline (from 1999, acreage metric) & 43.3 & 50.5 & -7.1 \\
\hline Historical trend (average rate of change from 1999 to 2002 , acreage metric) & 43.3 & 31.5 & 11.8 \\
\hline Reconstructed & 43.3 & 83.3 & -39.9 \\
\hline \multicolumn{4}{|l|}{ Food Processing } \\
\hline Fixed base year absolute & 167 & 345 & -435 \\
\hline Fixed multiyear average absolute & 167 & 259 & -93 \\
\hline Future target $-10 \%$ & 167 & 336 & -416 \\
\hline Fixed base year rate & 167 & 391 & -224 \\
\hline Fixed multiyear average rate & 167 & 276 & -109 \\
\hline Arbitrary $1 \%$ rate of intensity decline (from 1999 ) & 167 & 379 & -212 \\
\hline Historical trend (average rate of change from 1999 to 2001) & 167 & 175 & -8 \\
\hline Reconstructed & 167 & 651 & -484 \\
\hline
\end{tabular}




\subsection{Municipalities: City of Berkeley Case Study ${ }^{35}$}

\subsubsection{Sector Background}

This case study focuses on development of metrics for GHG emissions under the operational control of municipal governments. The scope of emissions sources considered include "direct" emissions from fuel combustion, "indirect" emissions associated with the use of electricity, and methane emissions from landfills. Municipalities are difficult subjects for defining emissions metrics because of their diverse range of activities and the many end uses of energy they deploy to provide municipal services. Several sources of greenhouse gas emissions are common to almost all municipalities. These sources include emissions from:

- Energy used for space heating, cooling, lighting, and other electrical end uses in municipal buildings

- Fuels used in municipal vehicles

- Electricity used for traffic signals and street lights

- Waste facilities

Buildings' energy use in municipalities is a significant contributor to greenhouse gas emissions in California, and energy efficiency gains from retrofits and efficiency features in buildings can be both very economic and significant sources of GHG reductions. As they are often economically attractive investments with a short-term payback period, energy-efficiency improvements in buildings are likely to receive more attention compared to other initiatives.

Most municipalities in California currently continue to use traditional fuels for municipal vehicles, although some, like the City of Berkeley, are gradually turning to bio-diesel or compressed natural gas for their truck and bus fleets. Such fuel-switching can greatly reduce emissions of GHGs and other pollutants. Cities can also reduce GHG emissions by simply prioritizing higher fuel-efficiency when acquiring vehicles for their fleets.

Traffic signals and streetlights can consume a large amount of electricity in a city. However, significant energy savings can be realized through retrofitting existing traffic lights with LightEmitting Diode (LED) fixtures. Fluorescent and LED technologies for streetlight applications are also emerging.

Methane emissions from municipal landfills also represent an important GHG emissions source since methane has a much higher global warming potential than energy-related $\mathrm{CO}_{2}$ emissions.

\subsubsection{Overview of City of Berkeley}

The City of Berkeley, located across the bay from San Francisco in northern California, has a population of 103,000. Municipal services provided by the City of Berkeley are similar to those provided by most large cities, including police and fire services, municipal libraries, refuse services, and public parks and recreation services.

\footnotetext{
${ }^{35}$ A significant portion of this case study was written by Mary Jean Burer as a consultant to Berkeley Lab.
} 
The City of Berkeley has set a goal to reduce its GHG emissions by $15 \%$ below projected baseline levels in 2010. Berkeley was one of the first municipalities under the International Council for Local Environmental Initiatives program on climate change to publish a global warming abatement plan. The purpose of the project was to develop a plan to improve the efficiency of natural resources use to the extent that is feasible and can fit with other general City planning goals. The report presented 103 initiatives and documented the greenhouse gas reduction potential of various strategies. Figure 1 shows the shares of energy-related $\mathrm{CO}_{2}$ emissions by major fuel and end use for the City of Berkeley in 2001.

The City of Berkeley operates over 30 buildings; a municipal fleet of approximately 30 garbage trucks, 150 sedans, 100 light duty trucks, plus street sweepers and some heavy duty trucks; traffic signals at over 120 intersections, and approximately 40,000 streetlights (DeSnoo 2003b, Silva 2003). ${ }^{36}$ Like many smaller municipalities, the City of Berkeley does not operate its own landfill, but rather has a closed landfill with the capability for methane capture. ${ }^{37} \mathrm{We}$ focus on current activities under the city's management structure such as the city's transfer station activities where garbage is transferred from Berkeley to trucks going to the Altamont Pass landfill in Livermore, California. We also analyze the emissions from refuse trucks used in the city.

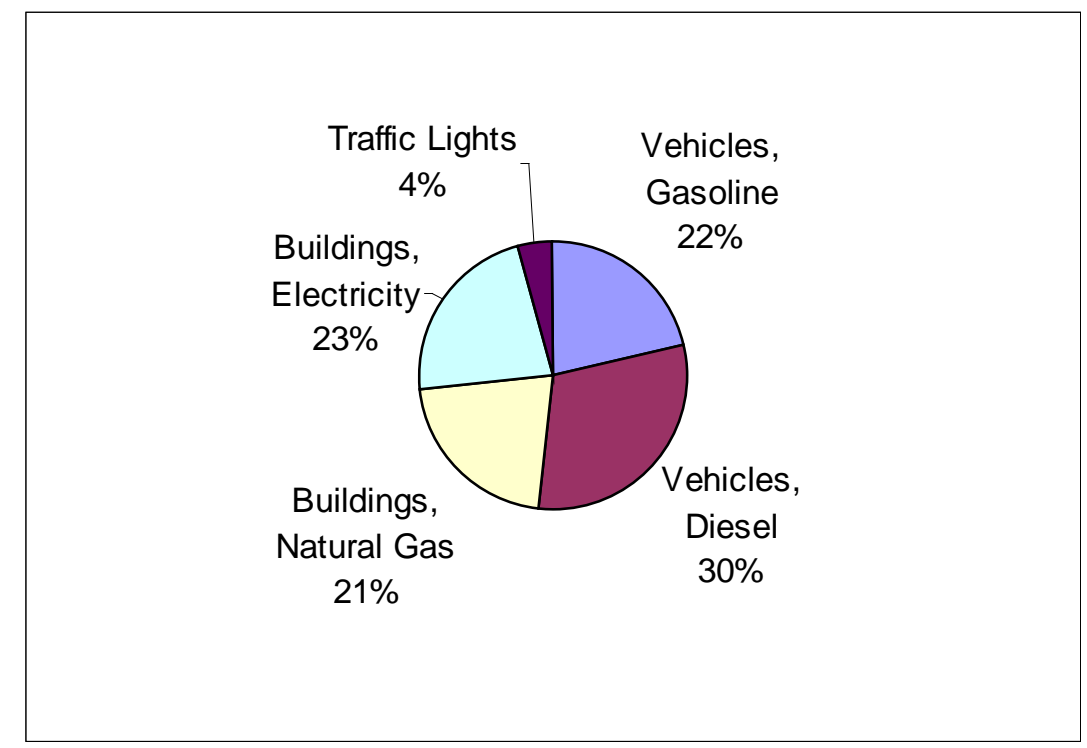

Figure 24. Shares of City of Berkeley's $2001 \mathrm{CO}_{2}$ Emissions by Major Fuel and End Use, Excluding Street Lights, Miscellaneous Vehicles, and Landfill Methane

\footnotetext{
${ }^{36}$ Other sources of emissions not under the City's jurisdiction are the public transit system and the Berkeley Unified School District emissions. The public transit system is operated by Alameda County, and the school district operates as an independent government entity. Additionally, recycling activities are out-sourced to the Ecology Center in Berkeley. We do not focus on such sources as they are not within the required reporting boundaries for participation in California's registry.

${ }^{37}$ This study does not investigate metrics for methane emissions from landfills. The landfill that is currently used is not managed by the city, and since there is currently no methane-reduction program in place at the former landfill, we did not analyze those emissions further.
} 


\subsubsection{Analysis of Possible Metrics}

In order for energy or GHG metrics to be useful, they must measure true energy intensities at a sufficiently disaggregated level such that GHG emissions measured are closely tied to the measure of activity used to normalize the emissions. Thus, while it would be easiest to use a highly aggregated metric such as total emissions per resident, the resulting metric would likely be subject to large fluctuations and would not provide accurate information about trends in efficiencies. Therefore, this study focuses on possible metrics for the major sources of GHG emissions for which data were available: buildings, vehicles, and traffic lights.

\subsubsection{Municipal Buildings}

The City of Berkeley operates over 30 buildings. Of these, the six largest energy-consuming building are responsible for nearly 70 percent of the total energy consumed by buildings. Table 20 lists these buildings and shows their electricity and natural gas consumption for 2001, except for the Main Library, which was closed for seismic retrofitting and expansion. Data from 1998 were used instead and were also included in the total to indicate the share it would have had if reopened.

Table 20 also indicates one of the primary difficulties encountered in conducting this case study. Seismic retrofits and expansions resulted in the closing of some of the largest energy consuming buildings, most importantly the Civic Center and the Main Library. The closing of the Civic Center in particular resulted in the relocation of approximately 300 city staff into other city buildings and various leased spaced in Berkeley, causing inconsistencies in the data series. Depending on the terms of the leases, in some cases the City was responsible for receiving and paying the utility bills, while in other cases the utility bills were paid by the property owners. Unfortunately, the latter case resulted in some "lost data" as some of the energy used to support some City services was no longer appearing in the City's energy records. However, the leased spaces for which energy and square footage data were available, account for about half of the total that had been used by the Civic Center.

In contrast to these buildings closed for retrofits, construction on the most energy consuming building, the Public Safety Building, was not completed until 2001. This building coming online is mostly responsible for the jump in electricity consumption in 2001 (see Figure 25).

\subsection{Municipal Buildings Energy Use and GHG Emissions}

Table 21 and Figure 25 provide information on the City of Berkeley's energy use and related GHG emissions from 1994 through 2001. As can be seen, overall energy use declined during the period, led by a decrease in natural gas use. ${ }^{38}$ Electricity consumption remained relatively stable

\footnotetext{
${ }^{38}$ Natural gas consumption was corrected for fluctuations in annual average temperatures using data on heating degree-days (NOAA, 2003). For each year, the natural gas consumed was multiplied by the average number of heating degree-days for the 1994 - 2001 period divided by that year's actual heating degree-days. This is meant to adjust each year's gas consumption to a normal heating year so that the energy need to heat a given area is more comparable from year to year.
} 
during the period, although an increase was seen in 2001. Energy-related GHG emissions closely mirror the trends in energy consumption.

Table 20. 2001 Energy Consumption, Square Footage, and Energy Intensity of Berkeley Municipal Buildings

\begin{tabular}{|c|c|c|c|c|c|c|c|}
\hline Building & $\begin{array}{l}\text { Square } \\
\text { footage }\end{array}$ & $\begin{array}{l}\text { Electricity } \\
\text { (MMBtu) }\end{array}$ & $\begin{array}{l}\text { Natural } \\
\text { Gas } \\
\text { (MMBtu) }\end{array}$ & $\begin{array}{l}\text { Total } \\
\text { Energy } \\
\text { (MMBtu) }\end{array}$ & $\begin{array}{l}\text { Energy } \\
\text { Intensity } \\
\left(\text { MBtu/ft' }{ }^{2}\right)\end{array}$ & $\begin{array}{l}\text { Closed } \\
\text { for } \\
\text { Retrofit }\end{array}$ & Reopened \\
\hline Civic Center & 89,075 & 2,093 & 2,478 & 4,571 & 51.3 & 1999 & 2001 \\
\hline Hall of Justice & 50,260 & 574 & 2,615 & 3,189 & 63.4 & N/A & N/A \\
\hline Main Library & 26,250 & 1,240 & 825 & 2,065 & 78.7 & 1999 & 2002 \\
\hline $\begin{array}{l}\text { Public Safety } \\
\text { Bldg }\end{array}$ & 66,000 & 3,954 & 1,232 & 5,186 & 78.6 & N/A & 2001 \\
\hline $\begin{array}{l}\text { Transfer } \\
\text { Station, Admin } \\
\text { and Scales }\end{array}$ & 31,200 & 158 & 1,234 & 1,392 & 44.6 & $2001 ?$ & \\
\hline $\begin{array}{l}\text { Veterans } \\
\text { Building }\end{array}$ & 35,936 & 355 & 2,095 & 2,450 & 68.2 & N/A & \\
\hline $\begin{array}{l}\text { Subtotal for Six } \\
\text { Largest }\end{array}$ & 298,721 & 8,374 & 10,479 & 18,853 & 63.1 & N/A & N/A \\
\hline $\begin{array}{l}\text { Total for all } \\
\text { buildings, } 2001\end{array}$ & 486,410 & 12,986 & 15,741 & 28,727 & 57.9 & N/A & N/A \\
\hline
\end{tabular}

Table 21. City of Berkeley Building Energy Consumption and GHG Emissions, 1994-2001.

\begin{tabular}{|c|c|c|c|c|c|c|c|c|}
\hline & 1994 & 1995 & 1996 & 1997 & 1998 & 1999 & 2000 & 2001 \\
\hline \multicolumn{9}{|l|}{ Energy } \\
\hline Electricity (kWh) & $3,508,917$ & $3,443,196$ & $3,354,928$ & $3,344,094$ & $3,627,120$ & $3,072,103$ & $2,979,056$ & $3,396,207$ \\
\hline Natural Gas (Therms) & 194,771 & 156,988 & 156,996 & 145,699 & 164,387 & 160,180 & 134,664 & 141,057 \\
\hline Electricity MMBtu & 11,972 & 11,748 & 11,447 & 11,410 & 12,376 & 10,482 & 10,165 & 11,588 \\
\hline Gas MMBtu & 19,477 & 15,699 & 15,700 & 14,570 & 16,439 & 16,018 & 13,466 & 14,106 \\
\hline Gas MMBtu, weather corrected & 17,723 & 18,164 & 16,929 & 17,957 & 14,423 & 14,119 & 13,564 & 13,682 \\
\hline Total MMBtu & 31,450 & 27,447 & 27,147 & 25,980 & 28,814 & 26,500 & 23,631 & 25,694 \\
\hline Total MMBtu, weather corrected & 29,696 & 29,912 & 28,376 & 29,367 & 26,798 & 24,601 & 23,729 & 25,270 \\
\hline \multicolumn{9}{|l|}{ GHG Emissions } \\
\hline $\mathrm{kgC}$ from electricity & 224,571 & 220,365 & 214,715 & 214,022 & 232,136 & 196,615 & 190,660 & 217,357 \\
\hline $\mathrm{kgC}$ from $\mathrm{NG}$ & 281,834 & 227,162 & 227,173 & 210,826 & 237,868 & 231,780 & 194,859 & 204,109 \\
\hline $\mathrm{kgC}$ from $\mathrm{NG}$, weather corrected & 256,454 & 262,833 & 244,959 & 259,838 & 208,696 & 204,304 & 196,277 & 197,984 \\
\hline Total $\mathrm{kgC}$, weather corrected & 481,024 & 483,197 & 459,674 & 473,860 & 440,832 & 400,918 & 386,937 & 415,341 \\
\hline
\end{tabular}



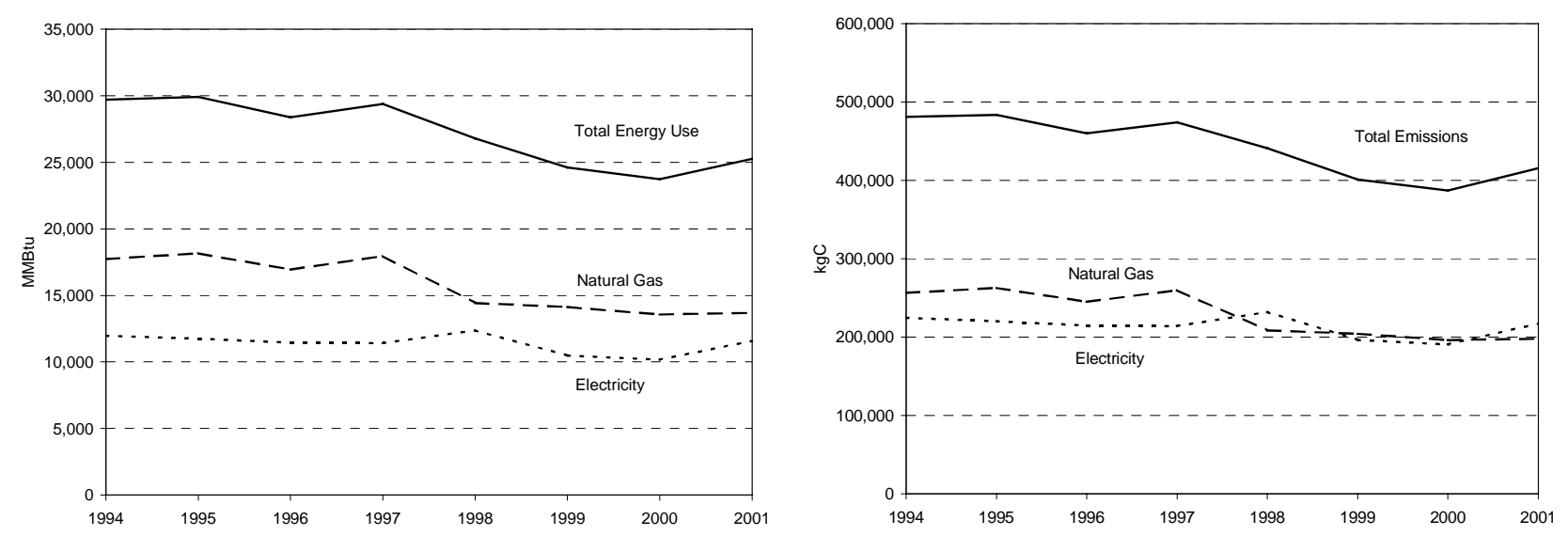

Figure 25. City of Berkeley Energy Use and Associated GHG Emissions, 1994-2001.

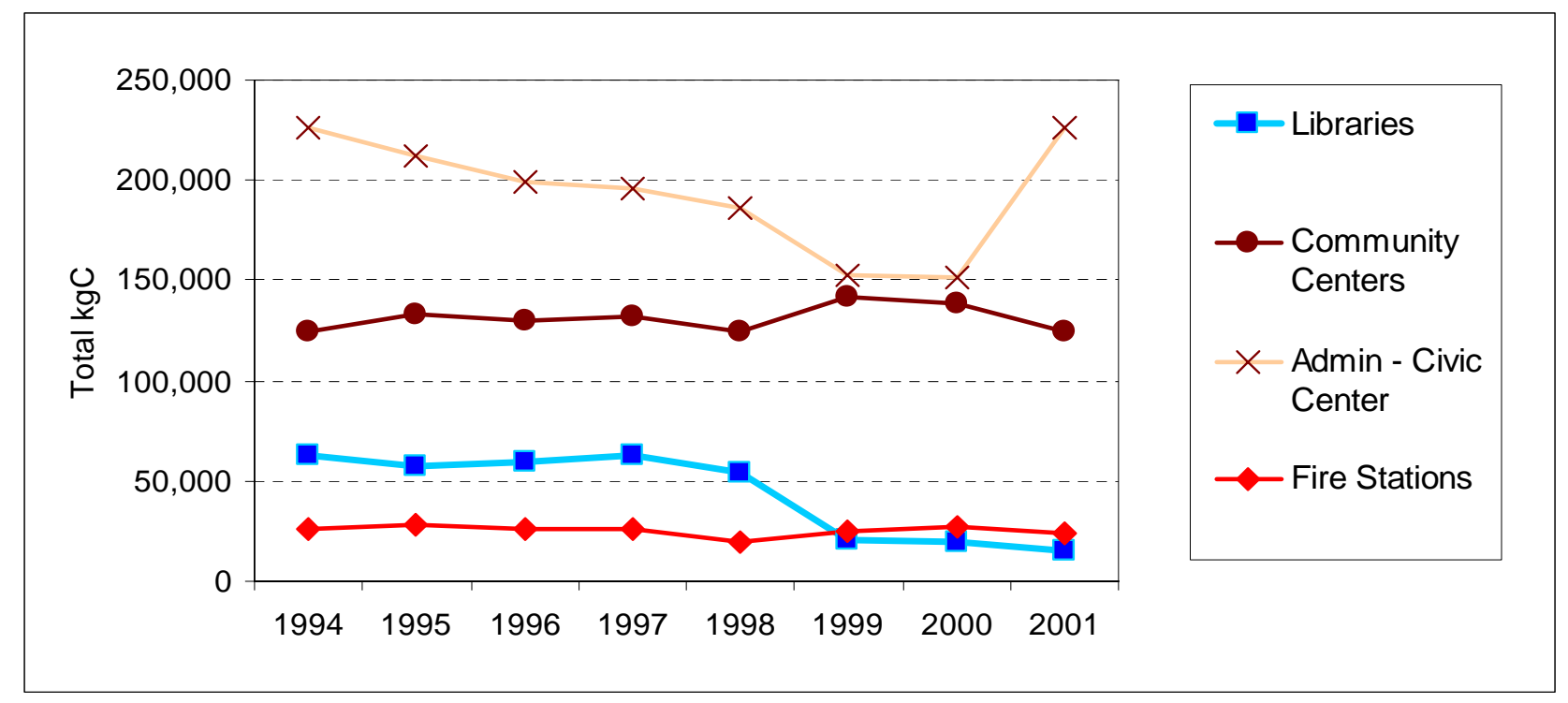

Figure 26. Total $2001 \mathrm{CO}_{2}$ Emissions by Building Type

\subsection{Municipal Buildings Metrics}

In order to develop useful metrics for buildings, an appropriate normalization factor must be chosen. Buildings contain a wide variety of energy uses, and the most precise metrics would measure energy consumed by each of major end use, such as lighting, heating, cooling, and the use of various types of appliances and office equipment. However, each building is usually only fed by one gas meter and one electricity meter. Thus, obtaining data for more disaggregated uses would require the purchase of sub-metering equipment and an extensive data gathering effort. These data limitations largely prohibit the use of disaggregated metrics without elaborate efforts to estimate the electricity consumed by various end-uses. More aggregate indicators of intensity must be chosen. 
The most commonly used index for energy intensity studies of non-industrial buildings is the energy consumed per square foot (or meter). However, the use of energy consumption per employee has also been suggested since some end uses, such as energy for computers and other office equipment, depend more on the number of employees than on floor area per se. However, Krackeler, Schipper, and Sezgen (1998) note that roughly 75 percent of service sector energy consumption is used for end uses that are driven by floor area (e.g. heating, ventilation, cooling, and lighting) and conclude that in the absence of disaggregated data by end use, energy use (or emissions) per floor area is a more appropriate metric.

However, not all buildings can be compared equally with such a metric because they are not used for the same purposes. For example, building that do not require space conditioning (such as warehouses) will be less energy intensive than others. For this reason we grouped buildings according to four types and in some cases for excluding some types of sites from the floor area metric and developing specific metrics for special cases. For example, in this case study, we also developed a specific metric for the transfer station in Berkeley based on tonnage of waste brought into the site.

While data for specific end uses is not available, it may be useful to separately index natural gas and electricity. This is because the use of the two fuels is affected by different factors. For municipal buildings, natural gas will be used almost entirely for space heating. Therefore, the use of natural gas will be affected by the weather, and efforts to improve insulation will appear more clearly in a gas only metric. Similarly, savings from lighting retrofits or acquisition of more efficient office equipment can be demonstrated in an electricity-usage metric.

In this case study, we chose the unit energy consumption per square foot, correcting the natural gas consumption for climate, as the best overall indicator for buildings. First, data were aggregated into groups of similar buildings types: libraries, fire stations, office buildings, and community centers/miscellaneous. Then we accounted for heating degree-days and corrected the natural gas usage data for weather. More specific data on various sites were collected to fill in gaps in the data and deal with areas where data were fluctuating or missing because of retrofits or the use of temporary buildings.

Figure 27 shows the City of Berkeley municipal buildings GHG emissions per square foot of floor area for total GHG emissions, electricity-related GHG emissions and natural gas-related GHG emissions. GHG emissions per floor area drop in 1998, consistent with the fact that the City of Berkeley began a number of retrofits that year. While we corrected the floor area to account for this where possible, the fact that the energy-intensive Main Library was closed for an extensive retrofit at this time most likely explains the drop in the metric. In addition, some of the leased buildings that were used to house occupants of all of the buildings involved in the retrofits did not report energy use on the city's energy management program because they were managed by other entities. 
Table 22. City of Berkeley Municipal Building Energy and GHG Metrics

\begin{tabular}{|c|c|c|c|c|c|c|c|c|}
\hline & 1994 & 1995 & 1996 & 1997 & 1998 & 1999 & 2000 & 2001 \\
\hline SqFt & 408,409 & 408,409 & 403,723 & 408,409 & 406,662 & 351,744 & 351,744 & 428,960 \\
\hline \multicolumn{9}{|l|}{ Energy } \\
\hline $\mathrm{kBtu} / \mathrm{sqft}$, gas & 47.7 & 38.4 & 38.9 & 35.7 & 40.4 & 45.5 & 38.3 & 32.9 \\
\hline $\mathrm{kBtu} / \mathrm{sqft}$, gas, weather corrected & 72.7 & 73.2 & 70.3 & 71.9 & 65.9 & 69.9 & 67.5 & 58.9 \\
\hline kBtu/sqft, electricity & 29.3 & 28.8 & 28.4 & 27.9 & 30.4 & 29.8 & 28.9 & 27.0 \\
\hline $\mathrm{kBtu} / \mathrm{SqFt}$, total & 77.0 & 67.2 & 67.2 & 63.6 & 70.9 & 75.3 & 67.2 & 59.9 \\
\hline $\mathrm{kBtu} / \mathrm{SqFt}$, total weather corrected & 102.0 & 102.0 & 98.6 & 99.8 & 96.3 & 99.7 & 96.4 & 85.9 \\
\hline \multicolumn{9}{|l|}{ GHG Emissions } \\
\hline Electricity $\mathrm{kgC} / \mathrm{Sq} . \mathrm{Ft}$ & 0.55 & 0.54 & 0.53 & 0.52 & 0.57 & 0.56 & 0.54 & 0.51 \\
\hline $\mathrm{NG} \mathrm{kgC/SqFt}$ & 0.69 & 0.56 & 0.56 & 0.52 & 0.58 & 0.66 & 0.55 & 0.48 \\
\hline $\mathrm{NG} \mathrm{kgC/SqFt}$, weather corrected & 0.63 & 0.64 & 0.61 & 0.64 & 0.51 & 0.58 & 0.56 & 0.46 \\
\hline Combined kgC/Sq. Ft. & 1.24 & 1.10 & 1.09 & 1.04 & 1.16 & 1.22 & 1.10 & 0.98 \\
\hline Total kgC/Sq.Ft., weather corrected & 1.18 & 1.18 & 1.14 & 1.16 & 1.08 & 1.14 & 1.10 & 0.97 \\
\hline
\end{tabular}

The drop in GHG emissions per floor area that occurred in 2001 is most likely due to a combination of factors. First, the Civic Center (Berkeley's main administration building) underwent a seismic renovation between 1999 and 2001 that incorporated energy-efficient strategies including the installation of natural ventilation shafts that use stack effect assisted by efficient fans to remove warm air from the building while drawing cooler air in from outside (Miller 2002). When the Civic Center returned to service in 2001, these improvements significantly reduced energy consumption - and related GHG emissions - per floor area. In addition, some of the buildings that were leased to during the Civic Center retrofit were not used after it reopened in 2001. Finally, the addition of the new Public Safety building in 2001 may have also led to a reduction in the GHG emissions per floor area for the municipal buildings.

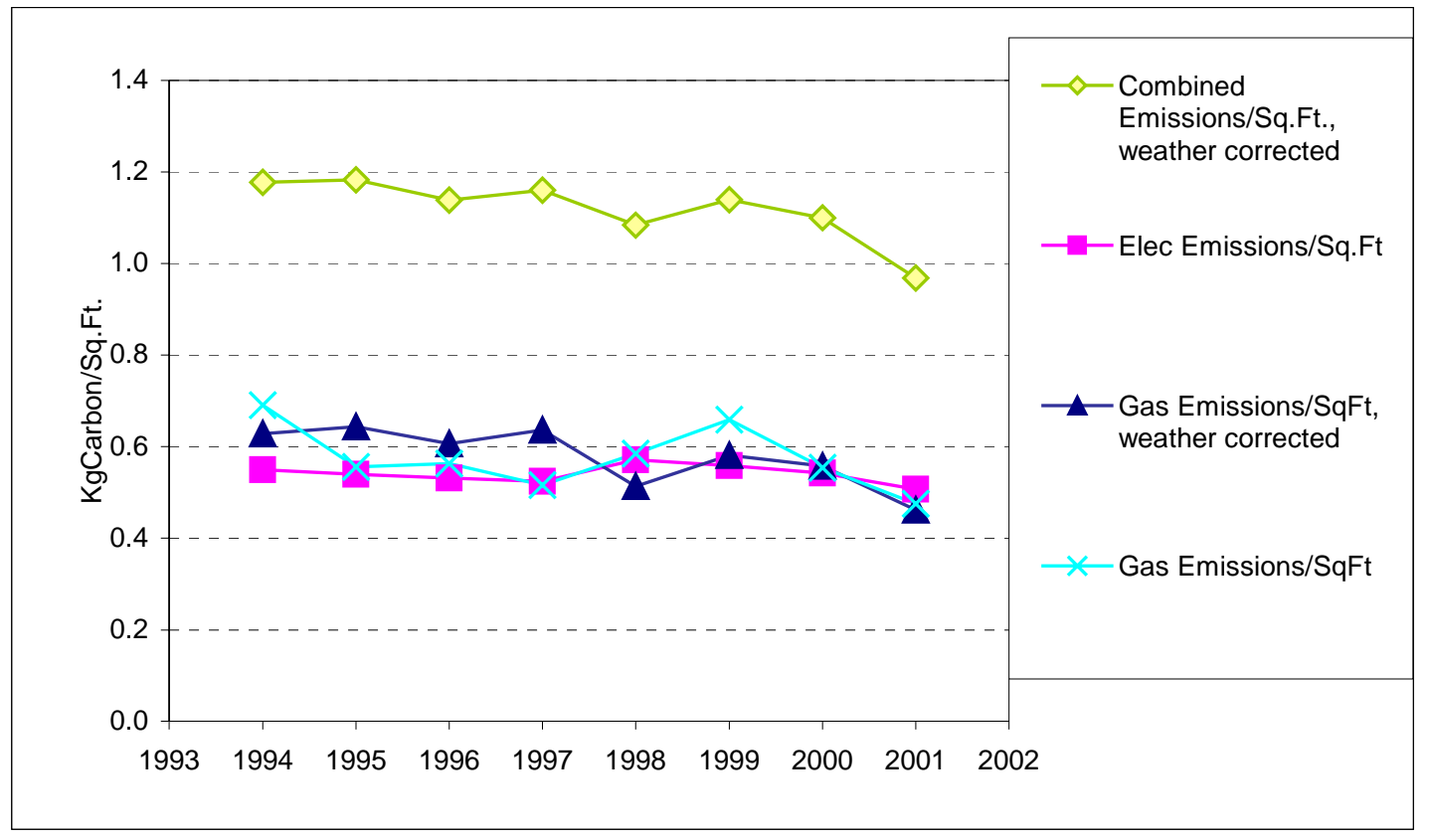

Figure 27. City of Berkeley Municipal Buildings GHG Emissions Metrics by Fuel 
Figure 28 illustrates the City of Berkeley municipal buildings metric for specific buildings or groups of buildings: the Civic Center, the libraries, the community centers, and the fire stations. Overall, GHG emissions per unit of floor area decreased in all major building types, except the community centers, which did not receive retrofits. The fire stations show a significant decrease after 1996, which may be because buildings were temporarily off-line for retrofits during this period.

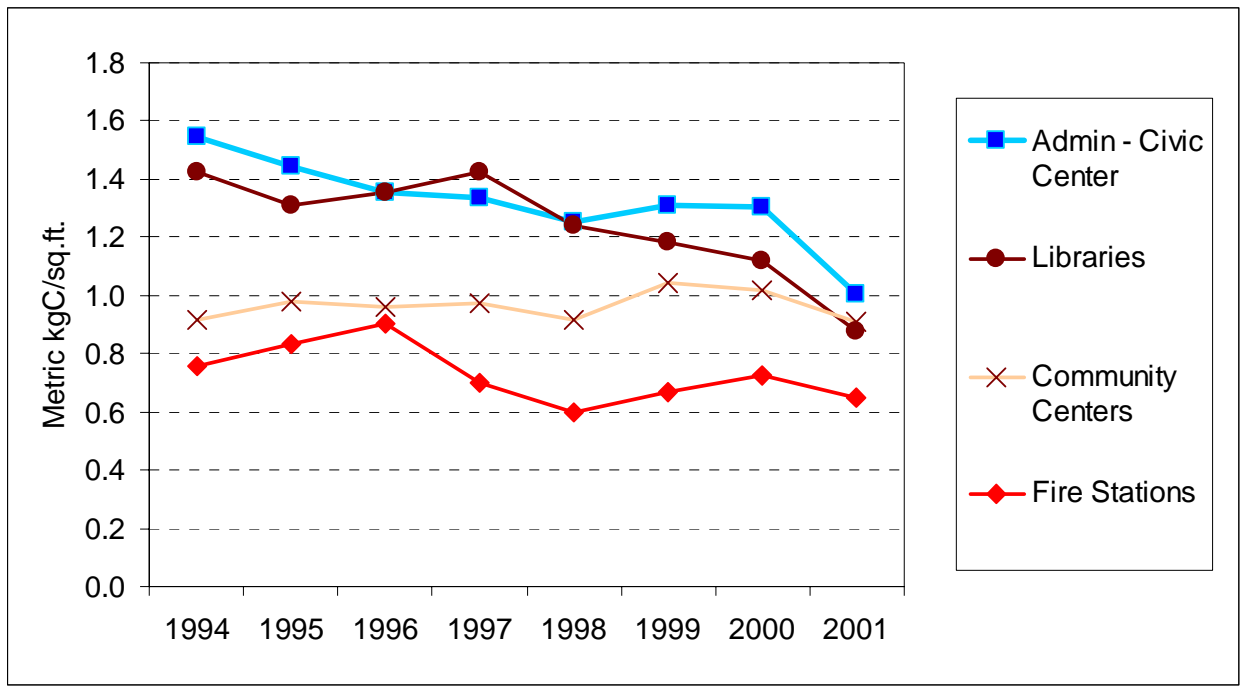

Figure 28. City of Berkeley Municipal Buildings GHG Emissions Metric by Building Type

Figure 28 shows that the GHG intensities of the building types vary considerably. But does the Registry need to track separate intensities for each building type? The usual justification for tracking more disaggregated metrics is whether changes in the mix of activities could produce a lower or higher metric with no real change in intensity occurring. In the manufacturing sector, a shift to lighter industries would lower the amount of energy needed to produce a dollar's worth of manufacturing value added even if no change in efficiency occurs within any given industry. A municipality, however, will not generally experience a major shift in total floor space among the types of buildings that it manages. Asking participants to track the data by separate building types may not justify the effort. However, since separate data for electricity and natural gas are always available, municipalities can easily report separate metrics for these two energy sources. Separate gas and electricity metrics provide useful information since they show more clearly how a city is working to reduce its GHG intensity.

\subsubsection{Municipal Vehicles}

The City of Berkeley municipal vehicles analyzed for this case study include the refuse trucks that use diesel fuel and the sedans used for police and municipal activities that consume unleaded gasoline. These two main types of vehicles constitute the majority of gasoline- and dieselpowered vehicles in the city's fleet (Ivie 2003). Data on other types of vehicles including dump trucks, large fire trucks, approximately 20 sport utility vehicles, miscellaneous small vehicles, 
light duty trucks, and lawn mowers were not available. The City of Berkeley fleet manager provided aggregated fuel consumption and mileage data by fuel type and vehicle-mile traveled (VMT) data for 2000 through 2002. We corrected for the use of $20 \%$ biodiesel in refuse trucks starting in 2001.

\subsection{Municipal Vehicles Energy Use and GHG Emissions}

Table 23 shows the fuel consumption and GHG emissions data for the City of Berkeley automobile and refuse vehicles for 2000 through 2002, as well as total emissions for these vehicles. For the automobile fleet, fuel use and related emissions rose steadily all three years. The use of biodiesel in 2001 and 2002 as fuel for a portion of the garbage fleet reduced the use of diesel significantly, leading to a reduction in GHG emissions for those two years. Even with the biodiesel use, though, emissions from the garbage trucks increased between 2001 and 2002, due to increased use of diesel fuel. Overall, GHG emissions for the City of Berkeley automobiles and garbage trucks dropped between 2000 and 2001 but then increased significantly in 2002.

Table 23. City of Berkeley Vehicle Fleet Fuel Consumption and GHG Emissions

\begin{tabular}{|c|c|c|c|}
\hline Automobile Fleet & 2000 & 2001 & 2002 \\
\hline Unleaded Gasoline (gallons) & 69,122 & 85,614 & 92,906 \\
\hline GHG Emissions (MtC) & 166 & 205 & 222 \\
\hline \multicolumn{4}{|l|}{ Garbage Trucks } \\
\hline Diesel (gallons) & 142,973 & 84,219 & 112,922 \\
\hline Biodiesel (gallons) & & 21,055 & 28,231 \\
\hline Total fuel (gallons) & 142,973 & 105,274 & 141,153 \\
\hline GHG Emissions (MtC) & 392 & 289 & 387 \\
\hline \multicolumn{4}{|c|}{ Total Automobiles and Garbage Trucks } \\
\hline Fuel (gallons) & 212,095 & 190,888 & 234,059 \\
\hline GHG Emissions (MtC) & 557 & 494 & 609 \\
\hline
\end{tabular}

\subsection{Municipal Vehicles Metrics}

Metrics for municipal vehicles can be based on the use of either gallons of fuel or GHG emissions from the fuel per vehicle mile traveled (VMT). While a metric based on mileage is the most practical choice for municipalities and allows one to observe the most important changes in the fleet's GHG intensity over time, this metric does not capture the effect of shifting transport activity to non-motorized modes. For example, police officers and other staff use bicycles in some parts of Berkeley. While this reduces fuel consumption, it also reduces VMT, leaving the metric fairly constant.

Table 24 provides the City of Berkeley municipal transportation fleet metrics developed for this case study. Both the fuel use per VMT and GHG emissions per VMT metrics increase over time for the automobile fleet. The increase in this metric may be due to the fact that the city acquired three new departments (including Animal Services and Neighborhood Services) to manage in 2001 and older vehicles were used in those new fleets. In 2003, new hybrid vehicles have been 
acquired for the police fleet, so the metric is expected to decrease gradually in the future (Ivie 2003).

In contrast, the fuel use metric decreases between 2000 and 2002 for the garbage trucks while the emissions metric first drops between 2000 and 2001 and then increases between 2001 and 2002 for these vehicles. ${ }^{39}$ The City of Berkeley has recently switched to $100 \%$ biodiesel for all 38 refuse and curbside recycling trucks and to compressed natural gas for four other heavy trucks used in Berkeley (City of Berkeley, 2003). Therefore, very significant reductions in GHG emissions are expected beginning in 2003 since biodiesel use results in almost no GHG emissions. Carbon dioxide emissions from biodiesel are sequestered when the source crops are grown, and only small amounts of energy from fossil-fuels are used in the growing of the crop and the fuel process for each unit of fuel energy produced (Argonne National Laboratory, 2001).

Table 24. City of Berkeley Vehicle Fleet Metrics

\begin{tabular}{|c|c|c|c|}
\hline Automobile Fleet & 2000 & 2001 & 2002 \\
\hline VMT & 803,304 & 890,275 & 958,957 \\
\hline Fuel metric (gallons/VMT) & 0.086 & 0.096 & 0.097 \\
\hline Emissions metric ( $\mathrm{kgC} / \mathrm{VMT})$ & 0.206 & 0.230 & 0.232 \\
\hline \multicolumn{4}{|l|}{ Garbage Trucks } \\
\hline VMT & 71,608 & 54,780 & 61,799 \\
\hline Fuel metric (gallons/VMT) & 2.00 & 1.92 & 1.83 \\
\hline Emissions metric ( $\mathrm{kgC} / \mathrm{VMT})$ & 5.47 & 5.27 & 6.26 \\
\hline \multicolumn{4}{|c|}{ Total Automobiles and Garbage Trucks } \\
\hline VMT & 874,912 & 945,055 & $1,020,756$ \\
\hline Fuel metric (gallons/VMT) & 0.242 & 0.202 & 0.229 \\
\hline Emissions metric $(\mathrm{kgC} / \mathrm{VMT})$ & 0.637 & 0.522 & 0.597 \\
\hline
\end{tabular}

The fuel and emissions metrics for the combined automobile and garbage fleets fall between 2000 and 2001, but then increase in 2002. This occurs despite the use of biofuel by a portion of the garbage fleet in 2001 and 2002. Further analysis of the underlying trends in vehicle types and vehicle miles per gallon efficiencies need to be done to better understand these trends.

\subsubsection{Traffic Signals}

The City of Berkeley retrofitted their traffic signals with LED ${ }^{40}$ traffic signals beginning with the replacement of red signals in 1999 and the replacement of green signals in three phases - one starting in March 2001 and ending in April 2001, the next started in September 2001 and ended in November 2001, and the final phase started in April 2002 and ended in October 2002. These

\footnotetext{
${ }^{39}$ In some cases, like garbage truck fleets, a metric based on tonnage may also be appropriate, although tonnage is difficult to accurately track. The energy or emissions intensity of such a transport service could theoretically be represented by energy/ton-km or GHG emissions/ton-km (Bosseboeuf et al., 1999).

${ }^{40}$ LEDs use 10-20\% of the energy of an incandescent lamp. Another advantage is the reduced maintenance since LEDs last approximately ten years versus one year for incandescent lamps. Red LEDs are a common retrofit, while other color retrofits are not as common. However, the biggest maintenance savings occur if all three colors are converted to LEDs (Energy Solutions, 1998).
} 
retrofits covered the majority of the 126 traffic intersections and 27 flasher locations considered in our calculations. ${ }^{41}$ As for yellow LED retrofits, only 9 intersections were completed before 2002, 6 of which were completed in April 2002.

Since electricity consumption by traffic signals changes very little from one day to another, Berkeley's electricity provider bills the city for several intersections by assuming fixed usage rates. These fixed usage rates are adjusted based on periodic measurements. Thus, there may be a lag between when retrofits occur and when the fixed usage rates are recalibrated to reflect the lower energy consumption. In order to track total electricity savings, the City of Berkeley has had to find ways to estimate savings, as many intersections are not metered. It is not known how common unmetered traffic signals are in other cities. However, streetlights are almost always unmetered (DeSnoo, 2003b).

Figure 29 shows GHG emissions per intersection for the City of Berkeley traffic lights for 1994 through 2003. There are two types of traffic signals differentiated in this graph - non-pushbutton and push-button. Non-push-button type signals contributed to more emissions than pushbutton signals overall, probably because there are more of them. However, push-button signals had a higher GHG emissions intensity per intersection than non-push button type signals. In a push button application, the red pedestrian signal burns almost constantly, unless a pedestrian signals for a cross. At automatic signal intersections, the red is frequently flashing as the green traffic signal is about to change. Since the red pedestrian signal is off about half the time while it is flashing, less energy is used for these signals.

For this case study, we used a metric defined as GHG emissions per intersection for traffic signals. Data on traffic signal energy use for each year is provided by simulations from a traffic signal model designed by the City of Berkeley's Energy Commission (DeSnoo, 2003c). These data are then divided by the total number of intersections with traffic signals in use that year. We note, however, that this metric cannot be fairly compared across different sizes of municipalities as larger cities will have more multilane streets and consequently, more signals per intersection on average.

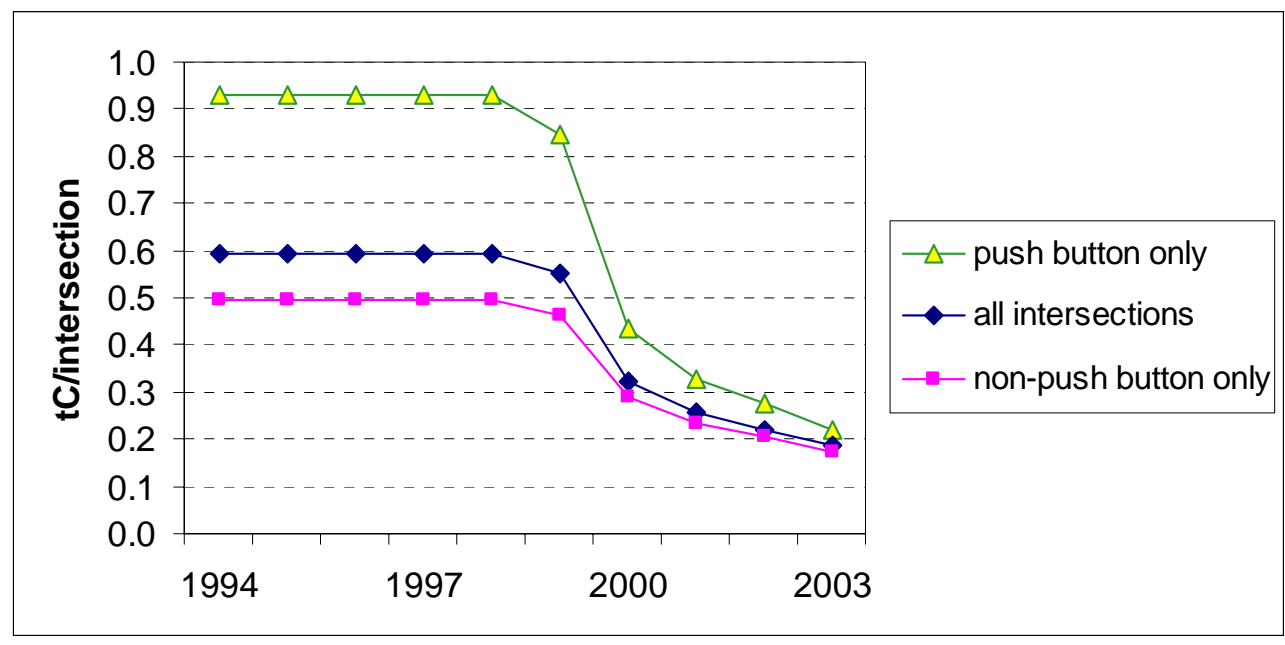

\footnotetext{
${ }^{41}$ We assumed that this number of intersections in Berkeley does not change significantly over time.
} 


\section{Figure 29. Carbon Metric for Traffic Signals}

After 1999, the red signal LED retrofits provided the greatest drop in GHG emissions and the sharpest improvement in the intensity metric. Then in 2001 to 2002, retrofits of green signals (which were mainly completed in 2001) resulted in additional reductions resulting in a gradual improvement in the carbon metric until $2003^{42}$.

In conclusion, LED signal retrofits have reduced GHG emissions significantly in the City of Berkeley. However, in order to estimate reductions city energy managers must use a model to simulate savings from retrofits when usage is not metered.

${ }^{42} 2003$ is shown here for the purpose of illustrating the reductions made due to retrofits in 2002. 


\section{Findings and Conclusions}

In the research related to industry-specific metrics, Berkeley Lab found that there are numerous methodologies, benchmarking programs, inventories, protocols, and registries that use industryspecific metrics to track trends in energy use or GHG emissions in order to determine what types of metrics have already been developed. Berkeley Lab also determined the relative importance of different potential Registry participant categories in order to assess the availability of sectoral or industry-specific metrics and then identified industry-specific metrics in use around the world. As a result of this review, Berkeley Lab recommends the development of a GHG intensity index as a new metric for reporting and tracking GHG emissions trends. Such an index would provide an industry-specific metric for reporting and tracking GHG emissions trends that could accurately reflect year-to-year changes while protecting proprietary data. A GHG intensity index could be constructed using detailed production and GHG emissions data provided by Registry participants. Only the index, and not the detailed proprietary data, would be reported publicly. Such an index would provide Registry participants with a means for demonstrating improvements in their energy and GHG emissions per unit of production without divulging specific values.

In the research related to baselines, Berkeley Lab evaluated various methods used to calculate baselines for documentation of energy consumption or GHG emissions reductions, noting those that use industry-specific metrics. Berkeley Lab developed a baseline typology and assessed the complexity and robustness of each type of baseline vis-à-vis potential future emissions limits and/or emissions trading schemes. We found that only a statutorily established future target baseline and an ex-post reconstructed baseline were robust enough to be considered as a basis for granting credits for early actions. Of these two baseline types, the future target baseline is the easiest to construct; the ex-post reconstructed baseline is accurate because actual emissions are known and reductions can be verified by a third party, but it can be more complex and costly.

Finally, Berkeley Lab conducted three case studies in order to explore issues related to both industry-specific metrics and baselines. These case studies were done for Advanced Micro Devices (AMD), Fetzer Vineyards, and the City of Berkeley. The case studies demonstrated numerous issues related to the use of metrics and recommended that industry-specific metrics be disaggregated to a certain degree, depending upon both the specific sector and data availability, in order to best capture the energy or GHG emissions trends experienced at the participant's facilities. The case studies also discussed various baseline issues and concluded that it is difficult to clearly identify any one baseline that is preferable to another based on the limited number of years of data available but also due to the wide variation in the differences between the baselines and actual GHG emissions. Data availability, baseline complexity, baseline robustness, and the ultimate desired use of the baseline must all be considered when choosing a baseline upon which to measure future GHG emissions reductions. 


\section{Acknowledgments}

This work was supported by the California Energy Commission (CEC) through the U.S. Department of Energy under Contract No. DE-AC03-76SF0098. This work does not necessarily represent the views of the CEC, its employees or the State of California.

We would like to thank Dan Seif and Reed Content of AMD for their helpful assistance and review of the AMD case study. We would also like to thank Ernst Worrell and Bill Tschudi of Lawrence Berkeley National Laboratory, and Mary Jean Burer for their helpful comments on the AMD case study. We would like to thank Patrick Healy and Susanne Zechiel for the data and information they provided related to the Fetzer case study. Their insights and comments on draft versions of the case study were valuable. We would like to acknowledge the significant amount of work that Mary Jean Burer undertook in the research and preparation of the City of Berkeley case study. We would also like to thank Neal DeSnoo, Bill Ivie, and Matt Nichols of the City of Berkeley for the enormous amount of data they provided along with their helpful reviews of the Berkeley case study.

We would especially like to thank Diane Wittenberg and Jill Gravender of the California Climate Change Registry for their active involvement in this project, providing us with the Registry's perspective as well as requirements throughout the research.

Finally, we thank Jeff Wilson, Pierre duVair, and especially Guido Franco and of the Energy Commission for their helpful guidance throughout this work. 


\section{References}

Advanced Micro Devices (AMD), 2002a. 2001 Sustainability Progress Report. http://www.amd.com/us-en/corporate/aboutAMD/0,51_52_531,00.html

Advanced Micro Devices (AMD), 2002b. Global Climate Protection Plan 2002. http://www.amd.com/us-en/corporate/aboutAMD/0,251_52_531,00.html

Archean Energy Limited, 1998. Submission to the Voluntary Challenge and Registry Program. June.

Argonne National Laboratory, 2001. Well-to-Wheel Energy Use and Greenhouse Gas Emissions of Advanced Fuel/Vehicle Systems - North American Analysis. Chicago: ANL.

Arthur D. Little, Inc., 2002. Guidance to the California Climate Action Registry: General Reporting Protocol. Draft Consultant Report. Sacramento: California Energy Commission (P500-02-005D).

Australian Greenhouse Office (AGO), 2000. About the Challenge.

http://www.greenhouse.gov.au/challenge/html/about/html

Australian Greenhouse Office (AGO), 2001. Greenhouse Challenge Factors and Methodologies. Version 2. http://www.greenhouse.gov.au/challenge/html/tools_for_success.html

Baseline Protection Initiative (BPI), 2002. Baseline Protection Initiative Reference Manual. http://nccp.ca/NCCP/pdf/media/news/manual_e.pdf

Baumert, K., Bandhari, R., and Kete, N., 1999. What Might a Developing Country Commitment Look Like? Washington, DC: World Resources Institute.

Bureau of Economic Analysis (BEA), U.S. Department of Commerce, 2003. Regional Accounts Data: Gross State Product Data, http://www.bea.gov/bea/regional/gsp/

Begg, K., Parkinson, S., Jackson, T., Morthorst, P-E., and Bailey, P., 1999. Overall Issues for Accounting for the Emissions Reductions of JI Projects. Presented at the Workshop on Baselines for CDM, Tokyo, February 25-26, 1999.

Bode, J-W., de Beer, J., Blok, K., and Ellis, J., 2000. An Initial View on Methodologies for Emission Baselines: Iron and Steel Case Study. OECD and IEA Information Paper.

Bosi, 2000. An Initial View on Methodologies for Emission Baselines: Electricity Generation Case Study. OECD and IEA Information Paper.

Bosseboeuf, D., Lapillonne, B., Eichammer, W., and Landwehr, M., 1999. Energy Efficiency Indicators : The European Experience. Paris: Ademe. 
Bosseboeuf, D., B. Chateau and B. Lapillonne, 1997. "Cross-Country Comparison on Energy Efficiency Indicators: The OnGoing European Effort towards a Common Methodology" Energy Policy 7-9 25 pp.673-682.

California Climate Action Registry, 2002a. http://www.climateregistry.org/

California Climate Action Registry, 2002b. General Reporting Protocol. Los Angeles: California Climate Action Registry.

http://www.climateregistry.org/files/general_reporting_protocol_102102.pdf

California Energy Commission, 1998. 1998 Baseline Energy Outlook. Sacramento, CA: CEC.

California Energy Commission (CEC), 2002. Inventory of California Greenhouse Gas Emissions and Sinks: 1990-1999. Sacramento, CA: California Energy Commission.

California Energy Commission and U.S. Dept. of Energy, Office of Industrial Technologies BestPractices, 2002. Energy Solutions for California Industry: Ways to Improve Operations and Profitability, Case Study. Clearinghouse@ee.doe.gov

California Senate, 2001. SB 527.

Canadian Association of Petroleum Producers (CAPP), 2000. Global Climate Change Voluntary Challenge Guide: $5^{\text {th }}$ Edition. Calgary, Alberta: CAPP.

Canadian Association of Petroleum Producers (CAPP), 2001. http://www.capp.ca/

Canadian Industry Program for Energy Conservation (CIPEC), 2001a. 1999/2000 Annual Report. Ottawa: Natural Resources Canada.

Canadian Industry Program for Energy Conservation (CIPEC), $2001 \mathrm{~b}$.

http://oee.nrcan.gc.ca/cipec/ieep/cipec/index.cfm

Center for Clean Air Policy (CCAP), 1998. Growth Baselines: Reducing Emissions and Increasing Investment in Developing Countries. Washington, DC: CCAP.

http://www.cdmcentral.org/docs/baselines/08.pdf

Center for Clean Air Policy (CCAP), 1999. Key Elements of a Domestic Program to Reward Early GHG Emissions Reductions. Washington, DC: CCAP.

City of Berkeley website, www.ci.berkeley.ca.us

City of Berkeley, 2003. Refuse and Recycling News. Spring.

Coalition to Advance Sustainable Technology (CAST), 1999. CEO CAST: First Movers Coalition Early Action Crediting Proposal, Washington, DC: CAST. 
Credit for Early Action Table, 1999. Report of the Credit for Early Action Table. http://www.nccp.ca/html/tables/pdf/options/CEA_Report_May99.pdf

Department for Environment, Food and Rural Affairs (DEFRA), 2001a. Margaret Beckett Sees UK Emissions Trading Scheme in Action. http://www.defra.gov.uk/news/2002/020418d.htm

Department for Environment, Food and Rural Affairs, 2001b. Guidelines for the Measurement and Reporting of Emissions in the UK Emissions Trading Scheme.

http://www.defra.gov.uk/environment/climatechange/trading/pdf/trading-reporting.pdf

DeSnoo, Neal (City of Berkeley, Energy Commission), 2003a. Microsoft Access database on energy use in buildings in Berkeley (used in SMR, Utility Manager Pro Software by the City of Berkeley for city energy management).

DeSnoo, Neal, (City of Berkeley, Energy Commission) 2003b, Personal Communication collection of data on energy use in buildings, traffic signals and discussion regarding other sources like street lights, 2003.

DeSnoo, Neal, (City of Berkeley, Energy Commission), 2003c. Microsoft Access database and simulation tool for traffic signals and LED retrofits in Berkeley.

Ellis, J. and Bosi, M., 1999. Options for Project Emissions Baselines. OECD and IEA Information Paper. Paris: Organization for Economic Co-operation and Development and International Energy Agency.

Ellis, J., 2000. An Initial View on Methodologies for Emission Baselines: Cement Case Study. OECD and IEA Information Paper.

Ellis, J., Missfeldt, F., Bosi, M., Painuly, J., 2001. Possibilities for Standardised Baselines for JI and the CDM. Background paper for UNEP/OECD/IEA workshop on baseline methodologies. Paris: Organization for Economic Co-operation and Development and International Energy Agency. http://www.uccee.org/baselineworkshop/BackgrdPaper.doc

Energy Solutions, with Jonathon Koomey, 1998. City of Berkeley Resource Conservation and Global Warming Abatement Plan, Berkeley, CA.

Farla, J., Blok, K., and Schipper, L., 1996. "Cross-country Comparison of Manufacturing Energy Efficiency using Physical Production Data: the Pulp and Paper Industry," Proceedings of the Workshop on Methodologies for International Comparisons of Industrial Energy Efficiency in Vancouver, Canada, April 1-2.

Farla, J., 2000. Physical Indicators of Energy Efficiency. Utrecht, The Netherlands: Utrecht University.

Fetzer Vineyards, 2001a. Come Visit Us. http://www.fetzer.com/comevisit/index.html 
Fetzer Vineyards, 2001c. About Our Winery: History.

http://www.fetzer.com/about/stor_hist.html

Fetzer Vineyards, 2001b. About Our Winery: Environmental Philosophy.

http://www.fetzer.com/about/stor_envi.html

Finden, P., 1998. "Norwegian Industry's Network for Energy Conservation," in Martin et al., (eds.) Industrial Energy Efficiency Policies: Understanding Success and Failure: Proceedings of a Workshop Organized by the International Network for Energy Demand Analysis in the Industrial Sector. Utrecht, The Netherlands, June 11-12, 1998. (LBNL-42368).

Fleet-Central, 2001. www.Fleet-Central.com

Fleet-Central, 2000. Automotive Fleet Factbook 2000. http://www.fleet-central.com/af/affb1.cfm

Fluck, R.C., 1992a. Energy for Florida Corn for Grain. Fact Sheet EES-92, a series of the Florida Energy Extension Service, Florida Cooperative Extension Service, Institute of Food and Agricultural Sciences, University of Florida, http://edis.ifas.ufl.edu/EH192

Fluck, R.C., 1992b. Energy Use in Florida Agriculture. Fact Sheet EES-79, a series of the Florida Energy Extension Service, Florida Cooperative Extension Service, Institute of Food and Agricultural Sciences, University of Florida, http://edis.ifas.ufl.edu/EH179

Fluck, R.C., 1992c. Energy for Florida Sugarcane. Fact Sheet EES-87, a series of the Florida Energy Extension Service, Florida Cooperative Extension Service, Institute of Food and Agricultural Sciences, University of Florida, http://edis.ifas.ufl.edu/EH187

Fluck, R.C., 1992d. Energy for Florida Peanuts. Fact Sheet EES-91, a series of the Florida Energy Extension Service, Florida Cooperative Extension Service, Institute of Food and Agricultural Sciences, University of Florida, http://edis.ifas.ufl.edu/EH191

Fluck, R.C., 1992e. Energy for Florida Oranges. Fact Sheet EES-81, a series of the Florida Energy Extension Service, Florida Cooperative Extension Service, Institute of Food and Agricultural Sciences, University of Florida, http://edis.ifas.ufl.edu/EH181

Freeman, S.L., Neifer, M.J., Roop, J.M., 1996. Measuring Industrial Energy Efficiency: Physical Volume Versus Economic Value. Richland, WA: Pacific Northwest National Laboratory (PNNL11435).

Galitsky, C., Martin, N., Worrell, N., and Lehman, B., 2003. Energy Efficiency Opportunities and Potential Cost Savings for Breweries: A Guide for Energy and Plant Managers. Berkeley, CA: Lawrence Berkeley National Laboratory (LBNL-50934).

GHGPI (Greenhouse Gas Protocol Initiative). 2000. Corporate Greenhouse Gas Inventories: Proposed Reporting Standard Guidance and Estimation Tools. http://www.ghgprotocol.org/dsg.html 
GHGPI (Greenhouse Gas Protocol Initiative). 2001a. http://www.ghgprotocol.org/

GHGPI (Greenhouse Gas Protocol Initiative). 2001b. The Greenhouse Gas Protocol: A Corporate Accounting and Reporting Standard. Washington, DC: World Resources Institute and Geneva: World Business Council for Sustainable Development.

Healy, P., 2002. Personal communications with Patrick Healy of Fetzer Vineyards.

Hu, S.C, and Chuah Y.K., 2003. Power consumption of semiconductor fabs in Taiwan. Energy, the International Journal 28(8): 895 - 907.

Institute for Energy Technology, 1998. Norwegian Industrial Energy Efficiency Network. Kjeller, Norway: Institute for Energy Technology.

Intergovernmental Panel on Climate Change (IPCC), 1996. Revised 1996 IPCC Guidelines for National Greenhouse Gas Inventories: Reference Manual http:/www.ipcc-nggip.iges.or.jp/public/gl/invs6.htm

Intergovernmental Panel on Climate Change (IPCC), 2000. Good Practice Guidance and Uncertainty Management in National Greenhouse Gas Inventories. http://www.ipcc-nggip.iges.or.jp/public/gp/gpgaum.htm

International Council for Local Environmental Initiatives (ICLEI), 2001. http://www.iclei.org/

International Energy Agency, 1997. Indicators of Energy Use and Efficiency: Understanding the Link Between Energy Use and Human Activity. Paris: OECD/IEA.

Ivie, Bill, (City of Berkeley, Public Works), 2003. Conversations and data on vehicle miles traveled and fuel consumption from fleet management programs.

Kerssemeeckers, M., 2002. The Dutch Long Term Voluntary Agreements on Energy Efficiency Improvement in Industry. Utrecht, The Netherlands: Ecofys.

Koomey, J., (Lawrence Berkeley National Laboratory), 2003. Personal Communication general discussion on work conducted in 1998 for the city.

Krackeler, T., Schipper, L., and Sezgen, O., 1998. Carbon Dioxide Emissions in OECD Service Sectors: the Critical Role of Electricity Use. Energy Policy 26 (15): 1137-1152.

Krarup, S. and Ramesohl, S., 2000. Voluntary Agreements in Energy Policy - Implementation and Efficiency: Final Report. Copenhagen: AKF.

La Pierre, Alice, (City of Berkeley, Energy Commission), 2003. Personal Communication and transmission of city data on energy use in buildings and waste from the city's transfer station. 
Lawrence Berkeley National Laboratory (LBNL), 1999. International Network for Energy Demand Analysis in the Industrial Sector. Berkeley, CA: Lawrence Berkeley National Laboratory (LBID-2297).

Margolick and Russell, 2001. Corporate Greenhouse Gas Reduction Targets. Washington, DC: Pew Center on Global Climate Change.

Marnay, C., Fisher, D., Murtishaw, A., Phadke, A., Price, L., and Sathaye, J., 2002. Estimating Carbon Dioxide Emissions Factors for the California Electric Power Sector. Berkeley, CA: Lawrence Berkeley National Laboratory (LBNL-49945).

Miller, J., 2002. "Monitoring of Low Energy Cooling Systems in Commercial Buildings: Berkeley Civic Center." Davis Energy Group, Davis, CA. October 2002. Work performed under contract with CEC/PIER Buildings Program Area.

Ministry of Economic Affairs, 1998. Long Term Agreements on Energy Efficiency: Progress in 1996. The Hague, The Netherlands: Ministry of Economic Affairs.

Ministry of Economic Affairs, 2000. Operational Guidelines for Baseline Studies, Validation, Monitoring, and Verification of Joint Implementation Projects. Volume 2a: Baseline Studies, Monitoring, and Reporting - A Guide for Project Developers. Netherlands: MEA. http://www.ceruleanconsultants.com/docs/Dutch\%20MERV\%20guidelines.pdf

Murtishaw S., Schipper L., Unander F., Karbuz S., and Khrushch M., 2001. Lost carbon emissions: the role of non-manufacturing "other industries" and refining in industrial energy use and carbon emissions in IEA countries, Energy Policy 29 (2): 83-102. LBNL-48781

Nanduri, M., Nyboer, J., and Jaccard, M., 2002. "Aggregating Physical Intensity Indicators: Results of Applying the Composite Indicator Approach to the Canadian Industrial Sector," Energy Policy 30: 151-163.

National Agricultural Statistical Service (NASS), U.S. Dept of Agriculture, 2002. Agricultural Statistical Review: California ftp://www.nass.usda.gov/pub/nass/ca/ AgStats/2001-ovw.pdf

National Oceanic and Atmospheric Administration (NOAA), 2003. Berkeley degree-day data series from the Climate Prediction Center, NOAA provided by Tom Heddinghaus (Thomas.Heddinghaus@noaa.gov)

National Roundtable on the Environment and the Economy, 2002. The ABCs of Emissions Trading: An Overview. Ottawa, Canada: NRTEE.

http://www.nrtee-trnee.ca/EmissionsTrading/en/ABCs-EmissionsTrading-e.pdf

Nichols, Matt, (City of Berkeley, Energy Commission), 2003. Personal Communication general discussion on main problem areas in collecting city GHG and activity data. 
Nordhaus, R., Fotis, S., and Feldman, V.N., 1998. Analysis of Early Action Crediting Proposals. Prepared for the Pew Center on Global Climate Change. Washington, DC: PEW.

Nuijen, W., 1998. "Long Term Agreements on Energy Efficiency in Industry," in Martin et al., (eds.) Industrial Energy Efficiency Policies: Understanding Success and Failure: Proceedings of a Workshop Organized by the International Network for Energy Demand Analysis in the Industrial Sector. Utrecht, The Netherlands, June 11-12, 1998. (LBNL-42368).

Nyboer, J. and Laurin, A., 2001a. Development of Energy Intensity Indicators for Canadian Industry: 1990 to 1999. Prepared for Canadian Industry Program for Energy Conservation and Natural Resources Canada. Vancouver: Canadian Industry Energy End-use Database and Analysis Center, Simon Fraser University.

Nyboer, J. and Laurin, A., 2001b. Development of Greenhouse Gas Intensity Indicators for Canadian Industry: 1990 to 1999. Prepared for Environment Canada and the Canadian Industry Program for Energy Conservation. Vancouver: Canadian Industry Energy End-use Database and Analysis Center, Simon Fraser University.

Oak Ridge National Laboratory, 2000. Transportation Energy Data Book: Edition 20. Oak Ridge, TN: ORNL http://www-cta.ornl.gov/data/tedb20/

ODYSEEE, 2001. Website of the ODYSSEE Database maintained by Enerdata S.A.: http://www.enerdata.fr/enerdata_UK/indexa.html (accessed November $13^{\text {th }}, 2001$ ).

Ontario Power Generation, 2000. Greenhouse Gas Action Plan - 1999. Submitted to Canada's Climate Change Voluntary Challenge and Registry, Inc. November.

Parkinson, S., Begg, K., Bailey, P., and Jackson, T., 2001. "Accounting for Flexibility Against Uncertain Baselines: Lessons from Case Studies in the Easter European Energy Sector," Climate Policy 1(2001): 55-73.

Patton, R. and Wiese, S., 1999. Worldwide Fab Energy Survey Report, Tech Transfer \# 99023669B-ENG, International SEMATECH.

Phylipsen, G.J.M., Nyboer, J., Oliver, J.T., Pape, A., Worrell, E., and Blok, K., 1996. Proceedings of a Workshop on Methodologies for International Comparisons of Industrial Energy Efficiency. April 1-2, 1996; Simon Fraser University, Vancouver, British Columbia.

Phylipsen, G.J.M., Blok, K., and Worrell, E., 1998. Handbook on International Comparisons of Energy Efficiency in the Manufacturing Industry, Utrecht, The Netherlands: Department of Science, Technology and Society, Utrecht University.

Sartor, D., Tsal, R., Arens, E., Stum, K., Tschudi, W., Federspiel, C., Bell, G., and Busch, J., 1999. Clean Rooms and Laboratories for High-Technology Industries. Sacramento, CA: California Energy Commission. 
Sathaye, J., Price, L., Worrell, E., and Ruth, M., 2001. Multi-Project Baselines for Evaluation of Industrial Energy-Efficiency and Electric Power Projects. Berkeley, CA: Lawrence Berkeley National Laboratory (LBNL-48242).

Schipper, L., Unander, F., Murtishaw, S., and Ting, M., 2001. "Indicators of Energy Use and Carbon Emissions: Explaining the Energy Economy Link," Annual Review of Energy and the Environment 26: 49-81.

Seif, 2003. Personal communication with Dan Seif, AMD Environmental, Health, \& Safety Department.

Semiconductor Industry Association, 1998. National Technology Roadmap for Semiconductors.

Silva, Ed, 2003. Personal communication with Ed Silva, City of Berkeley Public Works.

Solomon Associates, 1995. Word-wide Olefins Plant Performance Analysis, 1995, Solomon Associates Ltd., Windsor.

Solomon Associates, 2001. http://www.sa-inc.com/

Swanton, C.J., Murphy, S.D., Hume, D.J., and Clements, D.R., 1996. "Recent Improvements in the Energy Efficiency of Agriculture: Case Studies from Ontario, Canada," Agricultural Systems 52: 399-418.

Thomas, C., Tennant, T., and Rolls, J., 2000. The GHG Indicator: UNEP Guidelines for Calculating Greenhouse Gas Emissions for Businesses and Non-Commercial Organizations. Geneva: United Nations Environment Programme. http://www.climnet.org/pubs/Unepghg.pdf

Tschudi, W., Lawrence Berkeley National Laboratory, 2003. Personal communication.

United Nations, 1997. Kyoto Protocol to the United Nations Framework Convention on Climate Change, FCCC/1997/L.7/Add.1.

United Nations Framework Convention on Climate Change (UNFCCC), 2002a. Project Activity Design Requirements: Project Activity Baselines, http://unfccc.int/cdm/baseline.html\#MP37

United Nations Framework Convention on Climate Change (UNFCCC), 2002b. Kyoto Protocol Status of Ratification, http://unfccc.int/resource/kpstats.pdf

U.S. Census, 1997. 1997 Economic Census: Comparative Statistics for California 1987 SIC Basis. Washington, DC: U.S. Bureau of Census.

U.S. Census Bureau, 1997. 1997 Economic Census: Comparative Statistics for California. http://www.census.gov/epcd/ec97sic/E97SCA.HTM 
U.S. Department of Energy, Energy Information Administration, 2001. Updated State-Level Greenhouse Gas Emissions Factors for Electricity Generation. Washington, DC: U.S. DOE/EIA. http://tonto.eia.doe.gov/FTPROOT/environment/e-supdoc.pdf

U.S. Department of Labor, 2003. SIC Major Group 36.

http://www.osha.gov/cgi-bin/sic/sicser4?36

U.S. Department of Transportation, Federal Transit Administration, 1998. 1998 National Transit Database. www.fta.dot.gov/ntl/database/html

U.S. Energy Information Administration, 2002. Voluntary Reporting of Greenhouse Gases 2000 Report, DOE/EIA-0608. Washington, DC: U.S. EIA.

U.S. Environmental Protection Agency, 1995. EPA Office of Compliance Sector Notebook Project: Profile of the Electronics and Computer Industry, Washington, DC: U.S. EPA, http://www.p2pays.org/ref/03/02546.pdf

U.S. Environmental Protection Agency, 1998. Energy Use in the Semiconductor Manufacturing Industry. Washington, DC: U.S. EPA.

U.S. Environmental Protection Agency, 2002. Inventory of U.S. Greenhouse Gas Emissions and Sinks: 1990 - 2000.

http://yosemite.epa.gov/oar/globalwarming.nsf/content/ResourceCenterPublicationsGHGEmissio nsUSEmissionsInventory2002.html. EPA 430-R-02-003

U.S. Environmental Protection Agency (EPA), 2003a. Climate Leaders: Partner GHG Goals. http://www.epa.gov/climateleaders/goals.html

U.S. Environmental Protection Agency (EPA), 2003b. Global Warming Potentials. http://yosemite.epa.gov/oar/globalwarming.nsf/content/EmissionsNationalGlobalWarmingPotent ials.html

U.S. General Accounting Office, 1998. Climate Change: Basic Issues in Considering a Credit for Early Action Program. GAO/RCED-99-23. Washington, DC: U.S. GAO.

VanCity Savings Credit Union, 2000. Energy Management Action Plan. http://www.vcrmvr.ca/registry/out/C2014-24OCT00PL-DOC.PDF

VCR-MRV, Inc. 1999. Registration Guide 1999. http://www.vcr-mvr.ca/vcr-180.cfm

VCR-MRV, Inc. 2001. Canada's Climate Change Voluntary Challenge \& Registry. http://www.vcr-mvr.ca/home_e.cfm

VCR-MRV, Inc., 2002a. Canada's Climate Change Voluntary Challenge and Registry. http://www.vcr-mvr.ca/vcr-013.cfm 
VCR-MRV, Inc., 2002b. Baseline Protection Initiative (BPI).

https://www.vcr-mvr.ca/bpi_registry/BPI_text.cfm

Vine, E. and Sathaye, J., 1999. Guidelines for Monitoring, Evaluating, Reporting, Verification, and Certification of Energy-Efficiency Projects for Climate Change Mitigation. Berkeley, CA: Lawrence Berkeley National Laboratory (LBNL-41543).

Wine Institute 2002a. California Wine Industry Statistical Highlights, http://www.wineinstitute.org/communications/statistics/stathi01.htm

Wine Institute 2002b. California Winegrape Acreage, 1988 - 2001, http://www.wineinstitute.org/communications/statistics/keyfacts_cal_winegrape_acreage1988_0 $\underline{1 . h t m}$

Wisconsin Department of Natural Resources, 2002. Voluntary Emission Reduction Registry. Chapter NR 437. http://www.legis.state.wi.us/rsb/code/nr/nr437.pdf

Wittenberg, D., 2001. "California Climate Action Registry: Overview \& Issues," Presented at the California Climate Action Registry Design Charette, October 18 \& 19, 2001, San Francisco, CA.

World Bank, Prototype Carbon Fund, 2000a. Baseline Methodologies for PCF Projects. PCF Implementation Note Number 3. Washington, DC: World Bank.

World Bank Prototype Carbon Fund, 2000b. Learning from the Implementation of the Prototype Carbon Fund. Washington, DC: World Bank.

World Energy Council, 2001. Greenhouse Gas Emissions Pilot Programme. http://www.worldenergy.org/wec-geis/ghg2001/faqMain.asp

World Resources Institute/World Business Council for Sustainable Development, 2001. The Greenhouse Gas Protocol: A Common Corporate Accounting and Reporting Standard. http://www.ghgprotocol.org/standard/ghg.pdf

Worrell, E., Price, L., Martin, N., Farla, J., and Schaeffer, R., 1997. "Energy Intensity in the Iron and Steel Industry: A Comparison of Physical and Economic Indicators," Energy Policy 25(7-9): 727-744.

Zechiel, S., 2003. Personal communication with Susanne Zechiel of Fetzer Vineyards. 


\section{Appendix A: Calculation of the Energy Efficiency Index}

Indices can be used to estimate the energy intensity or to track developments in energy intensity or GHG emission intensity, as a way to normalize the intensity versus a reference plant or reference year. In this appendix we describe the use of an index for energy efficiency or energy intensity. However, the same concept can be used for GHG emissions by multiplying the different fuels and energy carriers with the appropriate emission factors.

This example describes the calculations for a hypothetical company, Twist-Fruit Inc. that produces two products: apples and oranges. For each production step, the company knows the energy consumption through its energy management system.

In the reference year, Twist-Fruit produced 4 million apples and 7 million oranges, consuming 14.5 Trillion Btu (see Table 1). In year $5(\mathrm{x}=5)$ Twist-Fruit produced 6 million apples and 6 million oranges, consuming 11.4 Trillion Btu (see table 2).

Table A-1. Energy consumption of Twist-Fruit Inc. in reference year.

\begin{tabular}{|l|c|c|c|}
\hline Reference Year & Production & Energy Use (Tbtu) & SEC (Mbtu/unit) \\
\hline Apples & 4 million & 4.0 & 1.0 \\
\hline Oranges & 7 million & 10.5 & 1.5 \\
\hline Total & 11 million & 14.5 & 1.32 \\
\hline
\end{tabular}

Table A-2. Energy consumption of Twist-Fruit Inc. in year 5.

\begin{tabular}{|l|c|c|c|}
\hline Year 5 & Production & Energy Use (Tbtu) & SEC (Mbtu/unit) \\
\hline Apples & 6 million & 5.4 & 0.9 \\
\hline Oranges & 6 million & 6.0 & 1.0 \\
\hline Total & 12 million & 11.4 & 0.95 \\
\hline
\end{tabular}

Table 1 and 2 show that energy use, energy intensity and product mix changed over the period. In this year the company installed new very efficient orange-makers, while fixing some of the problems it had with the apple-makers, so it would like to receive credit for the large efficiency gains it made through the investment in the orange-makers.

INCORRECT: If we would divide total energy use of year 5 by that of the reference year the total primary energy consumption would be equal to $79 \%$ of the reference year, or a $21 \%$ reduction in energy use. However this is not fair, as the company now makes more products, but also a mix with relatively more apples, which are less energy intensive to make.

INCORRECT: A comparison of the average SEC would provide a reduction to $72 \%$ of the reference year, or a saving of $28 \%$. Also, this is not fair, as the product mix has changed over time. Calculating the changes in SEC by product would not give the overall picture. 
CORRECT: the two previous methods resulted in incorrect answers, hence, we need to calculate an indexed development of the specific energy consumption for Twist-Fruit Inc. Using Equation 2 we calculate the EEI:

$100 *((6 * 0.9)+(6 * 1.0)) /(6 * 1.0)+(6 * 1.5))=100 * 11.4 / 15=76$

Hence, the energy intensity reduction in year 5, indexed based to the reference year is $24 \%$.

Indexing can also be used for plants that produce many different products, or that produce intermediate products that are processed further in the plant, sold or purchased. As long as the production quantities and energy consumption in each major process are available for the reference year and following years. The calculation of the EEI can be simplified by reducing the number of products by aggregating energy uses for the processes used to produce those products. The reported energy consumption or emissions should still be equal to the total of the plant. Simplification may lead to a larger uncertainty in the calculation of the EEI. Therefore, the products included in the calculation of the EEI should lead to a EEI within certain reliability boundaries, agreed on by the plants and the registry.

The EEI can be reported for every year, and used to track energy intensity developments, and estimate real reductions in energy intensity, as well as compare to sector-wide developments (by adding the data from different plants and using the same equation to estimate the plant-wide EEI).

Figure A-1. EEI development of Twist-Fruit Inc.

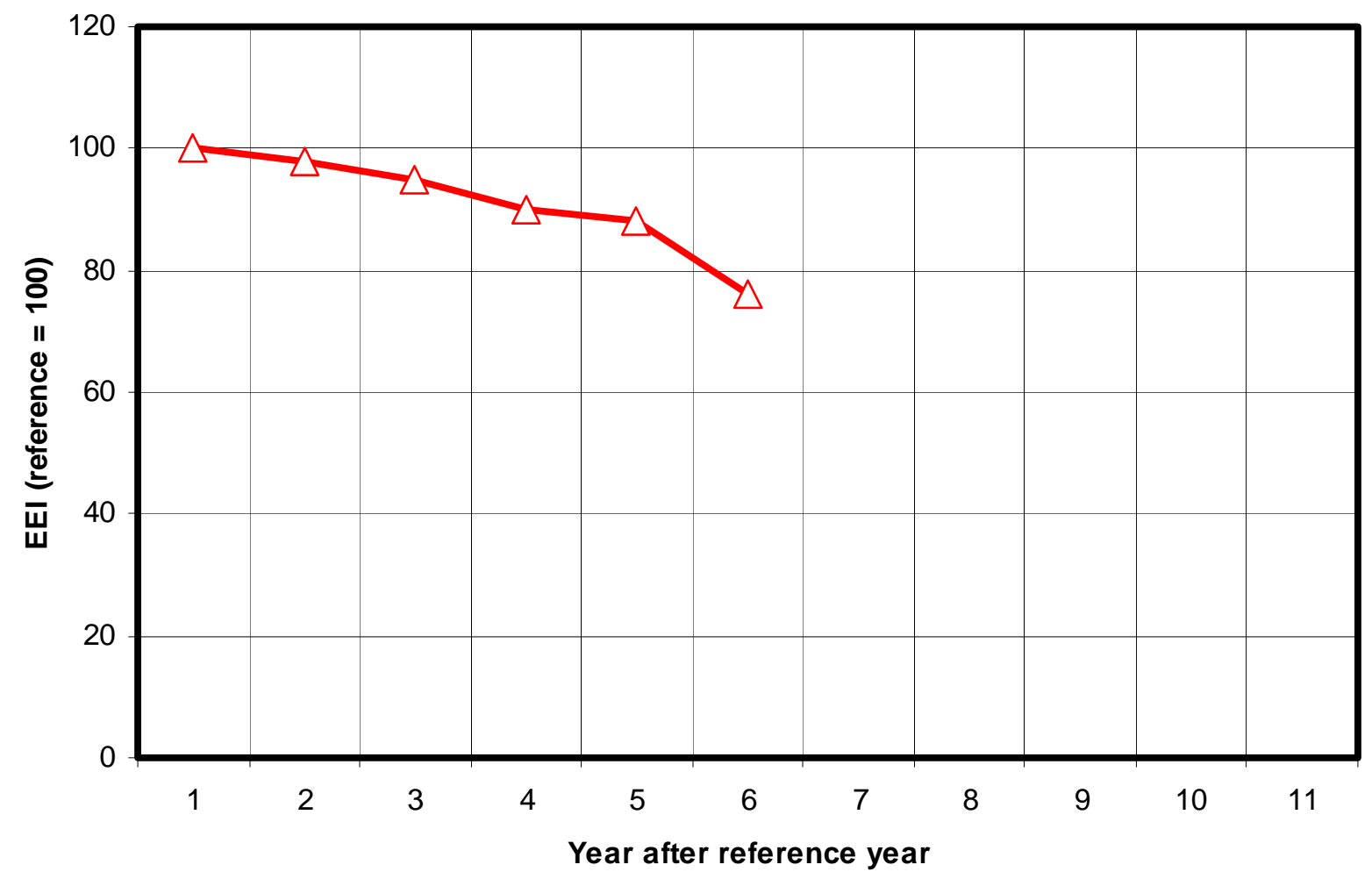

